\title{
The Importance of Fracture Geometry and Matrix Data on Transient Hydraulic Tomography in Fractured Rocks: Analyses of Synthetic and Laboratory Rock Block Experiments
}

\author{
by \\ Huawen Zhao \\ A thesis \\ presented to the University of Waterloo \\ in fulfillment of the \\ thesis requirement for the degree of \\ Master of Science \\ in \\ Earth Sciences
}

Waterloo, Ontario, Canada, 2020

(C) Huawen Zhao 2020 


\section{Author's declaration}

I hereby declare that I am the sole author of this thesis. This is a true copy of the thesis, including any required final revisions, as accepted by my examiners.

I understand that my thesis may be made electronically available to the public. 


\begin{abstract}
The accurate characterization of hydraulic properties within fractured geologic media as well as the imaging of fracture patterns and their connectivity have been difficult to accomplish over the last few decades. Recently, hydraulic tomography has been suggested as a promising approach for imaging the key hydraulic parameters such as hydraulic conductivity $(K)$ and specific storage $\left(S_{S}\right)$ distribution of fractured geologic media. This thesis investigates the importance of geologic information on HT analyses through synthetic experiments and laboratory rock block experiments conducted by Sharmeen et al. (2012). Specifically, three inverse modeling approaches with different types of geologic data included in the analyses were examined: 1) homogeneous estimates of hydraulic parameters without geologic data; 2) correct fracture locations and matrix data with correct hydraulic parameters; and 3) partially correct fracture locations and matrix data with incorrect hydraulic parameters. In this study, the assessment of transient hydraulic tomography (THT) is conducted in fractured dolomitic rock block through the Sequential Successive Linear Estimator (SSLE) developed by Zhu and Yeh (2005). The image of fracture patterns and their connectivity are presented through maps of $K$ and $S_{S}$ distributions (or tomograms). The validation of inverse modeling results is quantitatively performed through the prediction of independently conducted pumping tests not used in the calibration effort. The comparison among results obtained from different approaches indicates that: 1) THT analysis can capture the overall fracture pattern and their hydraulic properties $\left(K\right.$ and $S_{S}$ ), but the estimated values are higher where observations are limited; 2) using a correct geological model as prior information in a geostatistical inverse model can preserve geologic features especially within the matrix, where drawdown data are hard to obtain; 3) a simple model without any geologic information is more reliable than the one based on the wrong description of geologic features. Overall, the results from this study indicate the importance of incorporating accurate geological data in HT surveys when drawdown data are sparse and not available within the matrix, which could have critical implications for field research in fractured rock hydrogeology.
\end{abstract}




\section{Acknowledgements:}

This research project is based on the previous work done by Sharmeen (2011) who conducted the rock block experiments and the initial transient hydraulic tomography analyses of data. I want to give academic credit to Rubaiat Sharmeen and thank her support for providing both project data and model input files. Without her generosity, it would have been hard to complete this project.

I would like to thank my supervisor, Professor Walter Illman, for providing this precious opportunity for me to gain invaluable experience about groundwater modeling. I am greatly appreciative for his generous guidance and expertise during the entire project. The project could not have succeeded without his effort and support.

Thanks also go out to Ning Luo, Zeren Ning, Xihua Wang, and Xin Tong for their advice and knowledge about groundwater modeling. Many parts of this research have improved based on their suggestions.

Finally, I want to give my appreciation to my parents especially my father, without whose guidance and support I would have never achieved my Master's degree. 


\section{Table of Contents}

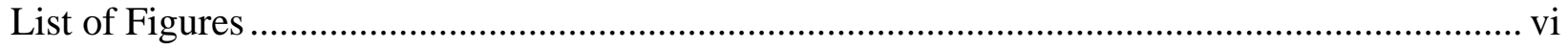

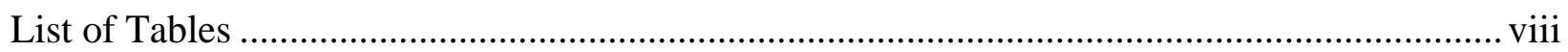

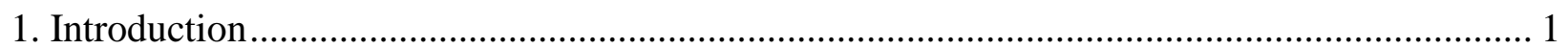

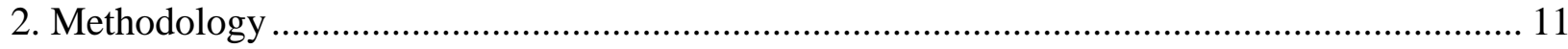

2.1 Description of Laboratory Experiments....................................................................... 11

2.2 Synthetic pumping tests designed for HT analysis ...................................................... 14

2.3 HT analysis of Synthetic and Real Pumping Test Data ................................................. 18

2.4 Input parameters for the inverse model .................................................................... 20

3. Results from Transient Hydraulic Tomography …………………………………..................... 23

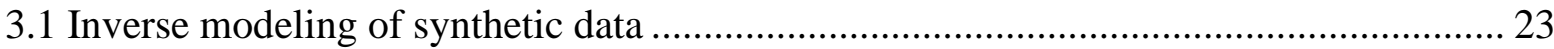

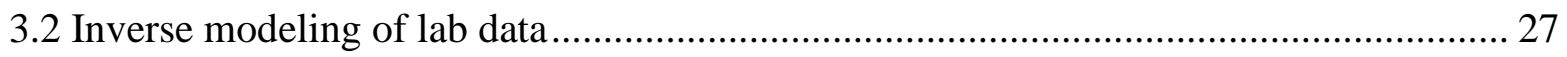

3.3 Calibration of drawdown data (Synthetic and Real data) ................................................ 31

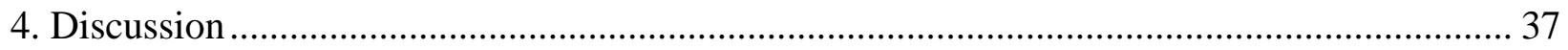

4.1 Comparison of estimated $K$ and $S_{s}$ values from SSLE to true values (synthetic data) .... 37

4.2 Prediction of pumping tests (Synthetic and Real data) ................................................... 38

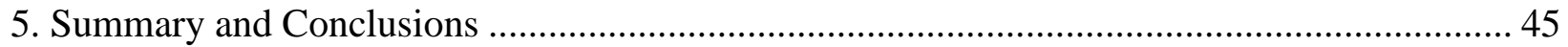

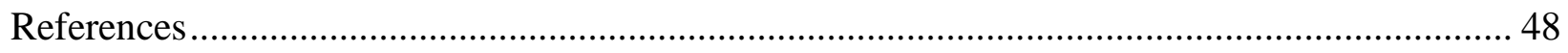

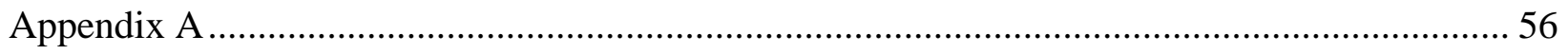

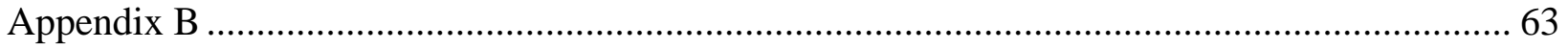

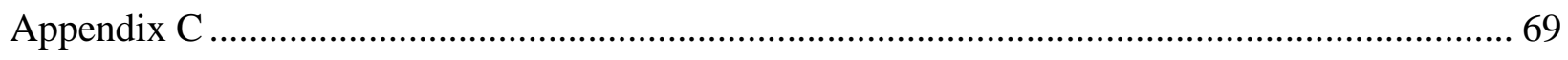




\section{List of Figures}

Figure 2.1: Profile of the fractured rock block. Circles represent ports located on fractures, and solid circles indicate the ports at the matrix and constant head reservoirs (modified from Sharmeen

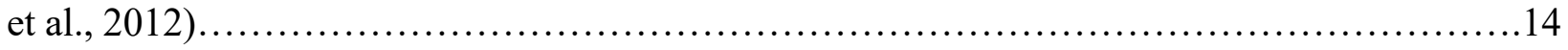

Figure 2.2: (a) HGS mesh used for synthetic pumping tests, (b) fracture elements within the fractured rock block (modified from Sharmeen, 2011) ................................... 15

Figure 2.3: Observed (black solid line) and calibrated (blue dashed line) drawdown curves using HGS during a pumping test at port 5 (modified from Sharmeen et al., 2012)...................17

Figure 2.4: Finite element mesh used for the inversion of synthetic and experimental data

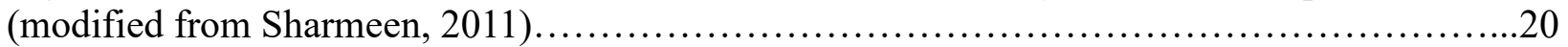

Figure 2.5: (a) Correct fracture locations; (b) partially correct fracture locations; (c) wrong fracture

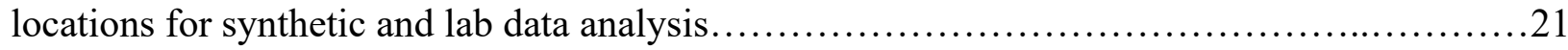

Figure 3.1: $K$ tomograms $\left(\mathrm{cm} \mathrm{s}^{-1}\right)$ delineated using synthetic data from three pumping tests (ports 3, 5, and 7): a) $K$ tomogram without prior geologic information; b) corresponding $\sigma^{2} \ln K$; c) $K$ tomogram with correct prior geologic information; d) corresponding $\sigma^{2}{ }_{\ln K}$; e) $K$ tomogram with

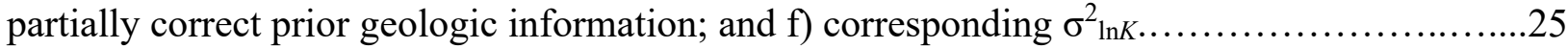

Figure 3.2: $S_{s}$ tomograms $\left(\mathrm{cm} \mathrm{s}^{-1}\right)$ delineated using synthetic data from three pumping tests (ports 3, 5, and 7): a) $S_{s}$ tomogram without prior geologic information; b) corresponding $\sigma^{2} \ln S s ;$ c) $S_{s}$ tomogram with correct prior geologic information; d) corresponding $\sigma^{2} \ln S s$; e) $S_{S}$ tomogram with partially correct prior geologic information; and f) corresponding $\sigma^{2} \operatorname{lnSs} \ldots \ldots \ldots \ldots \ldots \ldots \ldots \ldots . .27$

Figure 3.3: $K$ tomograms $\left(\mathrm{cm} \mathrm{s}^{-1}\right)$ delineated using laboratory experiment data from three pumping tests (ports 3, 5, and 7): a) $K$ tomogram without prior geologic information; b) corresponding $\sigma^{2} \ln K$; c) $K$ tomogram with correct prior geologic information; d) corresponding $\sigma^{2}{ }_{\ln K}$; e) $K$ tomogram with partially correct prior geologic information; and f) corresponding $\sigma^{2} \ln K \ldots \ldots \ldots \ldots \ldots \ldots . . . . .30$

Figure 3.4: $S_{S}$ tomograms ( $\mathrm{cm} \mathrm{s}^{-1}$ ) delineated using laboratory experiment data from three pumping tests (ports 3, 5, and 7): a) $S_{s}$ tomogram without prior geologic information; b) corresponding $\sigma^{2} \ln S s$; c) $S_{s}$ tomogram with correct prior geologic information; d) corresponding $\sigma^{2}{ }_{\ln S s}$; e) $S_{S}$ tomogram with partially correct prior geologic information; and f) corresponding $\sigma^{2} \ln S s \ldots \ldots \ldots \ldots \ldots \ldots . \ldots 31$

Figure 3.5: Scatter plots of observed versus simulated drawdowns for model calibration using three synthetic pumping tests (Ports 3, 5, 7) for the three cases (Homogeneous, Correct, Partially Correct). Results are plotted for all data, data from ports at fractures, and data from ports at matrix. Blue circles represent data points. Blue circles represent data points. Solid black line is the 1:1 line, and the dashed line indicates the best-fit line for data points..............................

Figure 3.6: Scatter plots of observed versus simulated drawdowns for model calibration using three laboratory pumping tests (Ports 3, 5, 7) for the three cases (Homogeneous, Correct, Partially Correct). Results are plotted for all data, data from ports at fractures, and data from ports at matrix. Blue circles represent data points. Blue circles represent data points. Solid black line is the 1:1 line, and the dashed line indicates the best-fit line for data points............................. 35

Figure 3.7: Observed and calibrated drawdown $(\mathrm{cm})$ versus time $(\mathrm{s})$ at ports during the pumping test at port 5 for laboratory data. The dark blue dashed line represents results from the homogeneous case. The solid black line indicates results from the lab experiment. The green 
dashed line represents results from the correct fracture location case. The red dashed line indicates results from the partially correct fracture location case ..................................... 36

Figure 4.1: Scatter plot of $K$ values comparing the inversion results from SSLE and calibration of HGS with PEST: a) homogeneous case without prior geologic information; b) case with correct prior geologic information; c) case with partially correct geologic information................ 37

Figure 4.2: Scatter plot of $S_{s}$ values comparing the inversion results from SSLE and calibration of HGS with PEST: a) homogeneous case without prior geologic information; b) case with correct prior geologic information; c) case with partially correct geologic information...................38

Figure 4.3: Scatter plots of observed versus simulated drawdowns for model validation using five synthetic pumping tests (Ports 4, 6, 12, 15, 18) for the three cases (Homogeneous, Correct, Partially Correct). Results are plotted for all data, data from ports at fractures, and data from ports at matrix. Blue circles represent data points. Solid black line is the 1:1 line, and the dashed line indicates the best-fit line for data points. .40

Figure 4.4: Scatter plots of observed versus simulated drawdowns for model validation using five laboratory pumping tests (Ports 4, 6, 12, 15, 18) for the three cases (Homogeneous, Correct, Partially Correct). Results are plotted for all data, data from ports at fractures, and data from ports at matrix. Blue circles represent data points. Solid black line is the 1:1 line, and the dashed line indicates the best-fit line for data points. 41

Figure 4.5: Observed and calibrated drawdown $(\mathrm{cm})$ versus time $(\mathrm{s})$ at ports during the pumping test at port 4 . The dark blue dashed line represents results from the homogeneous case. The solid black line indicates results from the lab experiment. The green dashed line represents results from the correct fracture location case. The red dashed line indicates results from the partially correct fracture location case.

Figure 4.6: Observed and calibrated drawdown $(\mathrm{cm})$ versus time $(\mathrm{s})$ at ports during a pumping test at port 18. The dark blue dashed line represents results from the homogeneous case. The solid black line indicates results from the lab experiment. The green dashed line represents results from the correct fracture location case. The red dashed line indicates results from the partially correct fracture location case. 43 


\section{List of Tables}

Table 2.1: Summary of flow-through tests (modified from Sharmeen, 2011)................... 12

Table 2.2: Summary of pumping tests in fractured dolomite rock block sample (modified from

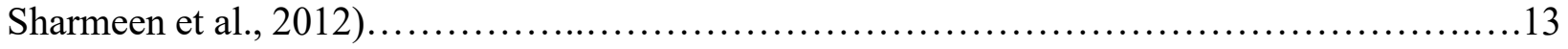

Table 2.3: Calibrated hydraulic properties of fractures from different pumping tests by HGS

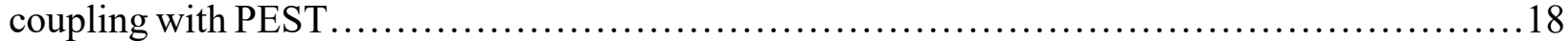

Table 2.4: Summary of initial estimates of hydraulic parameters for the synthetic and real THT...22 


\section{Introduction}

In recent years, groundwater flow and contaminant transport through aquifers have become a focus for hydrogeologists. The characteristics of aquifers are important for determining groundwater flow, especially the spatial distribution of hydraulic properties such as hydraulic conductivity $(K)$ and specific storage $\left(S_{s}\right)$. In a fractured aquifer, the large contrast of hydraulic properties between fractures and the matrix along with their variability can have a large influence on the estimation of hydraulic characteristics of the medium, which in turn could have impacts on groundwater resource management. Specifically, connected fractures typically consist of high- $K$ and low- $S_{s}$ zones, while the matrix consists of low- $K$, but high- $S_{s}$ zones. Therefore, during pumping tests, the pressure propagates rapidly through connected fractures than the matrix resulting in significant contrasts in drawdowns at monitoring wells and ports. These variabilities of hydraulic properties have guided the development of different conceptual models for modeling groundwater flow and contaminant transport through fractured geologic media (Oda, 1986; Neuman, 1987; Cacas et al., 1990; Tsang et al., 1996).

Over the past few decades, numerous new experimental techniques and interpretation frameworks have been developed to characterize fractured rock aquifers (NRC, 1996; Hamzah et al., 2006; Cherry et al., 2007; Cho et al., 2008). During the 1970s, the inability of technology produced challenges for scientists to obtain detailed information on subsurface fractures, and this deficiency led to the development of the Equivalent Porous Continuum concept (EPM) (Bear, 1972; Freeze and Cherry, 1979; Blessent et al., 2013). The large contrast in the volume between fractures and the matrix pores along with their hydraulic properties resulted in the dual porosity/mass transfer model (Moench, 1984; Lee et al., 1999; Cornaton and Perrochet, 2002; Worthington and Smart, 2017; Tao et al., 2019). The dual porosity model conceptualizes that groundwater takes place only in the fractures, but can be stored in both fractures and the matrix. This means that the matrix acts only as a non-conducting storage reservoir. In the dual permeability model (e.g. Choi et al., 1997; Illman and Hughson 2005; Guo et al., 2017), both the matrix and fractures can conduct 
and store the fluid. This model is used to describe or estimate the averaged flow and transport behavior over a large scale of fractured rock.

In various EPM models, the fractured medium is treated as a uniform material and various interpretation methods (e.g. type curves, straight line methods) have been developed for the analysis of pumping test data (Illman, 2014). With the evolution of technology and theories, the requirements for high-resolution descriptions of heterogeneity led to the introduction of discrete fracture network models (DFNM) in groundwater flow modeling studies (e.g. Dverstorp et al., 1993; Karimi-Fard et al., 2003; Erhel et al., 2009; Meyer and Bazan, 2011; Tueckmantel et al., 2013; Lei et al., 2017).

The discrete fracture network models (DFNMs) are applied frequently in flow and transport simulations where fractures are considered individually. However, accurate fracture information such as its geometry and their spatial distribution are difficult to capture in the field (Neuman 1987, 2005). Another difficulty for the application of DFNMs in field studies is defining a reliable relationship between fracture geometry data and hydraulic as well as transport parameters (Neuman, 1987; Tsang et al., 1996; Illman and Hughson, 2005; Illman et al., 2009; Sharmeen et al., 2012; Illman, 2014; Lei et al., 2017). Moreover, the connectivity among individual fractures is identified as another important property to determine groundwater flow paths, but this property varies significantly among rock types and is difficult to quantify between boreholes (Illman, 2014).

An alternative approach to EPM and DFNM proposed by Neuman (1987) was the Stochastic Continuum Modelling (SCM) approach. A SCM is typically constructed with $K$ data collected from single-hole packer tests at narrow intervals (e.g., Tsang et al., 1996; Follin and Thunvik, 1994; Neuman and Depner, 1998; Chen et al., 2000; Illman and Neuman, 2001; Hendricks Franssen and Gómez-Hernández, 2002). In the SCM approach, hydraulic conductivities estimated from packer tests are considered as a randomly correlated field over a continuum, which accommodates the uncertainty in the identification of fracture properties due to the inabilities of current technology (Neuman 1987; Vesselinov et al., 2001a,b; Sharmeen et al., 2012). 
During the past few decades, various hydraulic and pneumatic characterization approaches have been developed for the characterization of saturated and unsaturated fractured rock aquifers. Technologies developed include single- and cross-hole pumping or injection tests in the saturated zone, pneumatic injection tests in the unsaturated zone, hydraulic tomography, and electrical resistivity tomography (ERT) (Hsieh and Neuman, 1985; Hsieh et al., 1985; Illman and Neuman, 2000, 2001; Yeh and Liu, 2000; Hasan et al., 2019). Slug and single-hole tests have been used for obtaining hydraulic properties within the fractured rock by treating the tested rock as an isotropic, homogeneous porous medium, as these tests are only representative of a small volume surrounding the tested interval (NRC, 1996). In order to characterize fractured rocks at a larger scale, crosshole tests have been proposed. For example, Hsieh et al. (1985) developed a type curve approach to determine the hydraulic conductivity tensor from cross-hole tests by treating the fractured medium to be uniform and anisotropic. Pneumatic injection tests rely on air injection instead of water and are utilized to estimate the permeability of the unsaturated zone, but adopt the same traditional interpretation methods (Guzman et al., 1996).

When cross-hole tests are interpreted by treating the medium to be uniform, a scale effect in hydraulic conductivity has resulted (e.g., Clauser, 1992; Butler and Healey, 1998a,b; Illman and Neuman, 2001; Vesselinov et al., 2001a-b; Nastev et al., 2004). In Vesselinov et al. (2001b), the scale effect was pronounced in both permeability and porosity of fractured rock; however, it disappeared when the fractured rock was considered as a heterogeneous medium during inverse modeling. Illman and Neuman (2003) analyzed steady-state data from cross-hole pneumatic injection tests with analytical solutions and compared their estimates from single-hole data to strengthen their conclusion of the scale effect at their research site in central Arizona.

Previous studies have documented the presence of a scale effect at a site by comparing smalland large-scale estimates of hydraulic parameters. However, by examining permeability estimates from cross-hole pneumatic injection tests estimated over various distances between injection and observation intervals, Illman (2006) discovered a directional scale effect resulting from cross-hole tests alone and pointed out that the scale effect is caused through the connectivity of fractures at a 
given site. Illman (2006) then proposed that hydraulic tomography can be a promising tool to image the connectivity and hydraulic parameters of fractured geologic media.

Hydraulic tomography (i.e., a sequential aquifer tests) (HT) is an advanced aquifer testing technique proposed initially by Neuman (1987), who suggested that cross-hole hydraulic tests could be conducted across the rock with the signal interpreted in a similar way to geophysical tomography to yield hydraulic parameters. During cross-hole tests, water is extracted or injected into various intervals of screened well bores within the aquifer, and drawdowns are monitored at different, isolated intervals to collect more data than traditional aquifer tests (Yeh and Liu, 2000). To interpret results from hydraulic tomography (HT), a sequential inversion approach based on steady-state hydraulic tests was developed by Yeh and Liu (2000) and was named the Sequential Successive Linear Estimator (SSLE). This technique was first tested with synthetic simulations by Yeh and Liu (2000) and also through laboratory experiments (Liu et al., 2002, Illman et al. 2007). The sequential inversion approach utilized an iterative geostatistical inversion approach to estimate the conditional, effective hydraulic conductivity field and corresponding conditional variances of an aquifer based on the geostatistical inverse modeling of hydraulic head and discharge data (Yeh and Liu, 2000).

Zhu and Yeh (2005), then improved HT with an efficient SSLE for the interpretation of transient hydraulic data. However, the inversion of data for both $K$ and $S_{s}$ was found to be more computationally intensive than the use of steady state data alone. Liu et al. (2007), then conducted laboratory sandbox experiments and interpreted their data to validate the Transient Hydraulic Tomography code of Zhu and Yeh (2005). During this period, Illman et al. (2008) investigated the order of pumping test data interpreted with the SSLE algorithm and found that including data with the largest signal to noise $(\mathrm{S} / \mathrm{N})$ ratio first was of paramount importance of obtaining more accurate results. Including data with the lowest $\mathrm{S} / \mathrm{N}$ ratio first resulted in poor $\mathrm{HT}$ results. In order to avoid the influence of the order of tests included in inverse modeling, a Simultaneous SLE (SimSLE) was introduced by Xiang et al. (2009) to utilize all observed transient hydrographs from all crosshole tests simultaneously to characterize the heterogeneity of aquifer properties. 
To overcome the computationally intensive nature of THT, Zhu and Yeh (2006) developed a temporal moment approach for HT analysis (HT-m) to avoid the direct use of transient data in inverse modeling. Synthetic simulations revealed satisfactory results in estimating both $K$ and $S_{s}$ with the HT-m approach, but sandbox results by Yin and Illman (2009) showed the deterioration of results compared to THT results obtained by Liu et al. (2007) suggesting the superiority of THT over the HT-m approach.

A number of recent studies have shown that HT is an effective tool for delineating the $K$ and $S_{s}$ heterogeneity of porous (Liu et al., 2002; Zhu and Yeh, 2005; Berg and Illman, 2012, 2013, 2015; Cardiff et al., 2009; Zhao et al., 2016) and fractured rock aquifers (Illman et al., 2009; Castagna et al., 2011; Sharmeen et al., 2012; Illman, 2014; Zha et al., 2015, 2016; Wang et al., 2017; Tiedeman and Barrash, 2019). The reason that HT is more accurate than traditional pumping tests is because with the same number of wells, a HT survey collects more data, it integrates the information collected from such tests and yields information on heterogeneity that traditional interpretations of pumping tests do not yield. In addition, the resolution of the HT can be increased by raising the density of observed pressure record or through integrating different types of information (Illman, 2014).

In particular, Illman et al. (2009) conducted a THT analysis of two, large-scale cross-hole pumping tests with monitoring data from deep boreholes at the Mizunami Underground Research Site in Japan. Their results revealed the effectiveness of THT in imaging continuous high $K$ and low $S_{S}$ zones, which corresponded to known fault zones. However, due to the availability of only two cross-hole tests and a limited number of observation intervals, there were still some fault zones mapped by geologists that did not show up on the $K$ and $S_{s}$ tomograms.

To further study the effectiveness of HT in mapping $K$ and $S_{S}$ heterogeneities in fractured rocks, Hao et al. (2008) have applied HT and the SSLE algorithm to map the hydraulic property distributions in synthetic fractured aquifers. Their results revealed that preferential flowpaths (high $K$ zones) which followed the fracture pattern and its connectivity could be mapped quite effectively 
with SSLE. However, compared to the true $K$ and $S_{S}$ distributions used to conduct the synthetic simulations, the estimated $K$ and $S_{s}$ tomograms from SSLE were smoother. However, with an increasing number of wells and monitoring ports, the fracture zone distribution and its connectivity became more vivid and approached the true values (Hao et al., 2008).

Subsequent to the study by Illman et al. (2009), Sharmeen et al. (2012) conducted HT experiments on a dolomitic fractured rock block under controlled laboratory conditions. The THT analyses of these data successfully delineated the high $K$ and low $S_{s}$ zones that captured the fracture pattern in the rock block and the computed $K$ and $S_{S}$ tomograms improved with additional pumping tests included in the analysis. However, Sharmeen et al. (2012)'s results revealed smooth tomograms and that the estimated matrix hydraulic properties, especially $K$ values, were larger than expected for the matrix of the rock sample. In Sharmeen et al. (2012)'s study, the THT was conducted with the SSLE code by treating the fractured rock as a heterogeneous EPM concept (i.e., $\mathrm{SCM}$ ), which resulted in difficulties for the inverse model to handle the high contrast in hydraulic properties of the fractures and the matrix.

Other than the SSLE code, other mathematical approaches were also developed for the interpretation of HT results. For example, Wang et al. (2017) applied a stochastic Newton (SN) method to solve a high-dimensional hydraulic inverse problem at a highly heterogeneous research site. The inverse method was separated into two parts: a deterministic part and a stochastic part. The accuracy of stochastic Newton method was evaluated by a synthetic model constructed based on geological and hydrogeological information obtained from outcrops and boreholes. Then, the inverse approach was applied to estimate the transmissivity fields within a fractured and karstified aquifer with collected hydraulic head measurements. The results from synthetic model showed that the important features of 'true' transmissivity field such as trend and locations of the high-T channel can be better captured by the inverse approach with the use of more conditional data. Moreover, the estimated transmissivity field from the fractured and karstified aquifer using the hybrid inverse method presented the consistency in reproducing the hydrodynamic responses to the data observed at the site. 
Fischer et al. (2018a) proposed another inverse modeling method named as the Discrete Network Deterministic Inversion (DNDI) for characterizing the geometry and property of the synthetic discrete network of conduits and fractures in karstified aquifers. Results indicated that the DNDI could help to obtain satisfying results on reproducing the observed data and capturing the network geometry and property values within the 'true' model. However, the inversion process was limited by the non-uniqueness of the solution during the calibration. Therefore, using the DNDI method may require several prerequisites such as the geological or geophysical information, and scientists should be critical toward the results. As mentioned in Fisher et al. (2018a), the inversion approach is deterministic, hence the precision of the result is dependent on the initial model. In addition, the authors recommended a multi-scale inversion approach in which the inversion starts from a coarse model and progressively refined to improve the results.

A harmonic pumping tomography was applied to characterize the hydraulic properties and connectivity of a karstic and fractured aquifer by Fischer et al. (2018b). During the harmonic pumping tests, the pumping rate varied based on a sinusoidal function within a given time. The drawdown monitored during the harmonic pumping tests were interpreted by the Cellular Automata-based Deterministic Inverse (CADI) algorithm developed previously (Fisher et al., 2017) to quantitatively analyze the hydraulic properties within the karstic and fractured aquifer. The results have revealed the influence from different signal frequencies during the tomographic harmonic pumping tests on estimating structures of the karstic network. Higher frequency signals were found to assist the interpretation of most conductive structures and connectivity between boreholes, while lower frequency signals were more helpful in locating less conductive features.

Recognizing the difficulties with the EPM approach, a deterministic THT approach was proposed by Klepikova et al. (2020) based on the DFNM concept for imaging the connectivity, transmissivity, and storativity of a network of fractures with a fixed fracture pattern. The results from the research revealed that the proposed approach can be used to successfully calibrate a twodimensional DFNM and qualitatively match observations from cross-hole injection test data at the site. However, due to the highly simplified nature of the fracture network built in two-dimensions, 
only the dominant pathways that the researchers conceptualized could be included in the inverse model.

To evaluate the equivalence between EPM and DFNM, Dong et al. (2019) recently studied the extent to which HT with a heterogeneous EPM can characterize fracture networks generated by the DFNM approach and the importance of representative elementary volume (REV) sizes on HT performance in fractured media. Three DFNMs with different densities were constructed to generate the synthetic data used in heterogeneous EPM calibration. The concept of spatial REV in terms of probability of fracture connectivity was introduced by Dong et al. (2019) to assess the equivalence of HT results obtained through the heterogeneous EPM approach. Results indicated that if a spatial REV exists within the studied domain, a fracture network could be treated as a heterogeneous EPM (or SCM) approach. For a DFNM with sparse fractures in which the spatial REV cannot be identified, only the dominant fractures can be captured by EPM by HT as high $K$ zones with a limited number of wells. More monitoring wells are required for the accurate mapping of discrete fractures within a network (Dong et al., 2019). These observations suggest that additional improvements are necessary to HT.

Zha et al. $(2015 ; 2016)$ improved the THT analysis conducted by Illman et al. (2009) by including two additional tests in the analysis which were not available to Illman et al. (2009). Zha et al. (2015) also conducted synthetic HT analysis to investigate the effectiveness of HT in mapping hydraulic parameter heterogeneity. By replicating the similar fracture features in the synthetic model, it was discovered that high $K$ zones defined from HT analysis not only related to fracture network connected with pumping and observing location, but also presented the degree of connectivity of the network. Furthermore, $K$ and $S_{s}$ tomograms were found to be negatively correlated confirming the conclusion by Illman et al. (2009), while the $S_{s}$ tomogram was less indicative of geologic features. Due to the sparse monitoring interval density, HT yielded smooth maps of heterogeneity, and non-redundant datasets helped to improve the accuracy of characterizing faults and fracture zones as well as to improve their resolutions. As indicated by Illman (2014), improving the resolution of $K$ and $S_{s}$ tomograms is a significant challenge for 
fractured rock aquifers, and the integration of additional data types from surficial and borehole geological investigations, small-scale hydraulic tests, flowmeter surveys, tracer test data and geophysical tomography may potentially increase the resolution.

For the characterization of unconsolidated porous media, Zhao et al. (2016), Zhao and Illman (2017, 2018) and Luo et al. (2017) showed the potential for improving HT results through the integration of geological data. In particular, both correct and incorrect geologic information were included as prior information for the HT analysis. The study was systematically begun using sandbox experiments (Zhao et al., 2016; Luo et al., 2017) and demonstrated using data from a highly heterogeneous aquifer-aquitard system (Zhao et al., 2017, 2018). The results from different scales have revealed the same conclusion that correct geologic information can help to improve the accuracy of heterogeneity characterization. Then, the idea was extended by Zha et al. (2017) and applied at the Mizunami Underground Research site investigated by Illman et al. (2009) and Zha et al. (2015, 2016). In particular, Zha et al. (2017) included a single, planar fault as a prior information during their HT analysis and found that this method improved the estimation of hydraulic properties by the validation of pumping tests that were not used in model calibration. However, as in the work of Sharmeen et al. (2012), the fractured rock had higher values of K for areas that are thought to be dominated by the hydraulic properties of the matrix. Therefore, additional information such as geological information may potentially improve the quality of estimated $K$ and $S_{s}$ tomograms of fractured rocks, but the value of including such information in HT analyses requires further testing.

Therefore, the main objectives of this study are to investigate the importance of including various geologic data for THT analysis as an initial estimate to image the $K$ and $S_{S}$ tomograms of fractured geologic media. In particular, the value of including correct and incorrect fracture geometry data as well as matrix data is assessed through this study. The research is based on the previous HT analysis conducted by Sharmeen et al. (2012), who utilized synthetic and real data collected from a dolostone rock sample with known fracture locations. In this study, data from pumping tests along with various geologic data are interpreted using the SSLE code developed by 
Zhu and Yeh (2005) to perform the THT analyses of various cases, which simultaneously estimate the hydraulic parameter fields of $K$ and $S_{S}$ as well as its uncertainty. The computed $K$ and $S_{S}$ tomograms are validated through other tests not used during the calibration effort and the results with and without geologic data included in the THT analyses are critically assessed. 


\section{Methodology}

\subsection{Description of Laboratory Experiments}

The fractured dolostone rock from the Guelph Formation was acquired and fitted in a flow cell as described in the following section to conduct various hydraulic and tracer tests (Sharmeen 2011; Sharmeen et al., 2012). The dimensions of the sample rock were $91.5 \mathrm{~cm}$ in length, $60.5 \mathrm{~cm}$ in height and $5.0 \mathrm{~cm}$ in depth. The dolomite rock sample was fractured in the laboratory as described in Sharmeen (2011). There were 29 ports installed on the flow cell that were used to monitor water pressure, conduct pumping tests or to take water samples. In total, seventeen pressure transducers were installed on ports completed on fractures, while ten pressure transducers were installed on the rock matrix. Two extra pressure transducers were placed on the adjoining constant head reservoirs to record pressure head during hydraulic tests (Figure 2.1). The port locations were intended to simulate typical vertical or slanted borehole configurations in the field (Sharmeen, 2011). To allow for fluid flow, both left and right boundaries of the reservoir were open to the rock block. Furthermore, both left and right reservoirs were maintained at a specified constant head $(63.5 \mathrm{~cm})$, while "no-flow" conditions were kept at the other boundaries.

Four flow-through tests (Table 2.1) along with 17 pumping tests (Table 2.2) were conducted to estimate the fracture aperture and the heterogeneity of hydraulic properties within the fractured geologic medium. More detailed information on the rock block facility and laboratory experiments are provided in Sharmeen et al. (2012). 
Table 2.1: Summary of flow-through tests (modified from Sharmeen, 2011)

\begin{tabular}{cccccc}
\hline Test No. & Flow direction & $\begin{array}{c}\text { Hydraulic } \\
\text { Gradient }\end{array}$ & $\begin{array}{c}\text { Flow Rate } \\
(\mathrm{mL} / \mathrm{s})\end{array}$ & $\begin{array}{c}\text { Estimated } \\
\text { Hydraulic } \\
\text { Aperture }(\mathrm{cm})\end{array}$ & $\begin{array}{c}\text { Effective } K \\
(\mathrm{~cm} / \mathrm{s})\end{array}$ \\
\hline 1 & Left $\rightarrow$ Right & 0.05 & 0.28 & 0.050 & $1.70 \times 10^{-2}$ \\
2 & Left $\rightarrow$ Right & 0.13 & 0.50 & 0.047 & $1.30 \times 10^{-2}$ \\
3 & Right $\rightarrow$ Left & 0.06 & 0.27 & 0.048 & $1.50 \times 10^{-2}$ \\
4 & Right $\rightarrow$ Left & 0.13 & 0.51 & 0.047 & $1.30 \times 10^{-2}$ \\
\hline
\end{tabular}


Table 2.2: Summary of pumping tests in fractured dolomite rock block sample (modified from Sharmeen et al., 2012).

\begin{tabular}{|c|c|c|c|c|}
\hline $\begin{array}{l}\text { Pumping } \\
\text { location }\end{array}$ & $\begin{array}{c}\text { Pumping Rate } \\
(\mathrm{mL} / \mathrm{s})\end{array}$ & $\begin{array}{l}\text { Pumping Period } \\
\text { (min) }\end{array}$ & $\begin{array}{c}\text { Maximum } \\
\text { Drawdown }(\mathrm{cm})\end{array}$ & $\begin{array}{l}\text { Location of } \\
\text { Maximum } \\
\text { Drawdown }\end{array}$ \\
\hline Port 1 & 4 & 10 & 8 & Port 3 \\
\hline Port 3 & 2.5 & 10 & 10 & Port 15 \\
\hline Port 4 & 2.5 & 10 & 10.4 & Port 3 \\
\hline Port 5 & 4 & 10 & 17.3 & Port 11 \\
\hline Port 6 & 2.5 & 10 & 10 & Port 11 \\
\hline Port 7 & 2.5 & 5 & 7.8 & Port 19 \\
\hline Port 8 & 4 & 10 & 9.5 & Port 7 \\
\hline Port 9 & 4 & 10 & 5.9 & Port 8 \\
\hline Port 11 & 4 & 10 & 17 & Port 13 \\
\hline Port 12 & 4 & 10 & 19.7 & Port 13 \\
\hline Port 13 & 4 & 10 & 18.7 & Port 12 \\
\hline Port 14 & 2.5 & 10 & 16.2 & Port 15 \\
\hline Port 15 & 1.7 & 10 & 14.9 & Port 16 \\
\hline Port 16 & 1 & 10 & 11.7 & Port 15 \\
\hline Port 17 & 2.5 & 3 & 29.7 & Port 18 \\
\hline Port 18 & 1.7 & 10 & 21.3 & Port 17 \\
\hline Port 19 & 1 & 10 & 18.4 & Port 18 \\
\hline
\end{tabular}




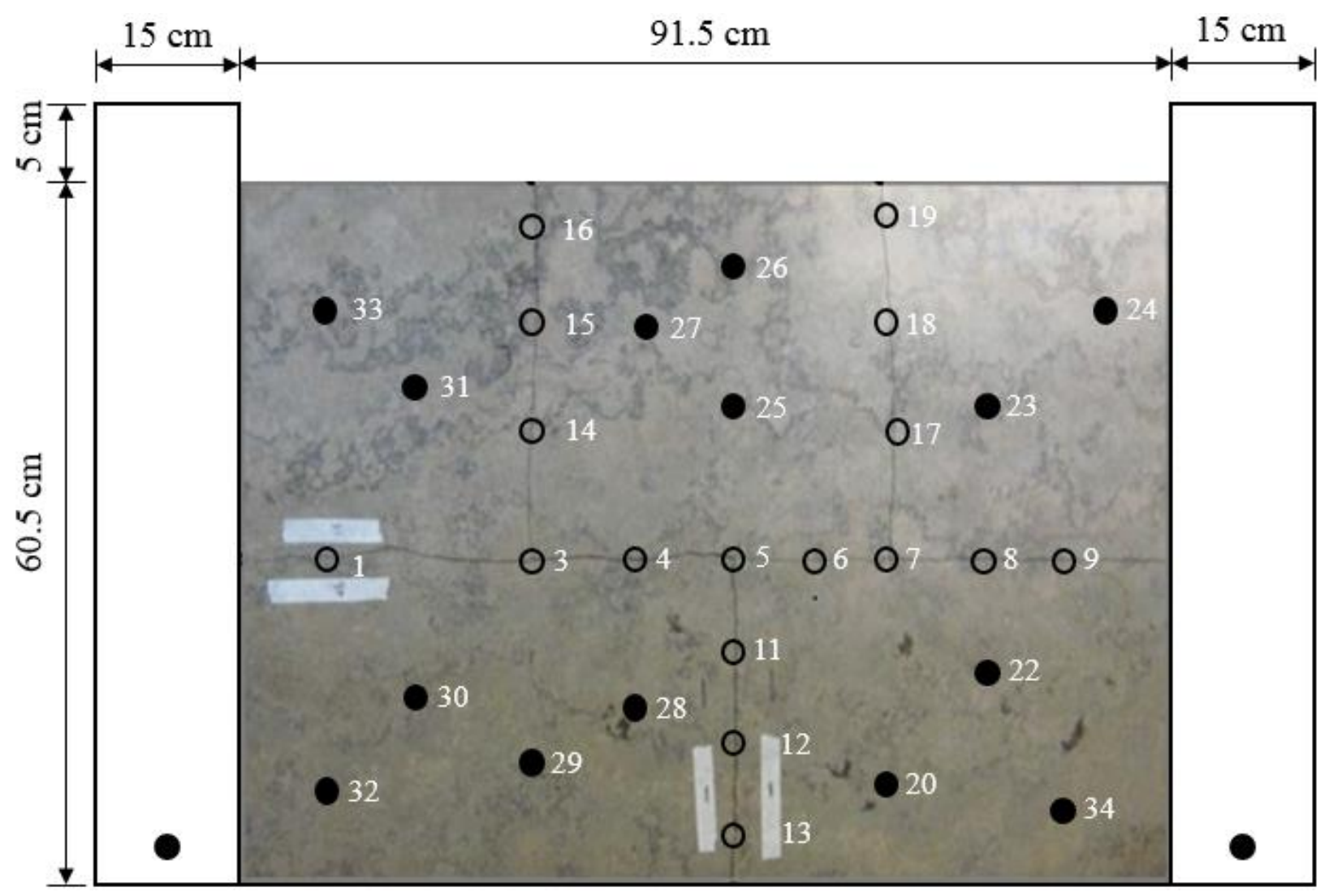

Figure 2.1: Profile of the fractured rock block. Circles represent ports located on fractures, and solid circles indicate the ports at the matrix and constant head reservoirs (modified from Sharmeen et al., 2012).

2.2 Synthetic pumping tests designed for HT analysis

In this study, a groundwater flow and solute transport model was utilized for the simulation of synthetic pumping tests that will be used for HT analysis. In particular, HydroGeoSphere (HGS) (Aquanty, 2019) was used to construct the synthetic fractured rock model with discrete fractures as shown on Figure 2.2. The model was constructed so that it has the same dimensions as the laboratory rock block. The finite elements utilized for the model varied from $0.05 \mathrm{~cm} \times 0.01 \mathrm{~cm} \times$ $5.0 \mathrm{~cm}$ to $1.375 \mathrm{~cm} \times 1.375 \mathrm{~cm} \times 5.0 \mathrm{~cm}$. The finer elements were located at fractures and ports, while the coarser elements were situated away from these features within the rock block (Figure 2.3). The domain was designed with 43,806 elements and 88,500 nodes. The fracture locations and 
its pattern observed on the laboratory rock block was replicated in the constructed HGS model.

Information for the synthetic model settings were obtained from Sharmeen et al. (2012). The fractures in the rock block were assumed to have the same aperture and to be straight (Figure 2.3). Based on the average hydraulic aperture $(0.049 \mathrm{~cm})$ estimated from the flow through tests (Table 2.1 ), the corresponding $K$ was estimated to be $17.46 \mathrm{~cm} / \mathrm{s}$, and a value of $S_{s}$ of $1.11 \times 10^{-2} \mathrm{~cm}^{-1}$ is used for the fractures. The equivalent $K_{f}$ value is calculated from the fracture aperture through the following equation (Aquanty, 2019):

$$
K_{f}=\frac{\rho g W_{f}^{2}}{12 \mu}
$$

where $K_{f}$ is hydraulic conductivity of the fracture, $W_{f}$ is the fracture aperture, $\rho$ is water density and $\mu$ is the dynamic viscosity of water. The fracture-matrix interface of the model is considered to be an impermeable boundary in which no flow takes place from the fracture into the matrix and vice versa. Therefore, in the model, groundwater flow only occurs within fractures.

(a)

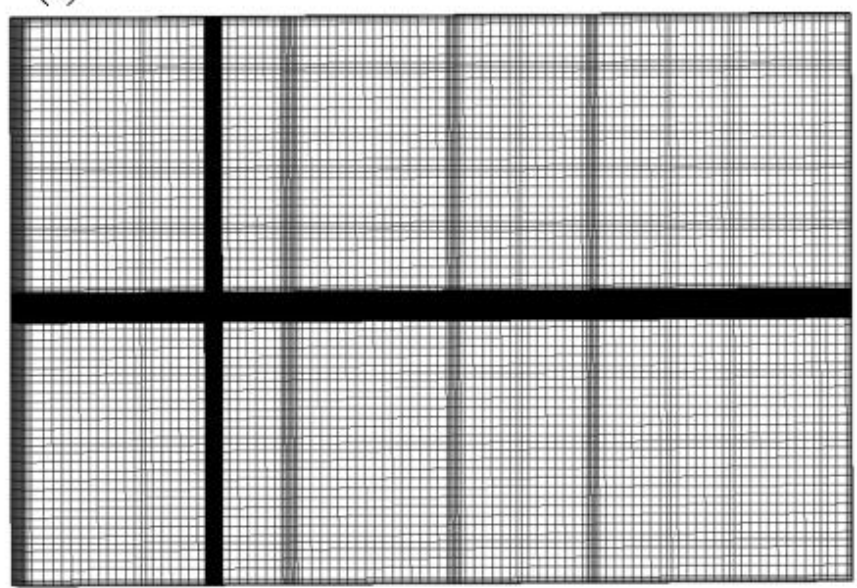

(b)

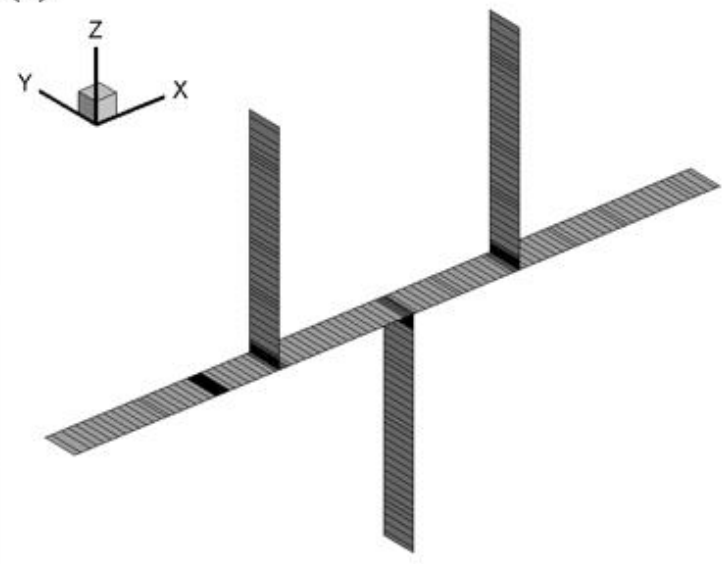

Figure 2.2: (a) HGS mesh used for synthetic pumping tests, (b) fracture elements within the fractured rock block (modified from Sharmeen, 2011)

The created DFNM was then utilized to generate synthetic pumping test data by pumping from one port, while monitoring the corresponding drawdown responses at monitoring ports. The synthetic data were generated using the same ports utilized for pumping tests in the actual rock block experiments. These synthetically generated data were then used for HT analyses described 
subsequently.

Initial parameters used for the forward simulations were obtained from Sharmeen (2011). A synthetic simulation of a pumping test at port 5 was conducted to check the correspondence of drawdown responses from the synthetic model to those observed in the actual rock block (Figure 2.3). The comparisons for the rest of the pumping tests are presented in Appendix A. Results from the simulation revealed drawdown responses at fracture ports, but as expected, no drawdowns were observed at matrix ports. The lack of drawdown responses at matrix ports is useful information and can be applied to HT analysis. Those ports are connected through the matrix material to the fractures where other ports are installed. However, the large difference on hydraulic property between fractures and the matrix results that head perturbations do not diffuse through the matrix over the measured time scale. In order to match the tests performed in the laboratory, similar pumping tests were simulated as shown in Table 2.2.

Prior to the HT analysis, the DFNM was calibrated with each synthetic pumping test automatically to estimate the hydraulic properties of the fracture network (Table 2.3) by treating the fracture elements to all have the same values of $W_{f}$ and $S_{s}$. Specifically, both the $W_{f}$ and $S_{s}$ of the fracture network were automatically adjusted through the calibration of each pumping test conducted at ports $3,4,6,7,12,15$, and 18 by coupling HGS with PEST which is a modelindependent parameter estimation and uncertainty analysis software (Doherty, 2005). Then, equation (1) was used to calculate the $K_{f}$ from the calibrated $W_{f}$ values. The calibration of the DFNM with different pumping tests was conducted to evaluate the consistency of $K_{f}$ and $S_{s}$ within fractured rock sample (Table 2.3). Results revealed that the estimated $K_{f}$ and $S_{S}$ values were not the same for all pumping tests and that the $95 \%$ confidence intervals of $K_{f}$ were considerably narrower than $S_{s}$ suggesting the larger uncertainty in estimated $S_{s}$ values. Overall, the estimated $K_{f}$ ranged from 14.13 to $28.61 \mathrm{~cm} / \mathrm{s}$, while $S_{s}$ had a wider range from $9.09 \times 10^{-3}$ to $6.53 \times 10^{-2} \mathrm{~cm}^{-1}$. It is important to keep in mind that the DFNM used for calibration assumes that the fracture pattern is perfectly known, which may be considered to be an unrealistic assumption for field data analysis. 

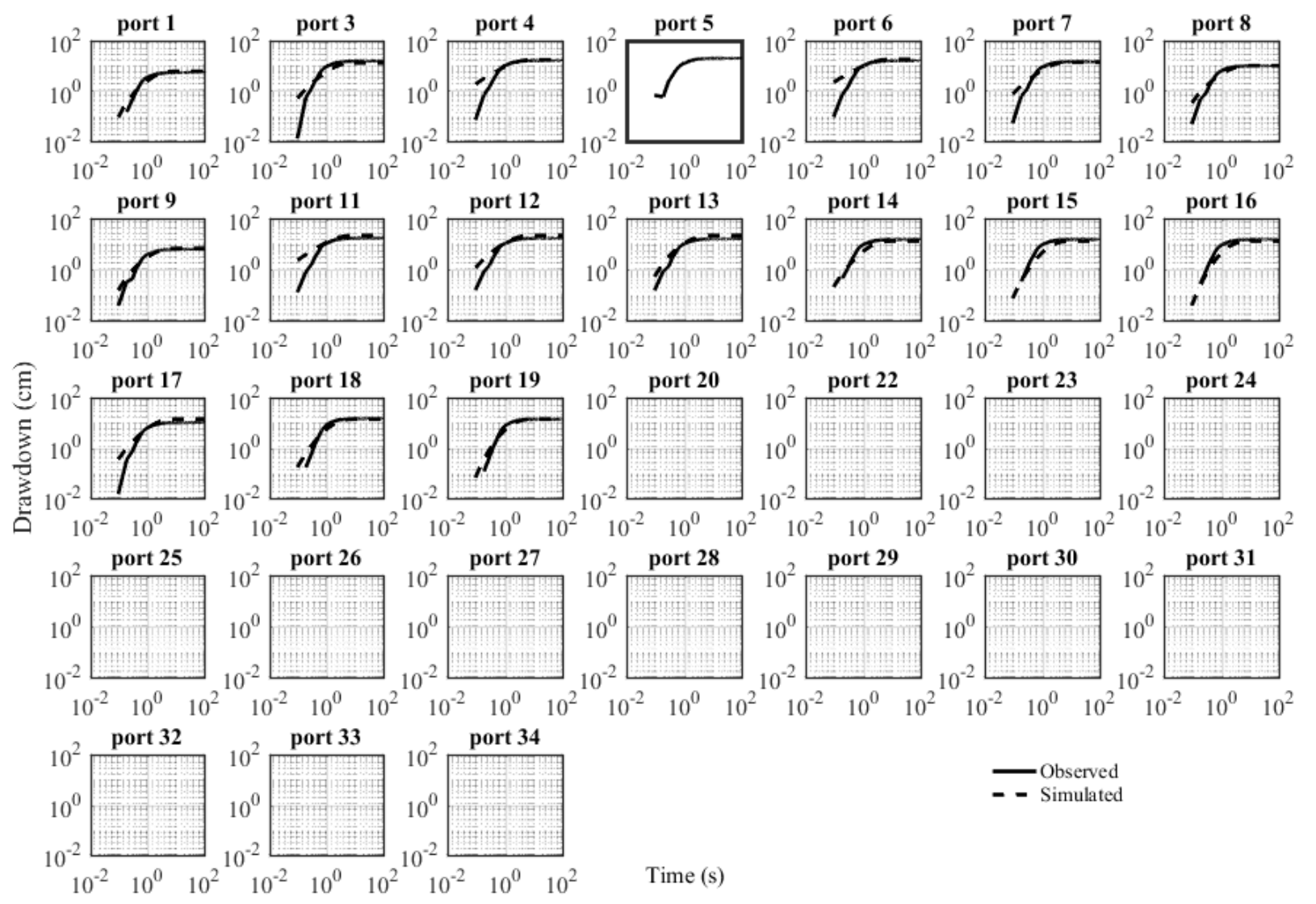

Figure 2.3: Observed (black solid line) and calibrated (blue dashed line) drawdown curves using HGS during a pumping test at port 5 (modified from Sharmeen et al., 2012) 
Table 2.3: Calibrated hydraulic properties of fractures from different pumping tests by HGS coupled with PEST.

\begin{tabular}{|c|c|c|c|c|c|c|c|}
\hline \multirow{4}{*}{$\begin{array}{l}\text { Pumping } \\
\text { Port }\end{array}$} & \multirow{4}{*}{$\begin{array}{l}\text { Aperture } \\
\text { (cm) }\end{array}$} & \multirow{4}{*}{$\begin{array}{c}K_{f} \\
(\mathrm{~cm} / \mathrm{s})\end{array}$} & \multicolumn{3}{|c|}{$95 \%$ percent confidence } & \multirow{2}{*}{\multicolumn{2}{|c|}{$\begin{array}{l}95 \% \text { percent confidence } \\
\text { limits }\end{array}$}} \\
\hline & & & & & \multirow{3}{*}{$S_{S}(/ \mathrm{cm})$} & & \\
\hline & & & Lower & Upper & & Lower & \multirow{2}{*}{ Upper Limit } \\
\hline & & & Limit & Limit & & Limit & \\
\hline Port 3 & $5.04 \times 10^{-2}$ & 18.48 & $5.03 \times 10^{-2}$ & $5.05 \times 10^{-2}$ & $9.26 \times 10^{-3}$ & $8.86 \times 10^{-3}$ & $9.68 \times 10^{-3}$ \\
\hline Port 4 & $4.85 \times 10^{-2}$ & 17.11 & $4.84 \times 10^{-2}$ & $4.86 \times 10^{-2}$ & $1.00 \times 10^{-2}$ & $9.73 \times 10^{-3}$ & $1.03 \times 10^{-2}$ \\
\hline Port 5 & $5.07 \times 10^{-2}$ & 18.48 & $5.06 \times 10^{-2}$ & $5.08 \times 10^{-2}$ & $8.32 \times 10^{-2}$ & $7.92 \times 10^{-3}$ & $1.03 \times 10^{-2}$ \\
\hline Port 6 & $4.94 \times 10^{-2}$ & 17.72 & $4.93 \times 10^{-2}$ & $4.95 \times 10^{-2}$ & $9.09 \times 10^{-3}$ & $8.71 \times 10^{-3}$ & $9.48 \times 10^{-3}$ \\
\hline Port 7 & $6.27 \times 10^{-2}$ & 28.61 & $6.26 \times 10^{-2}$ & $6.29 \times 10^{-2}$ & $4.26 \times 10^{-3}$ & $3.80 \times 10^{-3}$ & $4.78 \times 10^{-3}$ \\
\hline Port 12 & $5.53 \times 10^{-2}$ & 22.24 & $5.51 \times 10^{-2}$ & $5.55 \times 10^{-2}$ & $1.26 \times 10^{-2}$ & $1.18 \times 10^{-2}$ & $1.35 \times 10^{-2}$ \\
\hline Port 15 & $5.50 \times 10^{-2}$ & 21.96 & $5.49 \times 10^{-2}$ & $5.51 \times 10^{-2}$ & $1.78 \times 10^{-2}$ & $1.72 \times 10^{-2}$ & $1.84 \times 10^{-2}$ \\
\hline Port 18 & $4.41 \times 10^{-2}$ & 14.13 & $4.38 \times 10^{-2}$ & $4.44 \times 10^{-2}$ & $6.53 \times 10^{-2}$ & $6.27 \times 10^{-2}$ & $6.80 \times 10^{-2}$ \\
\hline
\end{tabular}

2.3 HT analysis of Synthetic and Real Pumping Test Data

The HT analyses of synthetic and real pumping tests were conducted with the Sequential Successive Linear Estimator (SSLE) developed by Zhu and Yeh (2005), which treats the fractured rock block as a SCM. In particular, a Transient Hydraulic Tomography (THT) analysis was performed to reproduce the drawdown curves instead of Steady-State Hydraulic Tomography (SSHT) to estimate both $K$ and $S_{s}$ simultaneously as the latter only estimates $K$. SSLE inverts individual data sets from each pumping test sequentially instead of inverting all pumping test data simultaneously through the SimSLE code developed by Xiang et al. (2009). In this study, we utilize SSLE instead of SimSLE as Sharmeen et al. (2012) utilized SSLE. In the SSLE model, the 
hydraulic parameters (e.g. $K$ and $S_{s}$ ) are regarded as a stochastic process, and geostatistical parameters such as correlation scale, spatial covariance functions are included as prior information.

The SSLE program begins with cokriging that utilizes available hydraulic properties and pressure heads from measurements to generate the conditional $K$ and $S_{s}$ fields. The computed conditional means of those hydraulic parameters are then used to generate new pressure heads at observed ports. Then, the parameter fields are iteratively revised by the SSLE algorithm to minimize the difference between simulated and observed drawdowns until it reaches user-defined stopping criteria (Zhu and Yeh, 2005).

The model domain for the THT analysis is the same utilized by Sharmeen et al. (2012) so that results could be compared. The model domain was designed to be consistent with the laboratory rock block $(91.5 \mathrm{~cm} \times 60.5 \mathrm{~cm} \times 5 \mathrm{~cm})$ (Figure 2.4). A single finite element was used to represent the thickness of the simulation domain because it was assumed that no heterogeneity existed along the thickness of the rock block. The entire simulation domain of SSLE was divided into 14,140 nodes and 6,900 elements, which was less than the HGS model described previously. The element sizes ranged from $0.5 \mathrm{~cm} \times 0.5 \mathrm{~cm} \times 5.0 \mathrm{~cm}$ to $1.75 \mathrm{~cm} \times 1.75 \mathrm{~cm} \times 5.0 \mathrm{~cm}$. The finer elements were located along the ports, with the center of the element having the same coordinates as the port center. The coarser elements were situated near the boundaries.

Constant head boundaries were assigned at left and right sides, while no flow conditions were prescribed at the rest of the boundaries. The initial constant head of domain was set to be $63.5 \mathrm{~cm}$ to match the constant head boundaries maintained in the lab experiment. This model setting was used for the THT analysis of both synthetic and real laboratory data. 


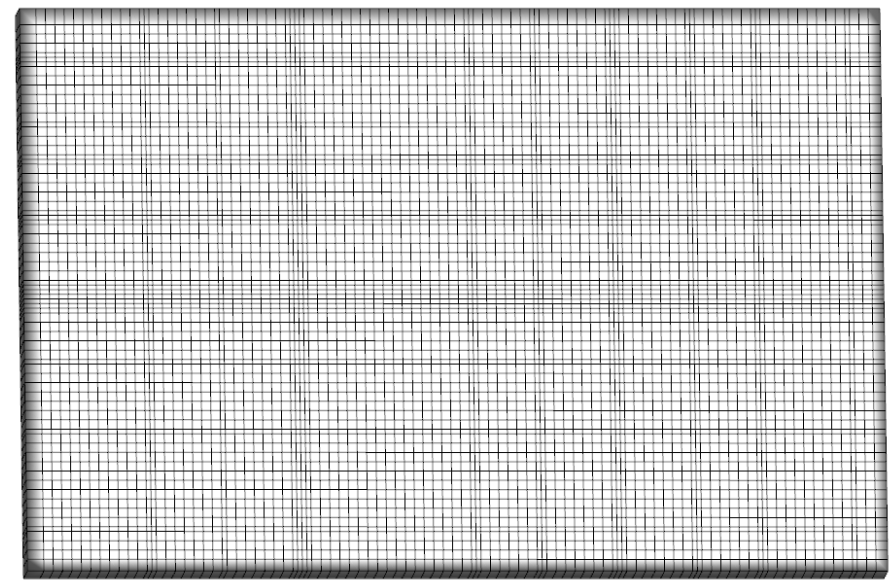

Figure 2.4: Finite element mesh used for the inversion of synthetic and experimental data (modified from Sharmeen, 2011).

\subsection{Input parameters for the inverse model}

Inputs to the SSLE for the synthetic and laboratory data analysis include various $K$ and $S_{S}$ values for the cases with and without prior geologic information. Based on previous work, the initial values of $K$ and $S_{s}$ were estimated from hydraulic tests and model calibration as done by previous researchers. For example, Sharmeen et al. (2012) coupled the forward groundwater simulation model built within SSLE with PEST to estimate the effective hydraulic parameters of the rock block. In particular, the estimated effective $K$ and $S_{S}\left(K=1.4 \times 10^{-2} \mathrm{~cm} / \mathrm{s}\right.$ and $S_{S}=5.0 \times 10^{-}$ ${ }^{3} \mathrm{~cm}^{-1}$ ) were included as initial inputs for the HT analysis, which is identical to the case done by Sharmeen (2011). Likewise, estimates of correlation length and variance were obtained from Sharmeen et al. (2012) to maintain consistency with published results. Then, in order to investigate the influence of geologic information on THT analyses, various prior geologic models were included in the inverse models.

To be consistent with work done by Sharmeen et al. (2012), data collected from the pumping tests at port 3, 5, 7 were used for model calibration. Specifically, following the guidelines of Illman et al. (2008), pumping test data from port 5 with the highest $\mathrm{S} / \mathrm{N}$ ratio was included first in the inverse model. Then, two additional tests (port 3 as second and port 7 as third test) with lower $\mathrm{S} / \mathrm{N}$ 
ratio were included subsequently. Illman et al. (2008) found that including higher $\mathrm{S} / \mathrm{N}$ ratio data first in the HT analysis helped to obtain better results than including lower $\mathrm{S} / \mathrm{N}$ data first.

Prior geologic information was included by inputting different hydraulic parameter values in the initial model settings (Figure 2.5; Table 2.4). The fracture patterns were divided into three different cases: 1) correct; 2) partially correct; and 3) wrong (Figure $2.5 \mathrm{a}, \mathrm{b}, \mathrm{c}$ ). These different prior fracture patterns were input to evaluate the influence of incorporating varying quality geologic information into the inverse model. In order to indicate the fracture properties within the fractured aquifer, the calculated $K(17.46 \mathrm{~cm} / \mathrm{s})$ and calibrated $S_{S}\left(1.11 \times 10^{-2} / \mathrm{cm}\right)$ values from HGS were input as the initial estimates. However, due to the large $K$ utilized for the fracture resulting in a large contrast between fracture and matrix $K$, the model for this particular case did not converge and further work on this issue is necessary. Therefore, instead of inputting the actual calculated value, I have reduced the contrast of $K$ (5000 times) and $S_{S}$ (10 times) between fractures and the matrix based on the geometric mean from the previous work (Table 2.4). The hydraulic parameters of the fracture and matrix are provided on Table 2.4, while the case without geologic information utilizes the geometric mean from Sharmeen et al. (2012). In terms of matrix hydraulic properties, low $K$ and relatively high $S_{s}$ values were included as an initial estimate.

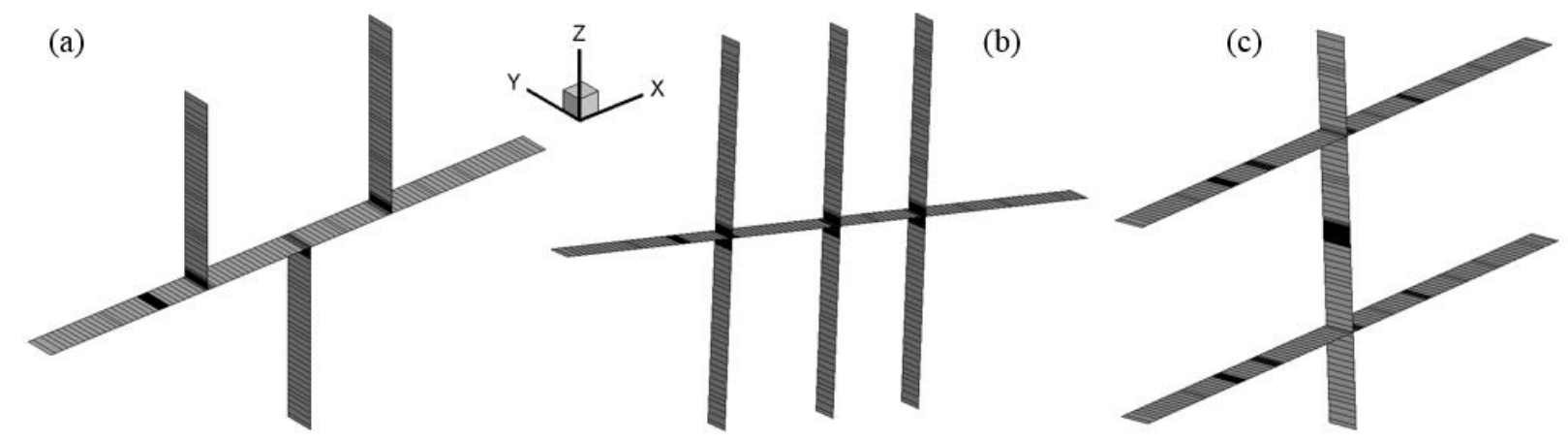

Figure 2.5: (a) Correct fracture locations; (b) partially correct fracture locations; (c) wrong fracture locations for synthetic and lab data analysis. 
Table 2.4: Summary of initial estimates of hydraulic parameters for the synthetic and real THT.

\begin{tabular}{cccc}
\hline Cases & Geologic Information & $K(\mathrm{~cm} / \mathrm{s})$ & $S_{s}\left(\mathrm{~cm}^{-1}\right)$ \\
\hline Homogeneous Case & None & $1.4 \times 10^{-2}$ & $5.0 \times 10^{-3}$ \\
Correct Fracture Location & Fractures & $7.0 \times 10^{-1}$ & $5.0 \times 10^{-4}$ \\
& Matrix & $1.4 \times 10^{-4}$ & $5.0 \times 10^{-3}$ \\
Partially Correct Fracture & Fractures & $7.0 \times 10^{-1}$ & $5.0 \times 10^{-4}$ \\
Location & Matrix & $1.4 \times 10^{-4}$ & $5.0 \times 10^{-3}$ \\
& Fractures & $7.0 \times 10^{-1}$ & $5.0 \times 10^{-4}$ \\
Wrong Fracture Location & Matrix & $1.4 \times 10^{-4}$ & $5.0 \times 10^{-3}$ \\
\hline
\end{tabular}

For the synthetic as well as the laboratory data cases, five data points $(0.5 \mathrm{~s}, 2 \mathrm{~s}, 7 \mathrm{~s}, 18 \mathrm{~s}, 20$ s) were selected from each observed port (located at both fractures and the matrix) to capture the entire drawdown curve. As observed in the lab and synthetic pumping test data, the drawdown was very small and unmeasurable at the matrix observation ports due to low $K$ and high $S_{S}$ of the matrix compared to the fractures. Therefore, zero drawdown was input to the inverse model for each matrix port for the calibration of both synthetic and laboratory cases. 


\section{Results from Transient Hydraulic Tomography}

The case with wrong fracture pattern showed that the results did not converge in the calculation. Therefore, it is not presented in the result part. The homogeneous case without extra geologic information as well as two other successful cases with geologic information are presented in the following sections.

\subsection{Inverse modeling of synthetic data}

Figures $3.1 \mathrm{a}$, c, e are the $K$ tomograms obtained by inverting the synthetic transient head data without prior geologic information, with correct geologic information, and with partially correct geologic information, respectively. Figures $3.1 \mathrm{~b}, \mathrm{~d}$, f are the estimated $\ln K$ variance $\left(\sigma^{2} \ln K\right)$ maps corresponding to the $K$ tomograms of Figures $3.1 \mathrm{a}$, c, e, respectively. All the tomograms are the result of sequentially calibrating the model with three pumping tests in the order of ports 5, 3, and 7. The black dashed circles within the tomograms represent the observed ports. Thin dashed lines on Figure 3.1a indicate the fracture locations in both horizontal and vertical directions. Model results for plotting and further analysis are selected based on the lowest point of the curve of the biggest head misfit (biddf) between simulated and observed drawdown values which indicates the convergence of the inverse model. Results showing the convergence of all model runs are presented in Appendix B.

Figure 3.1a reveals that without prior geologic information, the estimated high $K$ zones relative to the background corresponds quite well with fracture locations. This $K$ tomogram indicates that without prior geologic information, the inverse model is able to capture the substantial details of the fracture pattern and their connectivity away from the boundaries. However, the mapped fracture pattern near the left and right constant head boundaries is not as distinct, because the drawdowns are smaller near the left and right boundaries compared to that within the interior of the fractured rock sample due to the presence of constant head reservoirs. In addition, the value of $K$ is significantly lower immediately beyond the mapped high $K$ zones correctly showing the no flow boundary between the fracture and the matrix. The zero value of 
drawdown observed at the matrix ports may have caused the estimated $K$ values at the matrix part to approach the geometric mean of $K$ which is not a reasonable $K$ value for matrix.

In contrast, Figure 3.1c shows that with correct prior geologic information, the high $K$ values at fracture locations are distinctively mapped. In addition, compared to Figure $3.1 \mathrm{a}$, the fracture pattern is more distinguishable especially at the edge of the fractures. Moreover, due to the correct prior geologic information, $K$ estimates are considerably more accurate and approach the real condition.

Figure 3.1e is the estimated $K$ tomogram with partially correct geologic information as initial input. Similar to Figure 3.1c, the fracture pattern is delineated, but the incorrect piece of geologic information has a significant impact on the $K$ tomogram causing high $K$ values to persist along the wrongly estimated fracture locations. This suggests that incorrect fracture information could lead to artifacts to inverse modeling results.

The $\sigma^{2} \ln K$ map on Figure $3.1 \mathrm{~b}$ reveals that the lower $\sigma^{2} \ln K$ indicating lower uncertainty in estimated $K$ follows the fracture pattern, while higher $\sigma^{2} \ln K$ values are generally found within the matrix, where monitoring data are sparse. In Figures 3.1d and e, lower values of $\sigma^{2} \ln K$ are located where prior geologic information was input as the initial estimate. For all three uncertainty maps, the $\sigma^{2} \ln K$ is lower along the horizontal fracture. This situation is probably caused by the location of pumping tests used for calibration. The pumping tests conducted at ports 5, 3, and 7 are all located along the horizontal fracture, which may lead to more information acquired along the horizontal fracture than vertical fractures. This could potentially result in higher uncertainty at other fracture locations. More pumping tests could be input to improve the accuracy of results for future studies. 

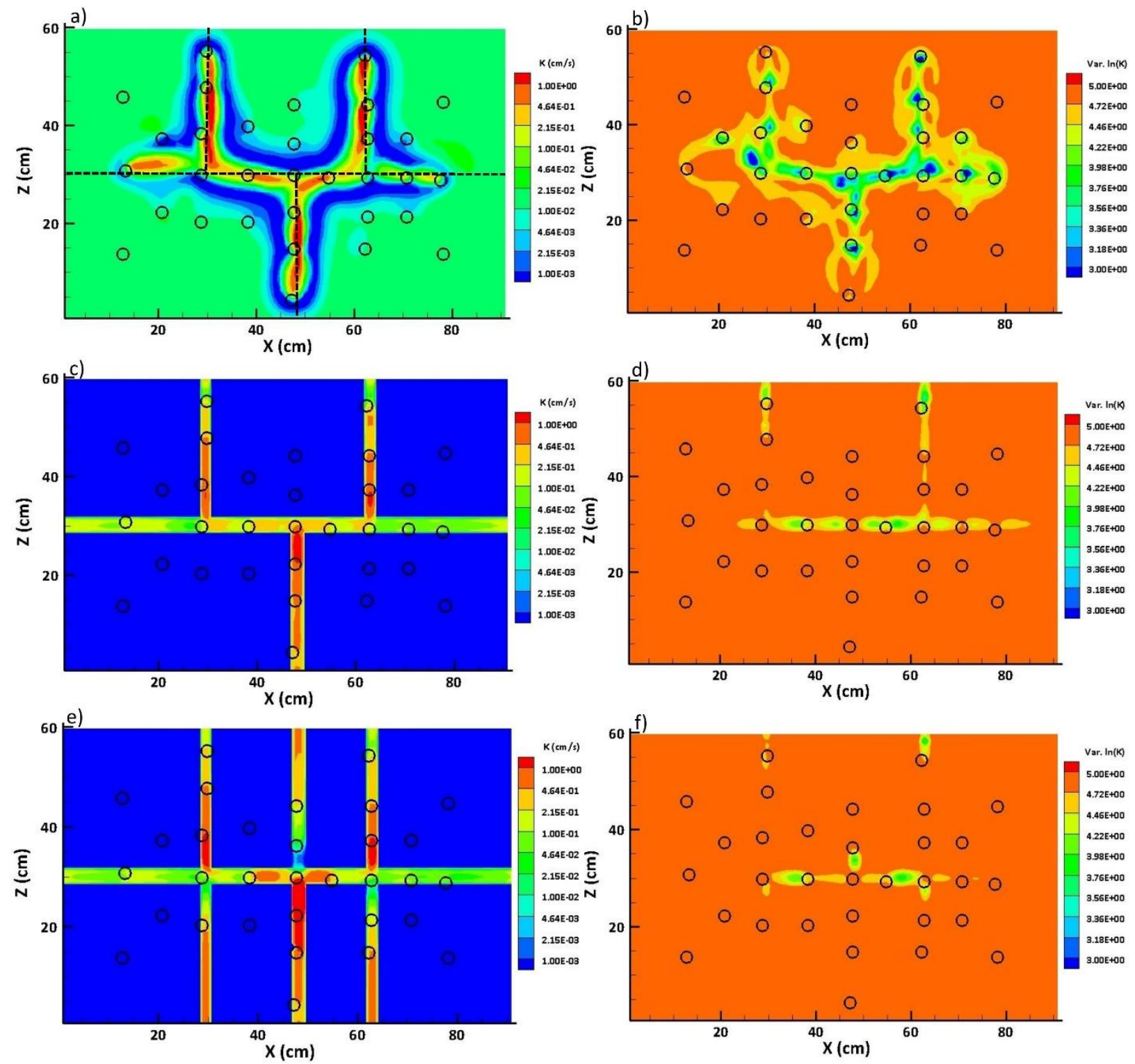

Figure 3.1: $K$ tomograms $\left(\mathrm{cm} \mathrm{s}^{-1}\right)$ delineated using synthetic data from three pumping tests (ports 3, 5, and 7): a) $K$ tomogram without prior geologic information; b) corresponding $\sigma^{2} \ln K$; c) $K$ tomogram with correct prior geologic information; d) corresponding $\sigma^{2}{ }_{\ln K}$; e) $K$ tomogram with partially correct prior geologic information; and f) corresponding $\sigma^{2} \ln K$.

Figure 3.2a, c, and e present the corresponding $S_{s}$ tomograms that were estimated simultaneously. The low $S_{s}$ zones mapped on the $S_{s}$ tomogram (Figure 3.2a) generally corresponds 
to the fracture pattern within the rock sample. However, there are some unexpected large $S_{s}$ areas developed around the estimated low $S_{s}$ zones delineating fractures, which is not strictly correct.

In contrast, similar to Figure 3.1c, details to the fracture pattern where $S_{s}$ values are lower than the background become more evident as correct geologic information is incorporated into the inverse model (Figure 3.2c).

Figure 3.2e is analogous to Figure 3.1e which is the estimated $S_{s}$ tomogram from the partially correct fracture pattern assigned as prior information for the HT analysis. The estimated fracture pattern is visible through the presence of relatively low $S_{s}$ zones. Incorrect fractures are preserved even after inverse modeling suggesting that the inclusion of wrong fracture data as prior information could have deleterious impacts on inverse modeling.

Figures $3.2 \mathrm{~b}, \mathrm{~d}$, f are the estimated $\ln S_{s}$ variance $\left(\sigma^{2} \ln S s\right)$ maps corresponding to the $S_{s}$ tomograms of Figures 3.1a, c, e. Similar to Figures 3.1b, d, f, the $\sigma^{2} \ln S s$ maps reveal that lower $\sigma^{2} \ln$ $S s$ values are mapped along the fractures. Compared to the $\sigma^{2}{ }_{\ln K}$ maps, the $\sigma^{2}{ }_{\ln S s}$ values exhibited a wider range, due to the difficulty in estimating $S_{S}$ as seen in other HT studies involving unconsolidated porous media (e.g., Berg and Illman, 2011; Zhao and Illman, 2018). 

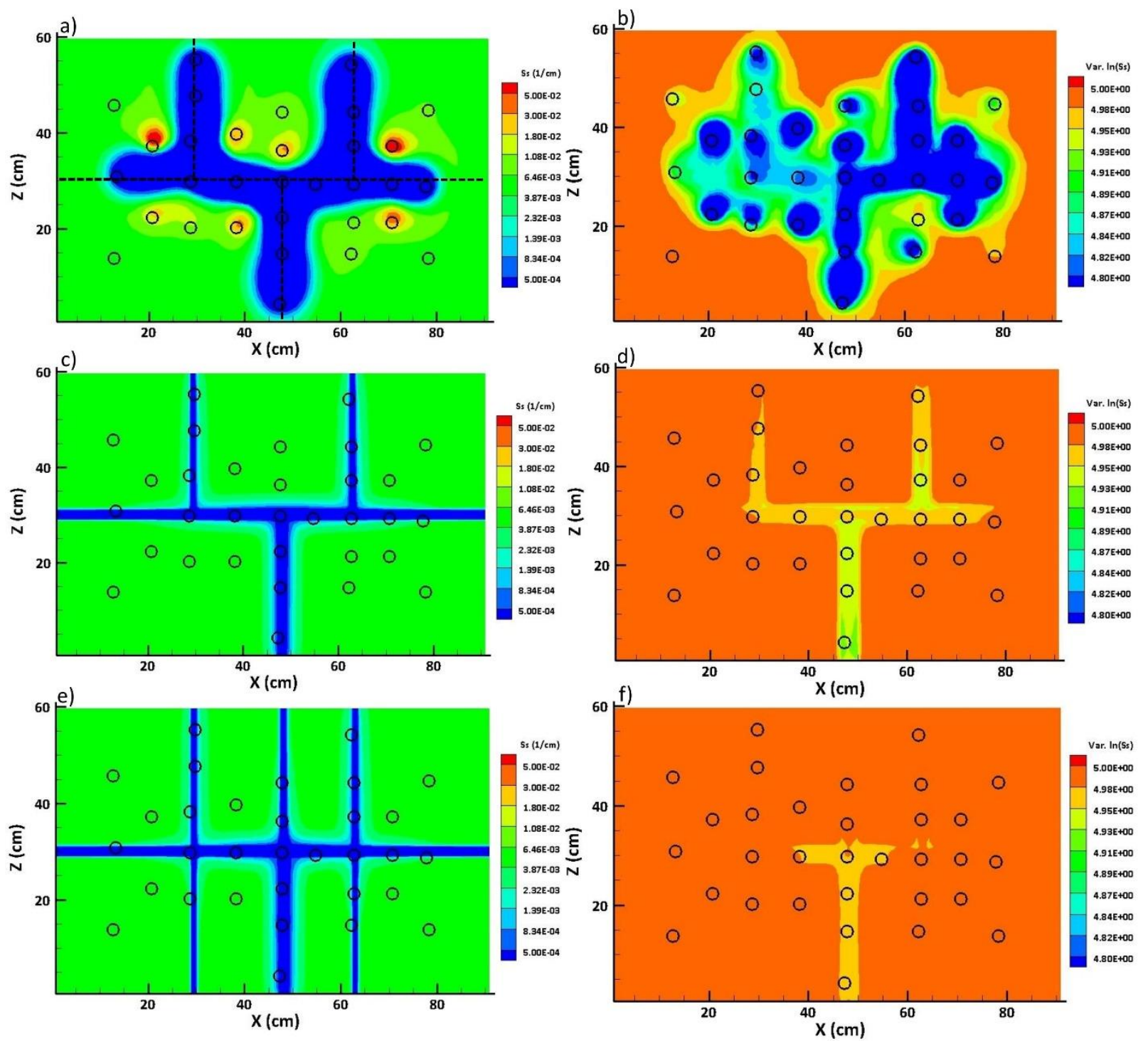

Figure 3.2: $S_{S}$ tomograms $\left(\mathrm{cm} \mathrm{s}^{-1}\right)$ delineated using synthetic data from three pumping tests (ports 3, 5, and 7): a) $S_{s}$ tomogram without prior geologic information; b) corresponding $\sigma^{2} \ln S s$; c) $S_{s}$ tomogram with correct prior geologic information; d) corresponding $\sigma^{2} \ln S s$; e) $S_{S}$ tomogram with partially correct prior geologic information; and f) corresponding $\sigma^{2} \ln S$ s.

\subsection{Inverse modeling of lab data}

Data from laboratory experiments conducted by Sharmeen (2011), which are the pumping test data from port 3, 5, 7 are also used for the calibration of hydraulic parameter fields. Compared 
to $K$ and $S_{s}$ tomograms estimated from synthetic data, tomograms obtained from the lab data show good correspondence. Model convergence results are presented in Appendix B.

Figures 3.3a and 3.4a present the estimated $K$ and $S_{S}$ tomograms. Overall, similar results are obtained from the real and synthetic data. Specifically, without prior geologic information, the SSLE approach is able to capture the general fracture pattern bordered by a low $K$ zone. Moreover, beyond the estimated low $K$ zone, the $K$ distribution approaches the initially estimated value of $K$, which is significantly higher than the actual value reported in the literature for dolomite (e.g. Muldoon et al., 2001; Singhal and Gupta, 2010; McLaren et al., 2012). For example, in McLaren et al. (2012), the geometric mean of permeability $(k)$ for dolomitic fractured rock was about $1.82 \times 10^{-14} \mathrm{~m}^{2}$ which was equivalent to $K$ of $1.36 \times 10^{-5} \mathrm{~cm} / \mathrm{s}$. Compared to geometric mean assigned to the inverse model, the actual hydraulic conductivity from the literature is relatively lower. The estimated matrix $K$ value is calibrated by the zero drawdown that may not help to improve the estimated tomograms, while large $S_{s}$ values appear around fractures. These incorrect details may lead to errors in drawdown predictions with additional tests not used in the calibration effort.

The comparison between Figures 3.3c and 3.4c with Figures 3.3a and 3.4a shows the improvement of the computed $K$ and $S_{S}$ tomograms as the correct geologic information is incorporated. With correct prior geologic information included as the initial estimates in HT analysis, the fracture pattern is more clearly delineated, and the estimated matrix $K$ values approach those from the literature (e.g., Freeze and Cherry, 1979; McLaren et al., 2012). The estimated $S_{s}$ tomogram becomes more vivid when the correct fracture pattern is included as an initial estimate.

As for the partially correct fracture location case, similar to the results from synthetic data, Figures $3.3 \mathrm{e}$ and $3.4 \mathrm{e}$ reveal that the model is not capable in overcoming the impacts of wrong geologic information on the estimated $K$ and $S_{S}$ tomograms. The wrong geologic information is still preserved suggesting that the inclusion of incorrect geologic information can cause more error to HT results. 
Figures 3.3b, d, f and Figures 3.4b, d, f are the corresponding estimated $\sigma^{2} \ln K$ and $\sigma^{2} \ln S s$ tomograms. Similar to the synthetic results, Figures $3.3 \mathrm{~b}$ and $3.4 \mathrm{~b}$ reveal that lower $\sigma^{2}{ }_{\ln K}$ and $\sigma^{2}{ }_{\ln S s}$ values implying lower uncertainty in estimated hydraulic properties appear around the fracture network. Furthermore, the lower uncertainty of estimated hydraulic properties from the cases with prior geologic information as the initial estimate emerges at locations where correct and partially correct geologic information were input, however this pattern is surprisingly less clear compared to the case when the inverse analysis begins with a homogeneous estimate (Figures $3.3 \mathrm{~b}$ and $3.4 \mathrm{~b}$ ). 

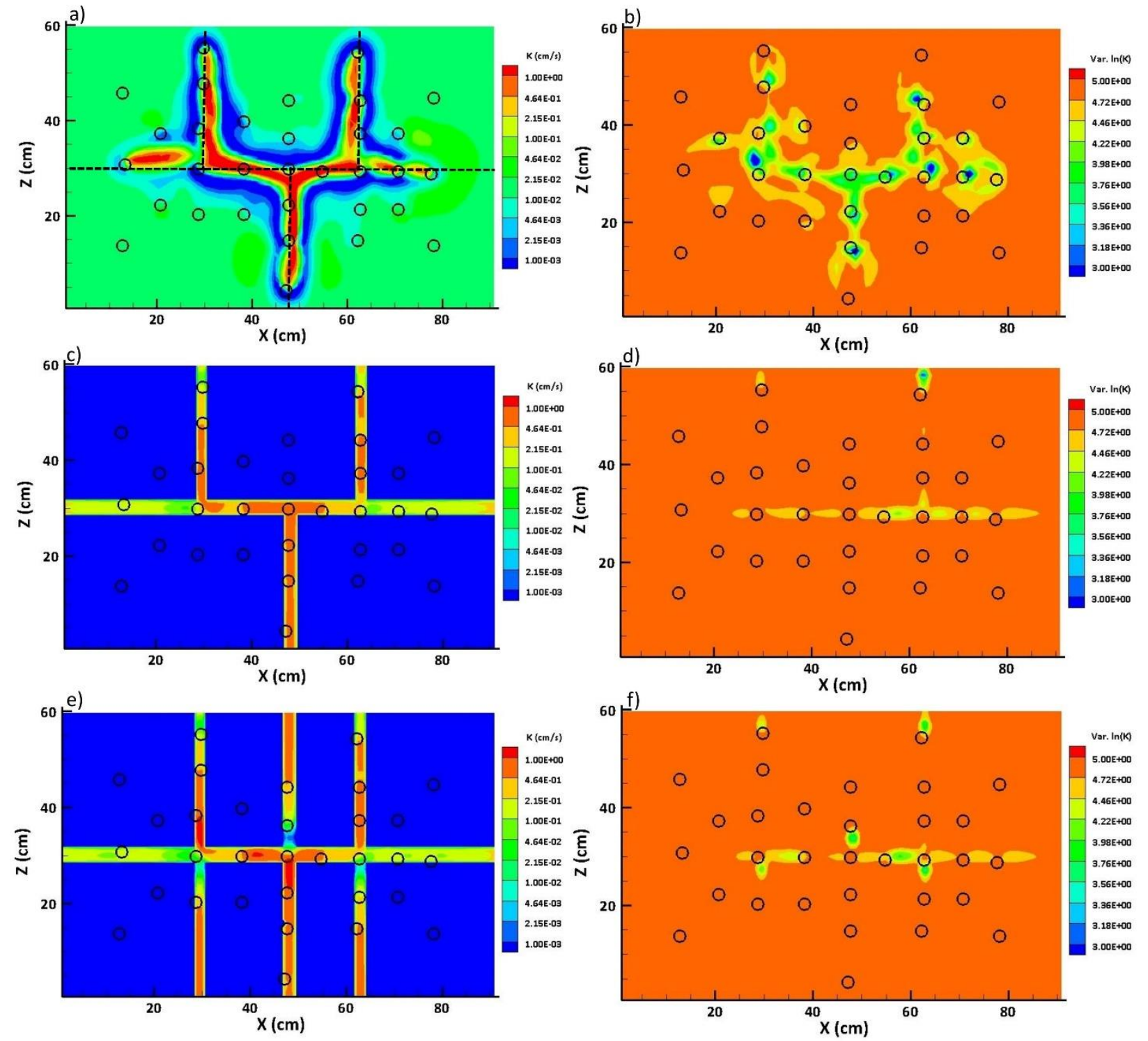

Figure 3.3: $K$ tomograms $\left(\mathrm{cm} \mathrm{s}^{-1}\right)$ delineated using laboratory experiment data from three pumping tests (ports 3, 5, and 7): a) $K$ tomogram without prior geologic information; b) corresponding $\sigma^{2} \ln K$; c) $K$ tomogram with correct prior geologic information; d) corresponding $\sigma^{2}{ }_{\ln K}$; e) $K$ tomogram with partially correct prior geologic information; and f) corresponding $\sigma^{2} \ln K$. 

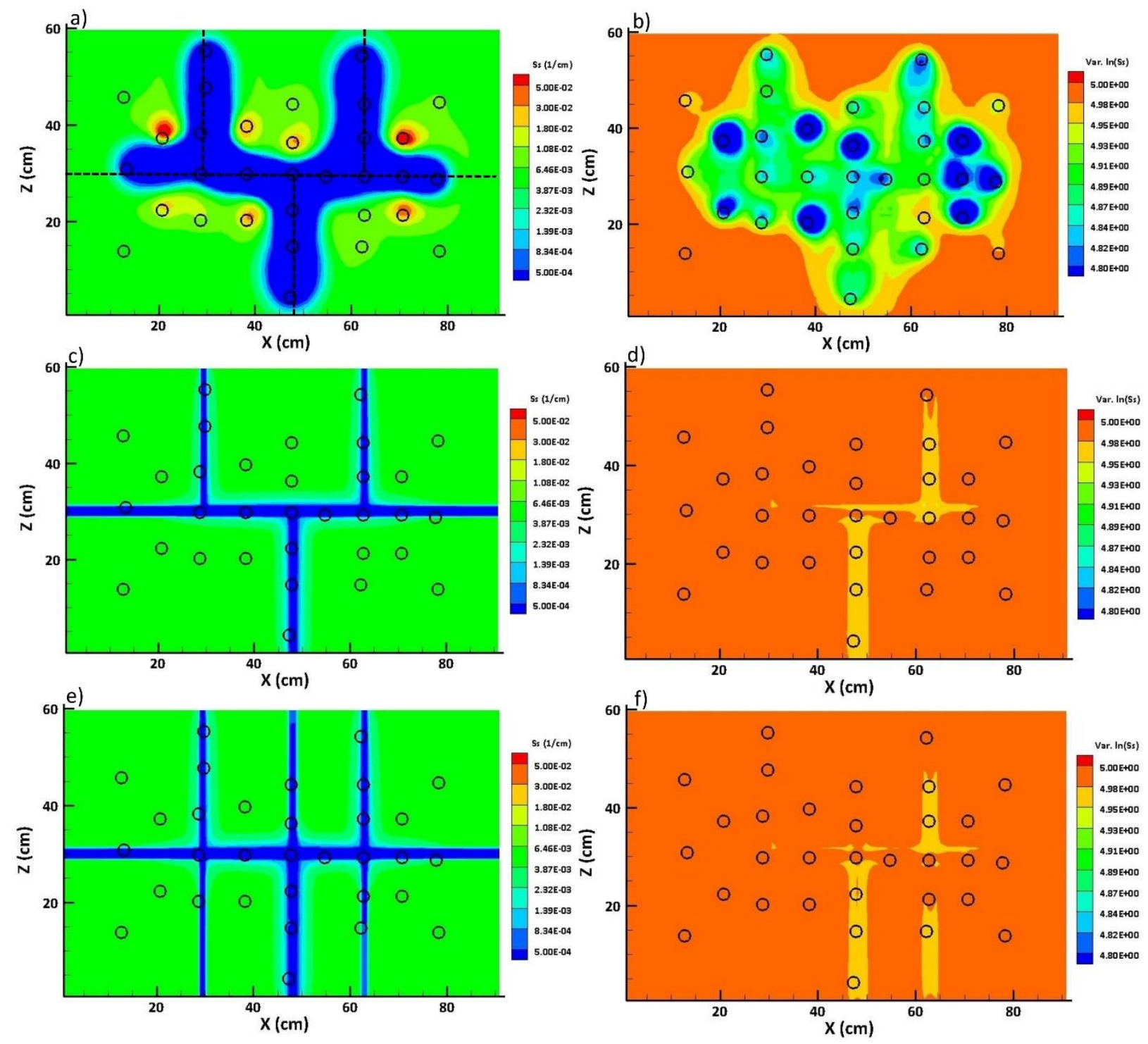

Figure 3.4: $S_{s}$ tomograms $\left(\mathrm{cm} \mathrm{s}^{-1}\right)$ delineated using laboratory experiment data from three pumping tests (ports 3, 5, and 7): a) $S_{s}$ tomogram without prior geologic information; b) corresponding $\sigma^{2} \operatorname{lns}$; c) $S_{s}$ tomogram with correct prior geologic information; d) corresponding $\sigma^{2} \operatorname{lnss}$; e) $S_{s}$ tomogram with partially correct prior geologic information; and f) corresponding $\sigma^{2} \operatorname{lnss}$.

\subsection{Calibration of drawdown data (Synthetic and Real data)}

The scatter plots of simulated and observed drawdown for both synthetic and real data are presented in Figures 3.5 and 3.6, respectively. Examination of these plots for both synthetic and 
lab test results reveal that the case with the homogeneous initial estimate can reproduce the observed drawdowns from the three pumping tests quite well. However, without prior geologic information, estimated matrix $K$ values are close to the geometric mean of $K$, which lead to small drawdowns simulated at the matrix ports. Furthermore, with the incorporation of correct fracture pattern and the matrix data, the drawdown responses at the monitoring ports concentrate more around the 1:1 line, and zero drawdown values are correctly simulated at matrix ports which match the observed data.

In contrast, for the scatter plot of the case in which the partially correct fracture pattern is included as an initial estimate, the drawdown values simulated at matrix ports located at incorrect fracture locations significantly deviate from zero. These unexpected drawdowns show that wrong geologic information can result in significant drawdown errors for the calibrated model.

To quantitatively assess the results, two criteria, the mean absolute error $\left(L_{l}\right)$ and mean square error $\left(L_{2}\right)$ norms as well as the coefficient of determination $\left(R^{2}\right)$ are calculated. The $R^{2}$ signifies the quality of match between simulated and observed drawdowns. These criteria are calculated as:

$$
\begin{gathered}
L_{1}=\frac{1}{n} \sum_{i=1}^{n}\left|X_{i}-\hat{X}_{i}\right| \\
L_{2}=\frac{1}{n} \sum_{i=1}^{n}\left(X_{i}-\hat{X}_{i}\right)^{2} \\
R^{2}=1-\frac{\sum\left(X_{i}-\hat{X}_{i}\right)^{2}}{\sum\left(X_{i}-\bar{X}\right)^{2}}
\end{gathered}
$$

where $n$ is the total number of pressure heads that used for calibration, $X_{i}$ is $i$-th observed pressure head, while $\hat{X}_{i}$ is corresponding pressure head from simulation. $\bar{X}$ is the mean of observed pressure head.

Figures 3.5 and 3.6 show the calibration results for the synthetic and laboratory HT analyses, respectively. In these figures, the calibration results are shown for all data, for fracture ports only, and the matrix ports only. For all figures, a linear model is fit and the corresponding equation is 
provided along with $L_{1}$ and $L_{2}$ norms as well as $R^{2}$ values. The trend line for the drawdown data from the matrix ports is $y=0$, which cannot be plotted properly and $R^{2}$ values cannot be computed, thus are not included.

The comparison of $L_{1}$ and $L_{2}$ norms indicate that the models calibrated with synthetic data (Figure 3.5) are better calibrated than those based on laboratory data (Figure 3.6). This is expected as synthetic data do not contain any experimental errors. Moreover, $L_{2}$ values from data at the matrix ports also suggest that with correct prior geologic information, the drawdowns simulated at matrix ports are closest to observed data. The reason for using $L_{2}$ than $L_{1}$ for the comparison is because $L_{2}$ squares the error, a much larger error is presented than the $L_{1}$ norm.

Figure 3.7 presents simulated versus observed drawdown curves for the laboratory pumping test at port 5. The black solid line represents the observed drawdown curve, while the dark blue dashed line indicates the simulated drawdowns from the homogeneous input, the green dashed line plots results from the correct prior geologic information case, while the red dashed line plots results from the partially correct prior geologic information case. The drawdown curves estimated at fracture ports with prior geologic information show a similar trend, because the correct fracture pattern is included. That is, with the incorporation of correct geologic information, the estimation of transient drawdowns improves significantly. Furthermore, the accuracy of predicted drawdown at the matrix ports is increased by inputting the correct fracture geometry and matrix information.

Shown by drawdown curves from the partially correct fracture case, there is a large pressure change that occurs at some of the matrix ports, which is even greater than the drawdown estimated from the homogenous case. This unexpected drawdown is caused by including wrong geologic information, where the matrix is assigned hydraulic property value of fractures. These values were not calibrated well during the inversion. Therefore, incorrect geologic information may lead to the error of drawdown prediction, which is even worse than the homogeneous case. Similar comparisons for the other pumping tests are provided in Appendix B. 

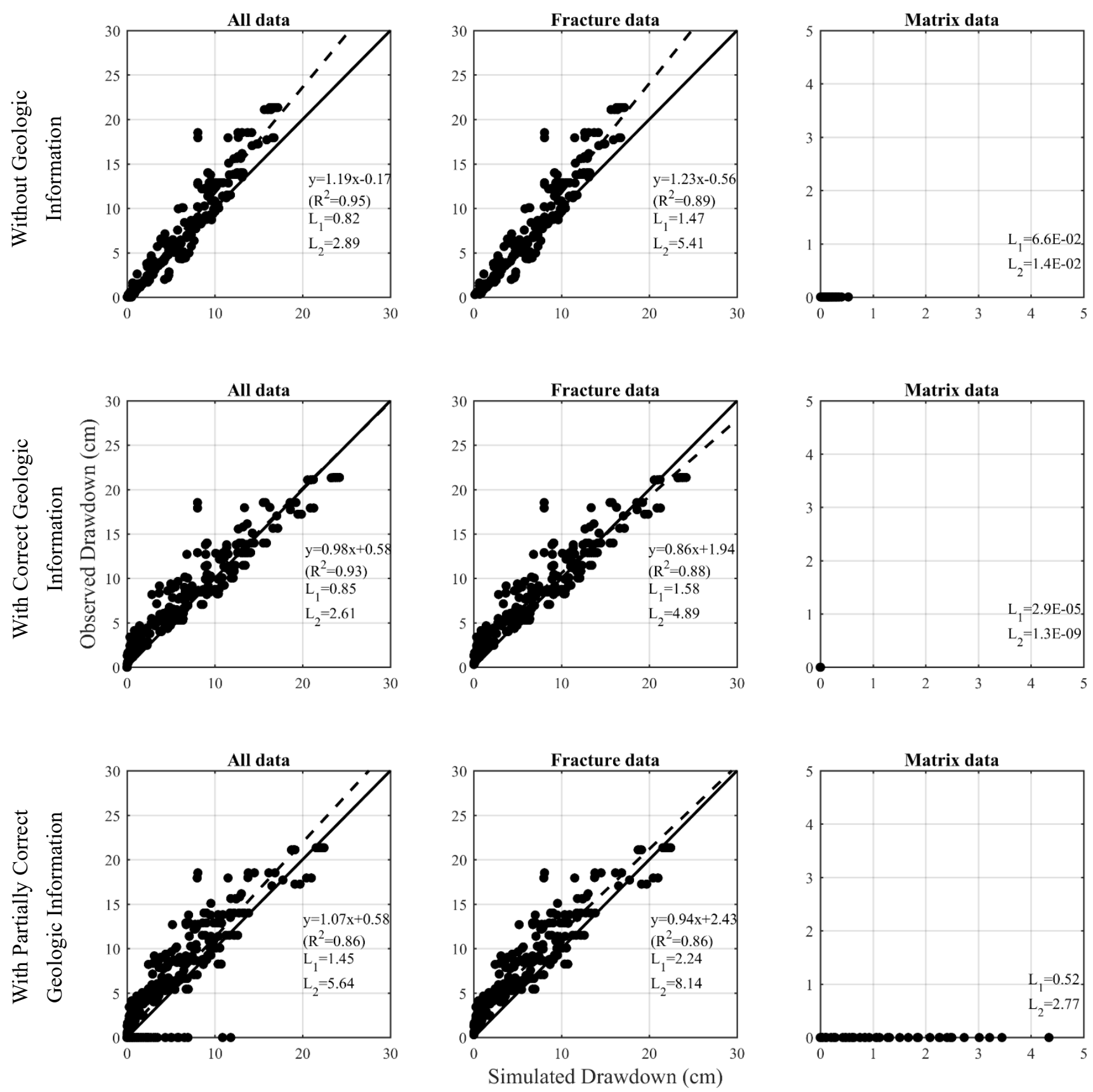

Figure 3.5: Scatter plots of observed versus simulated drawdowns for model calibration using three synthetic pumping tests (Ports 3,5,7) for the three cases (Homogeneous, Correct, Partially Correct). Results are plotted for all data, data from ports at fractures, and data from ports at matrix. Blue circles represent data points. Solid black line is the 1:1 line, and the dashed line indicates the best-fit line for data points. 

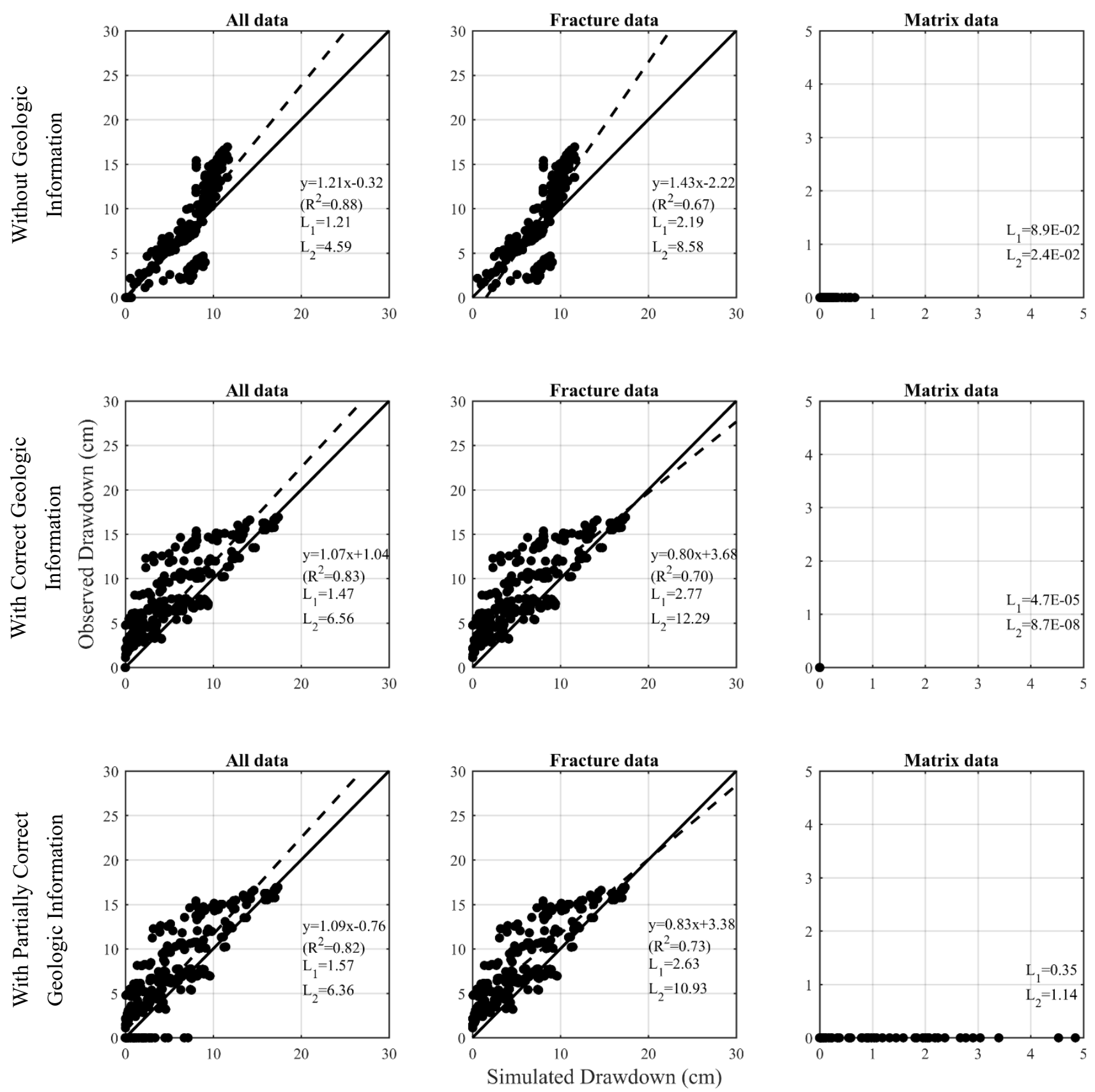

Figure 3.6: Scatter plots of observed versus simulated drawdowns for model calibration using three laboratory pumping tests (Ports $3,5,7$ ) for the three cases (Homogeneous, Correct, Partially Correct). Results are plotted for all data, data from ports at fractures, and data from ports at matrix. Blue circles represent data points. Solid black line is the 1:1 line, and the dashed line indicates the best-fit line for data points. 


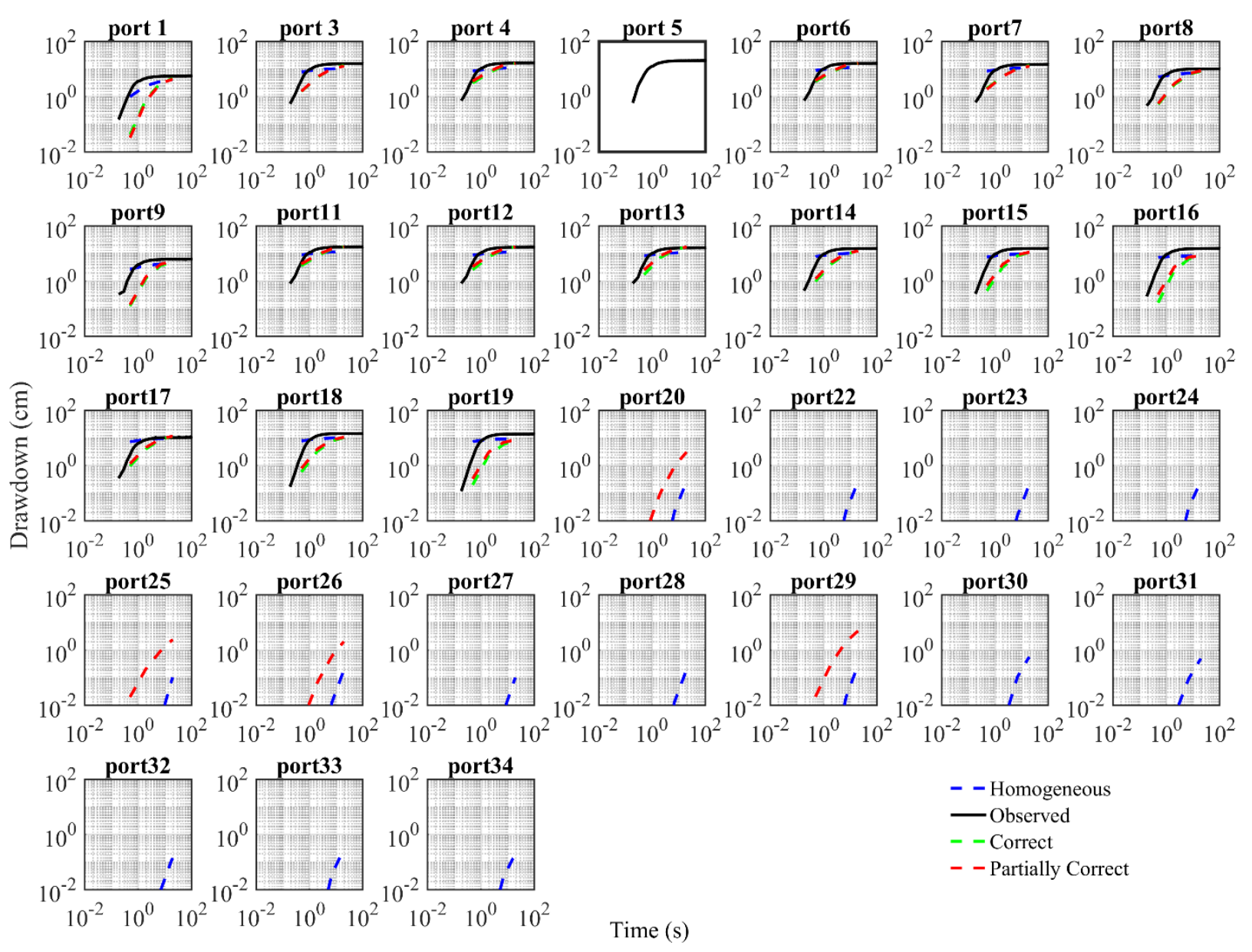

Figure 3.7: Observed and calibrated drawdown $(\mathrm{cm})$ versus time $(\mathrm{s})$ at ports during the pumping test at port 5 for laboratory data. The dark blue dashed line represents results from the homogeneous case. The solid black line indicates results from the lab experiment. The green dashed line represents results from the correct fracture location case. The red dashed line indicates results from the partially correct fracture location case. 


\section{Discussion}

4.1 Comparison of estimated $K$ and $S_{s}$ values from SSLE to true values (synthetic data)

The $K$ and $S_{S}$ values estimated by SSLE at fracture locations are compared to those calibrated by HGS coupled with PEST (Figure 4.1). The comparison is only conducted for the estimated hydraulic parameters at fractures, because the hydraulic properties at the matrix are not clear due to its impermeability. This comparison is made to evaluate how the estimates from the inversion of synthetic data approaches to the real condition. Figure 4.1a, b, c represents the scatter plot of $K$ value under the different types of prior geologic information. Figure 4.2a, b, c describes the distribution of estimated $S_{s}$ value with the same prior information as mentioned before. The visual assessment indicates the large difference between the estimated value and the 'true' hydraulic properties. The reason for this considerable difference may be caused by the assumption that in the SSLE. The fractured aquifer is treated as an EPM, while HGS has applied DFNM for the rock sample. The black circles illustrate the distribution of hydraulic parameters, while the solid line represents the 1:1 line. The comparison between Figure 4.1a, b and Figure 4.2a, b shows that the incorporation of geologic information comparably constrains the estimation of hydraulic properties. Furthermore, the contrast between Figure 4.1c and Figure 4.2c illustrates that the wrong geologic information influences the distribution of estimated $K$ more than $S_{s}$.
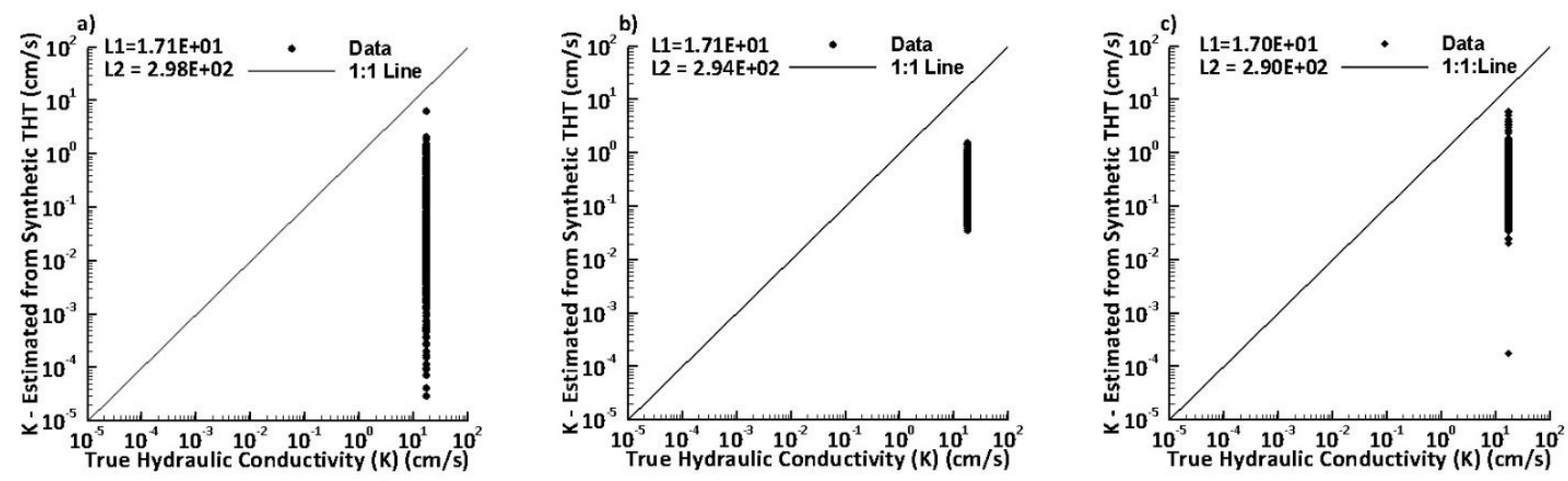

Figure 4.1: Scatter plot of $K$ values comparing the inversion results from SSLE and calibration of HGS with PEST: a) homogeneous case without prior geologic information; b) case with correct 
prior geologic information; c) case with partially correct geologic information.
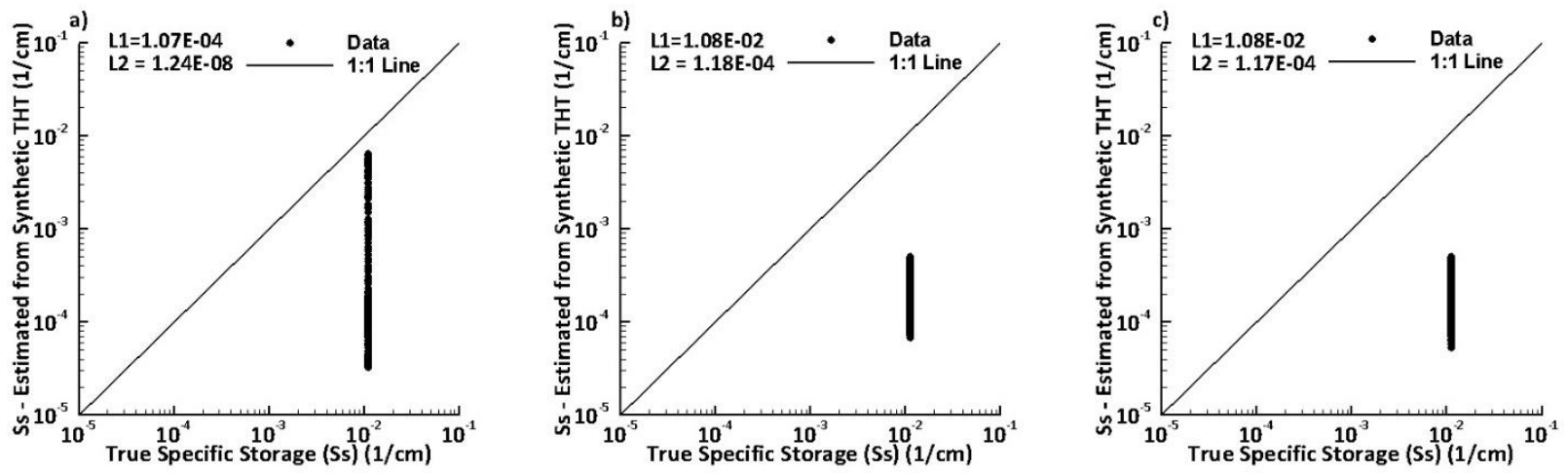

Figure 4.2: Scatter plot of $S_{S}$ values comparing the inversion results from SSLE and calibration of HGS with PEST: a) homogeneous case without prior geologic information; b) case with correct prior geologic information; c) case with partially correct geologic information

\subsection{Prediction of pumping tests (Synthetic and Real data)}

The $K$ and $S_{s}$ tomograms estimated from synthetic and lab data from all cases are next applied to predict 5 pumping tests (ports $4,6,12,15$ and 18) that were not used for model calibration. Illman et al. (2007) and Liu et al. (2007) both used such independent pumping tests to quantitatively assess their HT results. If the estimated $K$ and $S_{s}$ tomograms are able to accurately predict independent tests, then one could have more confidence in the HT results.

Forward simulations of the pumping tests are conducted using SSLE (Zhu and Yeh, 2005) with the same model settings as indicated in the inverse modeling. Figure 4.3 and 4.4 are the scatter plots of observed versus simulated drawdown data from five independent synthetic and laboratory pumping tests. The comparisons between observed and simulated drawdown are separated into three columns. The first column is the comparison between observed and simulated drawdowns in all ports. The second column is the comparison of drawdowns at ports completed on fractures, while the third column is the drawdown at ports completed on the matrix. The black solid line represents the 1:1 line indicating the perfect match, while the dashed line describes the best fit for the comparison. 
From Figures 4.3 and 4.4, the visual assessment of the scatter plots indicates that for all three cases, the data points concentrate around the 1:1 line with some bias that is visible through the slope of the linear model fit. However, the drawdowns simulated with correct prior geologic information input at the matrix ports have the best match to observed drawdowns compared to other two cases. With a partially correct geologic information input as the initial estimate into the model, the bias in the drawdowns estimated at the matrix port becomes more significant than that from the homogeneous case. The computed $L_{1}, L_{2}$ norms suggest that a better fit between simulated and observed drawdowns with the incorporation of geologic information in the data at all observed ports. Moreover, the value of $R^{2}$ indicates that estimated drawdowns with additional geologic information cluster around the 1:1 line more than the other cases. Therefore, with correct prior geologic information included as prior information, the predicted drawdowns from THT analysis become relatively accurate. While the wrong information is implied in the model, the $L_{1}$ and $L_{2}$ increase and $R^{2}$ value decreases, which reveals that predicted drawdown values are less accurate compared to the other two cases. Furthermore, unexpected drawdowns appear during the simulation at the matrix ports. Similar to calibration results, shown by the $L_{1}$ and $L_{2}$ norms, the simulated drawdowns are closer to observed data for the synthetic than the laboratory case. 

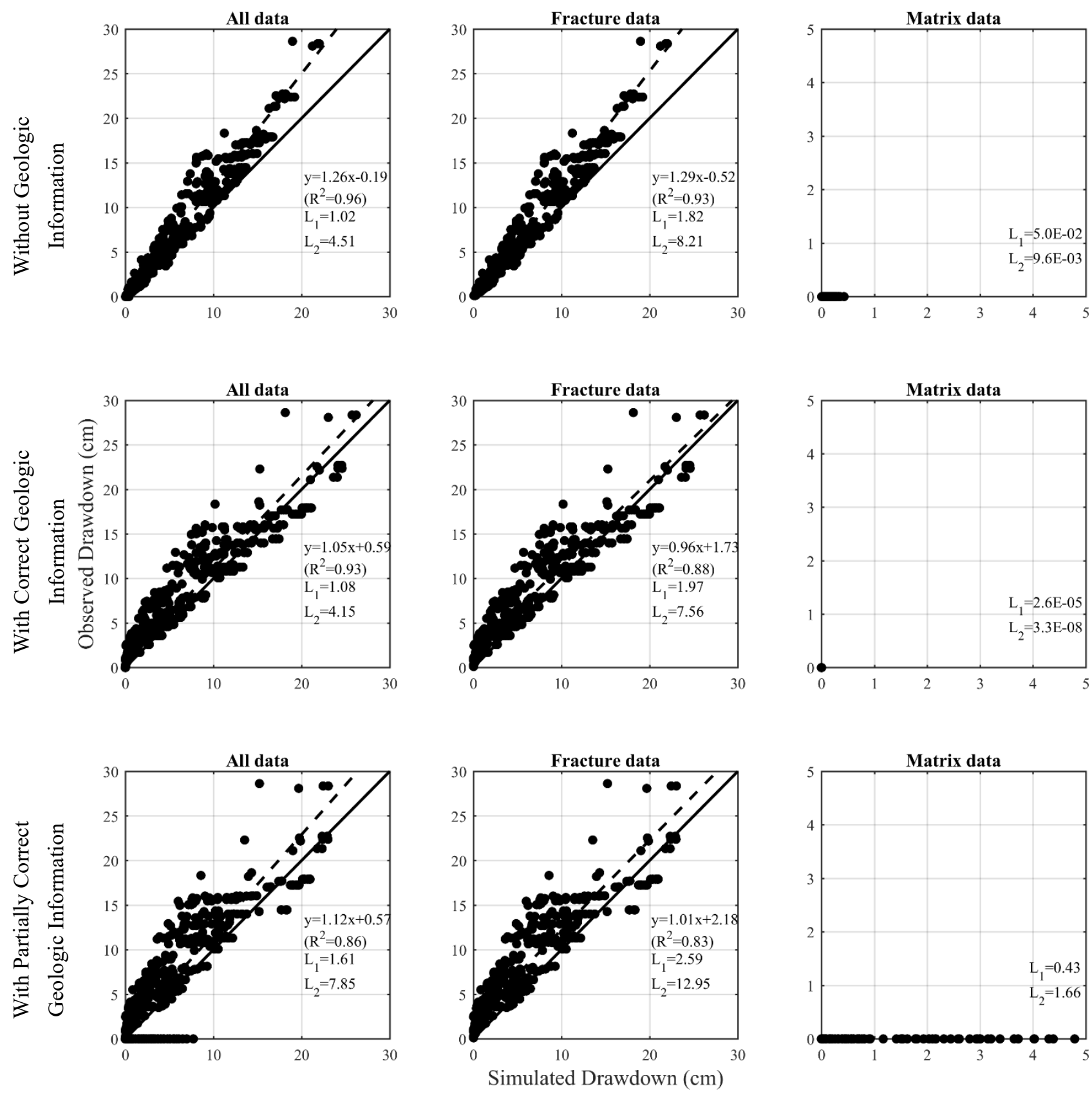

Figure 4.3: Scatter plots of observed versus simulated drawdowns for model validation using five synthetic pumping tests (Ports 4, 6, 12, 15, 18) for the three cases (Homogeneous, Correct, Partially Correct). Results are plotted for all data, data from ports at fractures, and data from ports at matrix. Blue circles represent data points. Solid black line is the 1:1 line, and the dashed line indicates the best-fit line for data points. 

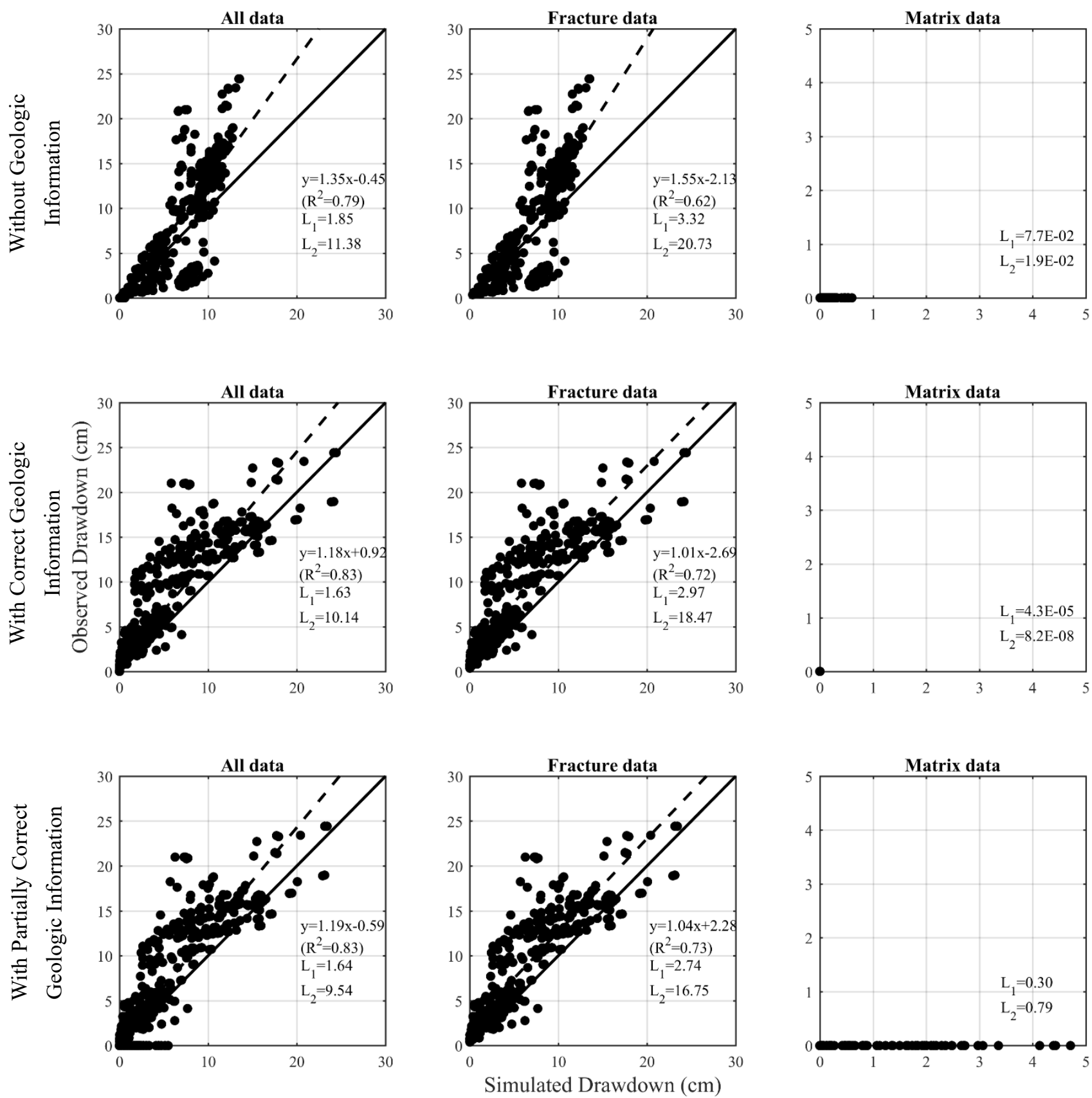

Figure 4.4: Scatter plots of observed versus simulated drawdowns for model validation using five laboratory pumping tests (Ports 4, 6, 12, 15, 18) for the three cases (Homogeneous, Correct, Partially Correct). Results are plotted for all data, data from ports at fractures, and data from ports at matrix. Blue circles represent data points. Solid black line is the 1:1 line, and the dashed line indicates the best-fit line for data points. 

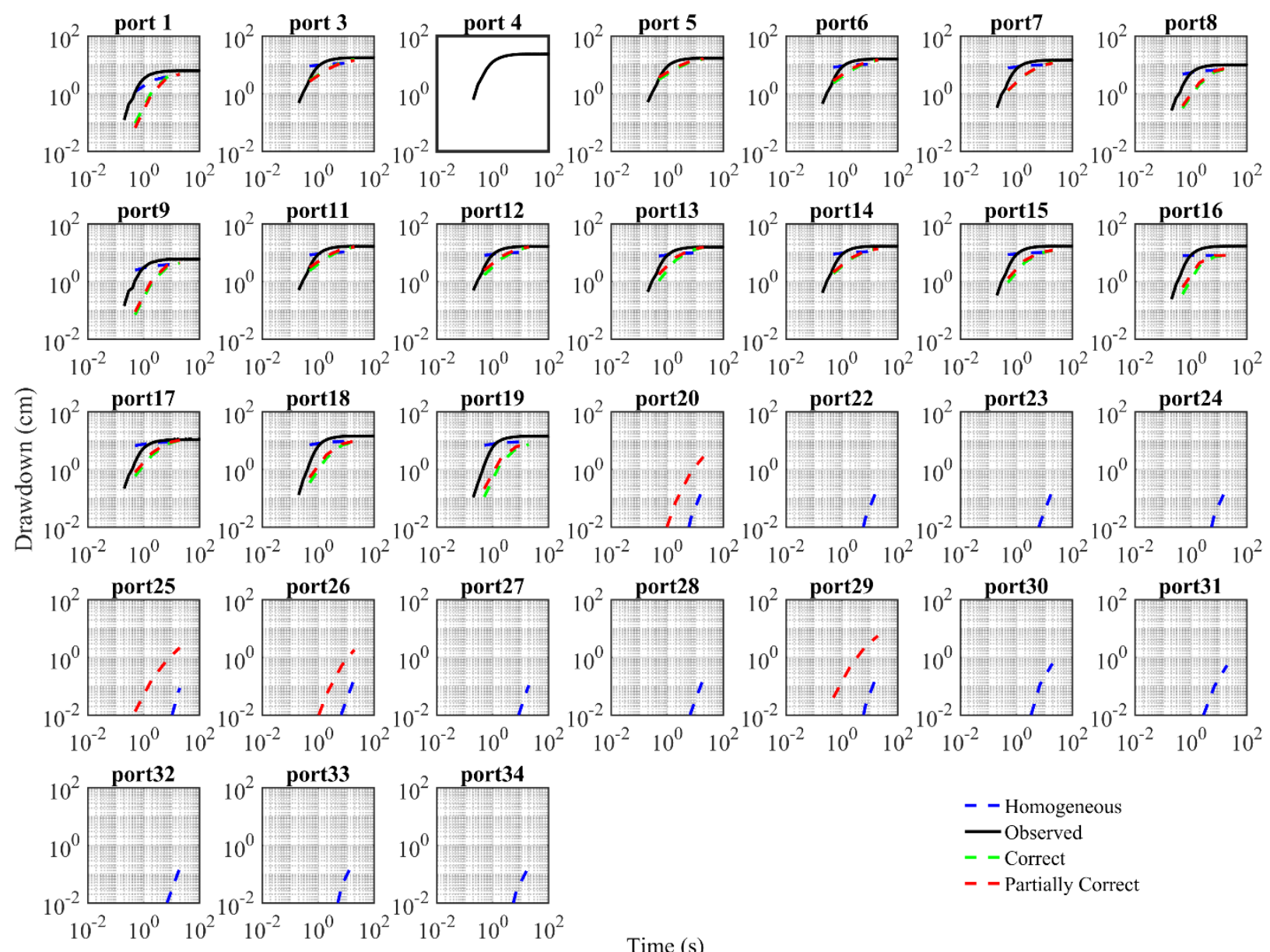

Time (s)

Figure 4.5: Observed and calibrated drawdown $(\mathrm{cm})$ versus time $(\mathrm{s})$ at ports during the pumping test at port 4 for lab data. The dark blue dashed line represents results from the homogeneous case. The solid black line indicates results from the lab experiment. The green dashed line represents results from the correct fracture location case. The red dashed line indicates results from the partially correct fracture location case. 

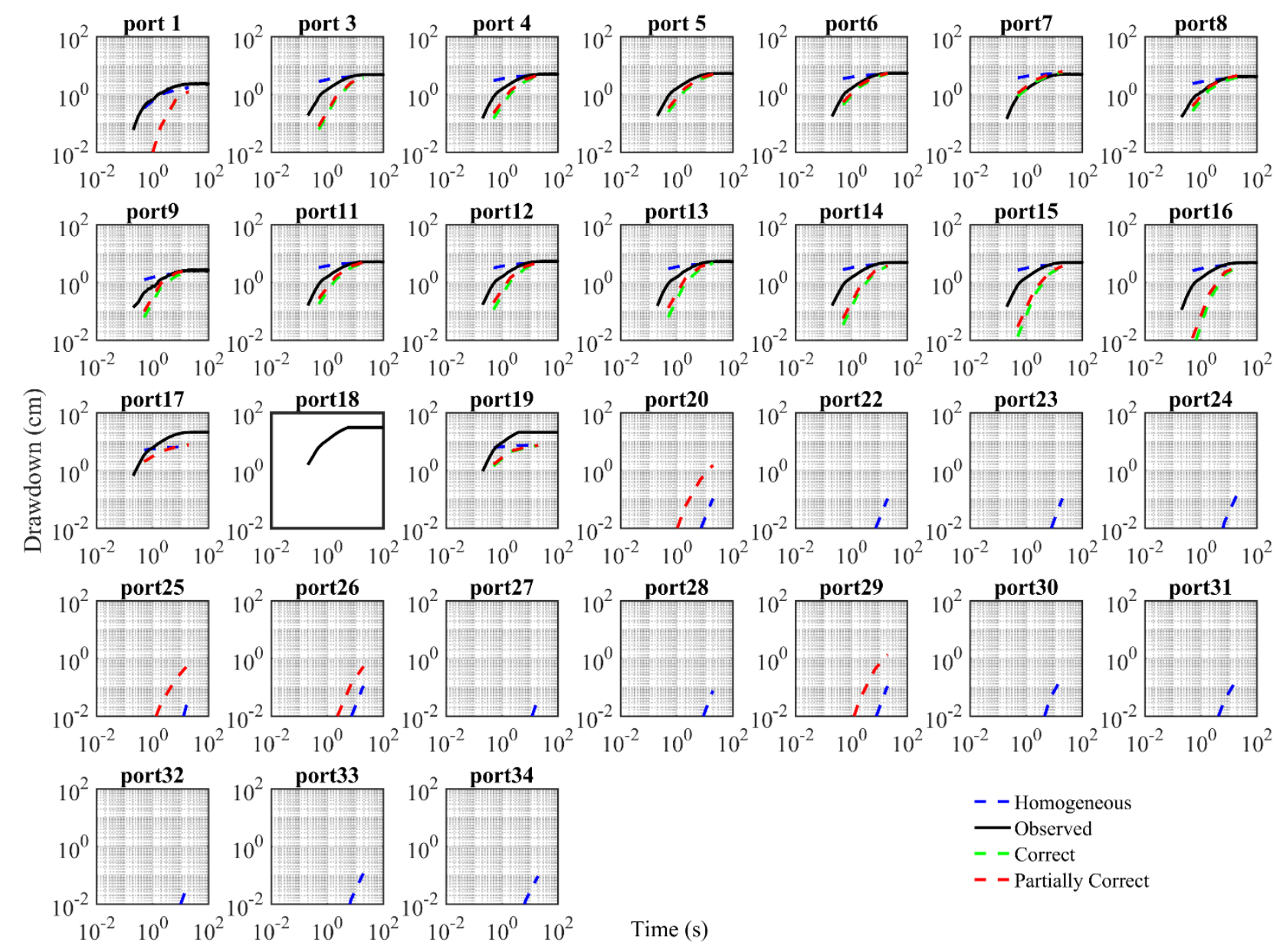

Figure 4.6: Observed and calibrated drawdown $(\mathrm{cm})$ versus time $(\mathrm{s})$ at ports during the pumping test at port 18 for lab data. The dark blue dashed line represents results from the homogeneous case. The solid black line indicates results from the lab experiment. The green dashed line represents results from the correct fracture location case. The red dashed line indicates results from the partially correct fracture location case.

Comparisons of observed (solid) and predicted (dashed) drawdown curves for the real THT cases are presented in Figures 4.5 and 4.6 for ports 4 and 18, respectively. Similar comparisons for other tests at ports 4, 6, 12, 15 are included in Appendix C. Examinations of Figures 4.5 and 4.6 reveal that at the observed port within fractures, drawdown curves estimated with $K$ and $S_{s}$ tomograms obtained with correct prior geologic information are better matched to observed 
drawdown curves, especially at transient condition when compared to the drawdown curves from the case without geologic information as a prior estimate. Similarly, the comparison of drawdown curves from the matrix ports shows that with homogeneous initial and incorrect geologic information inputs, there are small drawdowns appearing in the observed ports. However, zero drawdowns are visible in the matrix ports with correct geologic information as an initial estimate, which is exactly the same as observed in laboratory experiments.

Overall, drawdown curves match better at steady state than transient condition for the simulation results from the estimated $K$ and $S_{S}$ tomograms, when the model is calibrated without additional information. This may be caused by the uncertainty in the estimations of $K$ and $S_{S}$ value. Shown by Figures 4.1 and 4.2, without any geologic information, both estimated $K$ and $S_{S}$ located at fractures vary significantly. This unique distribution of hydraulic parameters may result from the lack of fit at the early time for the drawdown prediction. However, with correct prior geologic information, the predicted drawdowns are matched for both transient and steady states. Therefore, inversion without geologic information can delineate the fracture pattern, but cannot accurately replicate the fracture geometry and simulate hydraulic properties approaching to the real condition. The inversion with correct prior geologic information can more accurately resolve the fracture pattern, and the distribution of estimated $K$ and $S_{S}$ within the rock sample approaches the real condition and lab condition. Based on the profile shown in Figure 2.1, port 4 is located along the horizontal fracture, while port 18 is at one of the vertical fractures. The pumping tests used for the calibration of model are at ports 5, 3, 7 which are all placed along the horizontal fracture. Therefore, the information from the vertical fractures may not be obtained as much as that from the horizontal fracture, which could possibly lead to a less accurate prediction of drawdowns in the monitoring ports at vertical fractures. 


\section{Summary and Conclusions}

As indicated in Sharmeen et al. (2012), there are numerous possible hydraulic parameters fields that can provide similar good matches between the simulated and observed hydrographs for the HT survey in fractured rock aquifers due to incomplete constraints of inverse parameters. In the SSLE algorithm, the specified mean and covariance function can control the estimates of the hydraulic properties, and the results are unique based on those constraints. Therefore, those estimates are not essentially the true fracture and matrix $K$ and $S$ s distribution. Regardless of the uncertainty during the estimations, the estimates from SSLE algorithm have successfully simulated the response of aquifer for other independent tests that were not used during calibration for hydraulic tomography by other researchers (Illman et al., 2007, 2008, 2009; Liu et al., 2007; Xiang et al., 2009; Berg and Illman, 2011a,b). Thus, hydraulic tomography appears to be a promising tool to characterize the heterogeneity of hydraulic properties within fractured rocks.

In the previous study (Sharmeen et al., 2012), HT was proposed as an effective approach to image the hydraulic conductivity $(K)$ and specific storage $\left(S_{S}\right)$ distribution of the fractured geologic media. Furthermore, studies from recent years (Zhao et al., 2016; Zha et al., 2017) suggested that the incorporation of geologic data helped to improve the estimation of results, which has not been strictly assessed for fractured rocks in a controlled laboratory setting. Based on the model information and pumping tests conducted by Sharmeen et al. (2012), additional geologic data was incorporated into the inverse model with the Sequential Successive Linear Estimator (SSLE) code of Zhu and Yeh (2005) to perform THT analysis. Results show that by including correct geologic information into the THT analysis, the fracture pattern becomes more vivid compared to that computed without geologic information. This study leads to the following major findings and conclusions:

1. It is possible to characterize the fracture zones, their pattern and connectivity through the THT analysis of multiple pumping tests through the inverse code developed by Zhu and Yeh (2005) without any prior geologic data. However, the estimated hydraulic parameters (e.g. $K$ and $S_{s}$ ) 
within the matrix differ from the true hydraulic parameters value which generate unexpected pressure responses at the matrix ports.

2. The characterization of fracture zones, their pattern, and connectivity as well as data predicted at the matrix ports are all significantly improved as prior knowledge of fracture geometry and matrix properties are included in inverse modeling. Therefore, utilizing a perfectly known geologic model as the prior information in geostatistical inverse model results in the preservation of geologic features especially in the matrix where drawdowns are not typically available.

3. The comparison between the cases with different types of geologic data indicates that SSLE algorithm cannot revise the incorrect geologic model during the inversion, which introduces more error in the prediction of pressure responses at areas where drawdowns are not observed. Thus, a simple model without any geologic information is more reliable than the one based on the wrong description of geologic features such as incorrect spatial distribution of fracture network and matrix property value.

In this study, the fractured rock model is treated as a heterogeneous porous continuum, which limits the range of initial parameters. When a large contrast between hydraulic properties is taken as input, the SSLE code fails to converge. This weakness needs to be overcome in future studies. From the results of this study, it can be concluded that the patterns of $K$ and $S_{s}$ tomograms generated by THT analysis based on the inverse algorithm SSLE can be improved with the incorporation of correct prior geologic data, and the final tomograms are consistent with the geologic features of the rock sample. THT is a promising method in the characterization of fracture patterns and connectivity, and it can be strengthened with additional correct geologic information. However, it is difficult to obtain complete and accurate fracture information at field sites by boreholes alone; therefore, as suggested by Illman (2014), other data could be included to complement data from cross-hole pumping tests. In particular, geophysical techniques may provide information on fracture patterns that could be included in HT analyses. However, this research has shown that including wrong geologic data could corrupt HT results. Therefore, significant care needs to go 
into integrating other data types with HT analysis. There is clearly a need for more experimental work and corresponding analyses to improve HT in fractured geologic media. 


\section{References}

Aquanty, (2019), HydroGeoSphere: A three-dimensional numerical model describing fullyintegrated subsurface and surface flow and solute transport, Waterloo, Ontario, Canada.

Bear, J. (1972), Dynamics of Fluids in Porous Media, 764 pp., Dover, New York

Berg, S. J., and Illman, W. A. (2011a). Capturing aquifer heterogeneity: Comparison of approaches through controlled sandbox experiments, Water Resources Research, 47, W09514, doi:10.1029/2011WR010429

Berg, S. J., and Illman, W. A. (2011b). Three-dimensional transient hydraulic tomography in a highly heterogeneous glaciofluvial aquifer-aquitard system. Water Resources Research,47(10). doi:10.1029/2011wr010616

Berg, S. J., and Illman, W. A. (2012). Improved predictions of saturated and unsaturated zone drawdowns in a heterogeneous unconfined aquifer via transient hydraulic tomography: Laboratory sandbox experiments. Journal of Hydrology, 470-471, 172-183. doi: 10.1016/j.jhydrol.2012.08.044

Berg, S. J., and Illman, W. A. (2013). Field Study of Subsurface Heterogeneity with Steady-State Hydraulic Tomography. Groundwater, 51(1), 29-40. doi: 10.1111/j.17456584.2012.00914.x

Berg, S. J., and Illman, W. A. (2015). Comparison of Hydraulic Tomography with Traditional Methods at a Highly Heterogeneous Site. Groundwater, 53(1), 71-89. doi: 10.1111/gwat.12159

Blessent, D., Jørgensen, P. R., and Therrien, R. (2013). Comparing Discrete Fracture and Continuum Models to Predict Contaminant Transport in Fractured Porous Media. Groundwater, 52(1), 84-95. doi:10.1111/gwat.12032

Bohling, G. C. and Butler, J. J. (2010). A Potential-Based Inversion of Unconfined Steady-State Hydraulic Tomography. Groundwater, 48(3), 343-344. doi:10.1111/j.17456584.2010.00685_1.x

Butler, J. J., and Healey, J. M. (1998). Relationship Between Pumping-Test and Slug-Test Parameters: Scale Effect or Artifact? Groundwater, 36(2), 305-312. doi: 10.1111/j.17456584.1998.tb01096.x

Cacas, M. C., Ledoux, E., Marsily, G. D., Tillie, B., Barbreau, A., Durand, E., Feuge, B., and Peaudecerf, P. (1990). Modeling fracture flow with a stochastic discrete fracture network: calibration and validation: 1. The flow model. Water Resources Research, 26(3), 479-489. doi: 10.1029/wr026i003p00479

Cardiff, M., Barrash, W., Kitanidis, P., Malama, B., Revil, A., Straface, S., and Rizzo, E. (2009). A Potential-Based Inversion of Unconfined Steady-State Hydraulic Tomography. Groundwater, 47(2), 259-270. doi: 10.1111/j.1745-6584.2008.00541.x 
Castagna, M., Becker, M. W., and Bellin, A. (2011). Joint estimation of transmissivity and storativity in a bedrock fracture. Water Resources Research, 47(9). doi: 10.1029/2010wr009262

Chen, G., Illman, W. A., Thompson, D. L., Vesselinov, V. V., and Neuman, S. P. (2000). Geostatistical, type-curve, and inverse analyses of pneumatic injection tests in unsaturated fractured tuffs at the Apache Leap Research Site near Superior, Arizona. Dynamics of Fluids in Fractured Rock Geophysical Monograph Series, 73-98. doi: $10.1029 / \mathrm{gm} 122 \mathrm{p} 0073$

Cherry, J. A., Parker, B. L., and Keller, C. (2007). A New Depth-Discrete Multilevel Monitoring Approach for Fractured Rock. Groundwater Monitoring \& Remediation,27(2), 57-70. doi:10.1111/j.1745-6592.2007.00137.x

Cho, H. J., Fiacco, R. J., and Daly, M. (2008). Characterization of Crystalline Bedrock Contaminated by Dense Nonaqueous Liquid. Groundwater Monitoring \& Remediation,28(2), 49-59. doi:10.1111/j.1745-6592.2008.00191.x

Choi, E., Cheema, T., and Islam, M. (1997). A new dual-porosity/dual-permeability model with non-Darcian flow through fractures. Journal of Petroleum Science and Engineering, 17(34), 331-344. doi: 10.1016/s0920-4105(96)00050-2

Clauser, C. (1992). Permeability of crystalline rocks. Eos, Transactions American Geophysical Union, 73(21), 233-233. doi: 10.1029/91eo00190

Cornaton, F., and Perrochet, P. (2002). Analytical 1D dual-porosity equivalent solutions to 3D discrete single-continuum models. Application to karstic spring hydrograph modelling. Journal of Hydrology, 262(1-4), 165-176. doi: 10.1016/s0022-1694(02)000331

Doherty, J. (2005), PEST Model-independent parameter estimation user manual: 5th Edition. Watermark Numerical Computing, Brisbane, Australia.

Dong, Y., Fu, Y., Yeh, T. C. J., Wang, Y. L., Zha, Y., Wang, L., and Hao, Y. (2019). Equivalence of Discrete Fracture Network and Porous Media Models by Hydraulic Tomography. Water Resources Research, 55(4), 3234-3247. doi: 10.1029/2018wr024290

Dverstorp, B., Andersson, J., and Nordqvist, W. (1993). Discrete fracture network interpretation of field tracer migration in sparsely fractured rock. International Journal of Rock Mechanics and Mining Sciences \& Geomechanics Abstracts,30(2). doi:10.1016/01489062(93)90868-e

Erhel, J., Dreuzy, J. D., and Poirriez, B. (2009). Flow Simulation in Three-Dimensional Discrete Fracture Networks. SIAM Journal on Scientific Computing,31(4), 2688-2705. doi: $10.1137 / 080729244$

Freeze, R. A., and Cherry, J. A. (1979). Groundwater. Englewood Cliffs, NJ: Prentice-Hall. 
Fischer, P., Jardani, A., and Lecoq, N. (2017). A cellular automata-based deterministic inversion algorithm for the characterization of linear structural heterogeneities. Water Resources Research, 53(3), 2016-2034. doi: 10.1002/2016wr019572

Fischer, P., Jardani, A., and Lecoq, N. (2018a). Hydraulic tomography of discrete networks of conduits and fractures in a karstic aquifer by using a deterministic inversion algorithm. Advances in Water Resources, 112, 83-94. doi: 10.1016/j.advwatres.2017.11.029

Fischer, P., Jardani, A., Jourde, H., Cardiff, M., Wang, X., Chedeville, S., and Lecoq, N. (2018b). Harmonic pumping tomography applied to image the hydraulic properties and interpret the connectivity of a karstic and fractured aquifer (Lez aquifer, France). Advances in Water Resources, 119, 227-244. doi: 10.1016/j.advwatres.2018.07.002

Follin, S., and Thunvik, R. (1994). On the use of continuum approximations for regional modeling of groundwater flow through crystalline rocks. Advances in Water Resources, 17(3), 133-145. doi: 10.1016/0309-1708(94)90037-x

Guo, B., Tao, Y., Bandilla, K., and Celia, M. (2017). Vertically Integrated Dual-porosity and Dual-permeability Models for CO2 Sequestration in Fractured Geological Formation. Energy Procedia, 114, 3343-3352. doi: 10.1016/j.egypro.2017.03.1466

Guzman, A.G., Geddis, A.M., Henrich, M.J., Lohrstorfer, C.F. and Neuman, S.P. (1996). Summary of air permeability data from single-hole injection tests in unsaturated fractured tuffs at the Apache Leap Research Site: Results of steadystate test interpretation. NUREG/CR-6360. Washington, DC: US Nuclear Regulatory Commission.

Hamzah, U., Samsudin, A. R., and Malim, E. P. (2006). Groundwater investigation in Kuala Selangor using vertical electrical sounding (VES) surveys. Environmental Geology, 51(8), 1349-1359. doi: 10.1007/s00254-006-0433-8

Hao, Y., Yeh, T. C.J., Xiang, J., Illman, W., Ando, K., Hsu, K.-C., and Lee, C.-H. (2008). Hydraulic tomography for detecting fracture zone connectivity. Groundwater 46, no. 2: 183-192.

Hasan, M., Shang, Y., Jin, W., and Akhter, G. (2019). Investigation of fractured rock aquifer in South China using electrical resistivity tomography and self-potential methods. Journal of Mountain Science, 16(4), 850-869. doi:10.1007/s11629-018-5207-8

Hendricks Franssen, H. J. W. M. and Gómez-Hernández, J. J. (2002). 3D inverse modelling of groundwater flow at a fractured site using a stochastic continuum model with multiple statistical populations. Stochastic Environmental Research and Risk Assessment (SERRA), 16(2), 155-174. doi: 10.1007/s00477-002-0091-7

Hsieh, P.A., and S.P. Neuman. (1985 a). Field determination of the three-dimensional hydraulic conductivity tensor of anisotropic media, 1. Theory. Water Resources Research, 21(11), 1655-1665. doi: 10.1029/wr021i011p01655 
Hsieh, P. A., Neuman, S. P., Stiles, G. K., and Simpson, E. S. (1985 b). Field Determination of the Three-Dimensional Hydraulic Conductivity Tensor of Anisotropic Media: 2. Methodology and Application to Fractured Rocks. Water Resources Research, 21(11), 1667-1676. doi: 10.1029/wr021i011p01667

Illman, W. A. (2006), Strong field evidence of directional permeability scale effect in fractured rock. Journal of Hydrology, 319(1-4), 227-236, doi:10.1016/j.jhydrol.2005.06.032.

Illman, W. A. (2014). Hydraulic Tomography Offers Improved Imaging of Heterogeneity in Fractured Rocks. Groundwater, 52(5), 659-684. doi:10,111/gwat. 12119

Illman, W. A., Craig, A. J., and Liu, X. (2008). Practical issues in imaging hydraulic conductivity through hydraulic tomography, Groundwater, 46(1), 120-132

Illman, W. A., and Hughson, D. L. (2005). Stochastic simulations of steady state unsaturated flow in a three-layer, heterogeneous, dual continuum model of fractured rock. Journal of Hydrology, 307(1-4), 17-37. doi: 10.1016/j.jhydrol.2004.09.015

Illman, W. A., Liu, X., and Craig, A. (2007), Steady-state hydraulic tomography in a laboratory aquifer with deterministic heterogeneity: Multi-method and multiscale validation of hydraulic conductivity tomograms. Journal of Hydrology, 341(3-4), 222-234.

Illman, W. A., Liu, X., Takeuchi, S., Yeh, T. C. J., Ando, K., and Saegusa, H. (2009). Hydraulic tomography in fractured granite: Mizunami Underground Research site, Japan. Water Resources Research, 45(1). doi:10.1029/2007wr006715

Illman, W. A., and Neuman, S. P. (2001). Type-Curve Interpretation of Multirate Single-Hole Pneumatic Injection Tests in Unsaturated Fractured Rock. Groundwater, 38(6), 899-911. doi: 10.1111/j.1745-6584.2000.tb00690.x

Illman, W.A., and Neuman, S.P., (2003). Steady-state analyses of crosshole pneumatic injection tests in unsaturated fractured tuff. Journal of Hydrology, 281, 36-54. doi: 10.1016/s00221694(03)00199-9

Illman, W. A., Zhu, J., Craig, A. J., and Yin, D. (2010). Comparison of aquifer characterization approaches through steady state groundwater model validation: A controlled laboratory sandbox study. Water Resources Research, 46(4). doi:10.1029/2009wr007745

Karimi-Fard, M., Durlofsky, L., Durlofsky, L., and Aziz, K. (2003). An Efficient Discrete Fracture Model Applicable for General Purpose Reservoir Simulators. Proceedings of SPE Reservoir Simulation Symposium. doi:10.2523/79699-ms

Klepikova, M., Brixel, B., and Jalali, M. (2020). Transient hydraulic tomography approach to characterize main flowpaths and their connectivity in fractured media. Advances in Water Resources, 136, 103500. doi: 10.1016/j.advwatres.2019.103500

Lee, J., Choi, S. U., and Cho, W. (1999). A comparative study of dual-porosity model and discrete fracture network model. KSCE Journal of Civil Engineering, 3(2), 171-180. doi: 


\section{$10.1007 / \mathrm{bf} 02829057$}

Lei, Q., Latham, J., and Tsang, C. (2017). The use of discrete fracture networks for modelling coupled geomechanical and hydrological behaviour of fractured rocks. Computers and Geotechnics, 85, 151-176. doi:10.1016/j.compgeo.2016.12.024

Liu, S., Yeh, T. C. J., \& Gardiner, R. (2002). Effectiveness of hydraulic tomography: Sandbox experiments. Water Resources Research,38(4). doi:10.1029/2001wr000338

Liu, X., Illman, W. A., Craig, A. J., Zhu, J. and Yeh, T. C. J. (2007), Laboratory sandbox validation of transient hydraulic tomography. Water Resources Research, 43, W05404, doi:10.1029/2006WR005144.

Luo, N., Zhao, Z., Illman, W. A., and Berg, S. J. (2017). Comparative study of transient hydraulic tomography with varying parameterizations and zonations: Laboratory sandbox investigation. Journal of Hydrology, 554, 758-779. doi: 10.1016/j.jhydrol.2017.09.045

McLaren, R., Sudicky, E. A., Park, Y. J., and Illman, W. A. (2012). Numerical simulation of DNAPL emissions and remediation in a fractured dolomitic aquifer, Journal of Contaminant Hydrology, 136-137, 56-71. http://dx.doi.org/10.1016/j.jconhyd.2012.05.002.

Meyer, B. R., and Bazan, L. W. (2011). A Discrete Fracture Network Model for Hydraulically Induced Fractures - Theory, Parametric and Case Studies. SPE Hydraulic Fracturing Technology Conference. doi:10.2118/140514-ms

Moench, A. F. (1984). Double-Porosity Models for a Fissured Groundwater Reservoir With Fracture Skin. Water Resources Research, 20(7), 831-846. doi: 10.1029/wr020i007p00831

Muldoon, M. A., Simo, J. A., and Bardbury, K. R. (2001). Correlation of hydraulic conductivity with stratigraphy in a fractured-dolomite aquifer, northeastern Wisconsin, USA. Hydrogeology Journal, 9(6), 570-583. doi: 10.1007/s10040-001-0165-5

Nastev, M., Savard, M., Lapcevic, P., Lefebvre, R., and Martel, R. (2004). Hydraulic properties and scale effects investigation in regional rock aquifers, south-western Quebec, Canada. Hydrogeology Journal, 12(3). doi: 10.1007/s10040-004-0340-6

National Research Council. (1996). Rock Fractures and Fluid Flow: Contemporary Understanding and Applications. Washington, DC: The National Academies Press.http://doi.org/10.17226/2309

Neuman, S.P. (1987). Stochastic continuum representation of fractured rock permeability as an alternative to the REV and fracture network concepts. In Rock Mechanics: Proceedings of the 28th US Symposium, Tucson, AZ, ed. I.W. Farmer, J.J.K. Daemen, C.S. Desai, C.E. Glass, and S.P. Neuman, 533-561. Rotterdam, The Netherlands: A.A. Balkema, 1240. (Also in Groundwater Flow and Quality Modelling, ed. E. Custodio, A. Gurgui, and J.B. Lobo Ferreira, 331-362. NATO ASI Series C, 224. Dordrecht, Holland: D. Reidel, 843, 1988).

Neuman, S. P. (1988). Stochastic Continuum Representation of Fractured Rock Permeability as 
an Alternative to the REV and Fracture Network Concepts. Groundwater Flow and Quality Modelling, 331-362. doi: 10.1007/978-94-009-2889-3_19

Neuman, S. P. (2005). Trends, prospects and challenges in quantifying flow and transport through fractured rocks. Hydrogeology Journal, 13(1), 124-147. doi:10.1007/s10040-0040397-2

Neuman, S. P., and Depner, J. S. (1988). Use of variable-scale pressure test data to estimate the $\log$ hydraulic conductivity covariance and dispersivity of fractured granites near Oracle, Arizona. Journal of Hydrology, 102(1-4), 475-501. doi: 10.1016/0022-1694(88)90112-6

Neuman, S., and Federico, V. D. (2003). Multiple manifestations of hydrogeologic scaling and their joint theoretical interpretation. Groundwater Engineering - Recent Advances. doi: 10.1201/9781439833605.ch1

Oda, M. (1986). An equivalent continuum model for coupled stress and fluid flow analysis in jointed rock masses. Water Resources Research, 22(13), 1845-1856. doi:10.1029/wr022i013p01845

Schwartz, F.W., and Zhang, H. (2003), Fundamentals of Ground Water, 764 pp. John Wiley \& Sons.

Sharmeen, R. (2011). Hydraulic Tomography and Trichloroethene Dissolution in a Fractured Dolostone: Small Scale Laboratory Experiments (Unpublished M.Sc. thesis). University of Waterloo, Waterloo, Canada.

Sharmeen, R., Illman, W. A., Berg, S. J., Yeh, T. C. J., Park, Y., Sudicky, E. A., and Ando, K. (2012). Transient hydraulic tomography in a fractured dolostone: Laboratory rock block experiments. Water Resources Research,48(10). doi:10.1029/2012wr012216

Singhal, B. B. S., and Gupta, R. P. (2010). Applied hydrogeology of fractured rocks. Dordrecht: Springer.

Tao, Y., Guo, B., Bandilla, K. W., and Celia, M. A. (2019). Vertically integrated dual-continuum models for $\mathrm{CO} 2$ injection in fractured geological formations. Computational Geosciences, 23(2), 273-284. doi: 10.1007/s10596-018-9805-x

Tiedeman, C. R. and Barrash, W. (2019). Hydraulic Tomography: 3D Hydraulic Conductivity, Fracture Network, and Conductivity in Mudstone. Groundwater. doi:10.1111/gwat.12915

Tsang, Y. W., Tsang, C. F., Hale, F. V., and Dverstorp, B. (1996). Tracer transport in a stochastic continuum model of fractured media. Water Resources Research, 32(10), 3077-3092. doi:10.1029/96wr01397

Tueckmantel, C., Lamine, S., Huisman, B., and Swaby, P. (2013). Discrete Fracture Network Upscaling Workflows and Tools in SVS Fracture Solutions. Second EAGE Workshop on Naturally Fractured Reservoirs. doi:10.3997/2214-4609.20132027

Vesselinov, V. V., Neuman, S. P., and Illman, W. A. (2001a). Three-dimensional numerical 53 
inversion of pneumatic cross-hole tests in unsaturated fractured tuff: 1. Methodology and borehole effects. Water Resources Research, 37(12)., 3001-3018.

doi:10.1029/2000wr000133

Vesselinov, V.V., Neuman, S.P., and Illman, W. A. (2001b). Three-dimensional numerical inversion of pneumatic cross-hole tests in unsaturated fractured tuff: 2. Equivalent parameters, high-resolution stochastic imaging and scale effects. Water Resources Research 37(12)., 3019-3042. doi: 10.1029/2000wr000135

Wang X., Jardani, A., and Jourde, H. (2017). A hybrid inverse method for hydraulic tomography in fractured and karstic media. Journal of Hydrology, 551, 29-46. doi: 10.1016/j.hydrol.2017.05.051

Worthington, S. R. H., and Smart, C. C. (2017). Transient bacterial contamination of the dualporosity aquifer at Walkerton, Ontario, Canada. Hydrogeology Journal, 25(4), 1003-1016. doi: 10.1007/s10040-016-1514-8

Xiang, J., Yeh, T. C. J., Lee, C., Hsu, K., and Wen, J. (2009). A simultaneous successive linear estimator and a guide for hydraulic tomography analysis. Water Resources Research,45(2). doi:10.1029/2008wr007180

Yeh, T. C. J. (1992). Stochastic modelling of groundwater flow and solute transport in aquifers. Hydrological Processes, 6(4), 369-395. doi: 10.1002/hyp.3360060402

Yeh, T. C. J., and Liu, S. (2000). Hydraulic tomography: Development of a new aquifer test method. Water Resources Research,36(8), 2095-2105. doi:10.1029/2000wr900114

Yin, D., and Illman, W. A. (2009). Hydraulic tomography using temporal moments of drawdown recovery data: A laboratory sandbox study. Water Resources Research, 45(1). doi: $10.1029 / 2007 \mathrm{wr} 006623$

Zha, Y., Yeh, T. C. J., Illman, W. A., Tanaka, T., Bruines, P., Onoe, H., and Saegusa, H. (2015). What does hydraulic tomography tell us about fractured geological media? A field study and synthetic experiments. Journal of Hydrology, 531, 17-30. doi:10.1016/j.jhydrol.2015.06.013

Zha, Y., Yeh, T. C. J., Illman, W. A., Tanaka, T., Bruines, P., Onoe, H., Saegusa, H., Mao D., Takeuchi, S., and Wen, J. (2016). An Application of Hydraulic Tomography to a LargeScale Fractured Granite Site, Mizunami, Japan. Groundwater, vol.54, 793-804. doi:10.1111/gwat.12421

Zha, Y., Yeh, T. C. J., Illman, W. A., Onoe, H., Mok, C. M. W., Wen, J,-C., Huang, S. W., and Wang, W. (2017). Incorporating geologic information into hydraulic tomography: A general framework based on geostatistical approach. Water Resources Research, 53(4), 2850-2876. doi:10.1002/2016wr019185.

Zhao, Z., Illman, W. A., and Berg, W. S. (2016). On the importance of geological data fro hydraulic tomography analysis: Laboratory sandbox study. Journal of Hydrology, 45(1). 
doi:10.1016/j.jhydrol.2016.08.061

Zhao, Z., and Illman, W. A. (2017). On the importance of geological data for three-dimensional steady-state hydraulic tomography analysis at a highly heterogeneous aquifer-aquitard system. Journal of Hydrology, 544, 640-657. doi: 10.1016/j.jhydrol.2016.12.004

Zhao, Z., and Illman, W. A. (2018). Three-dimensional imaging of aquifer and aquitard heterogeneity via transient hydraulic tomography at a highly heterogeneous field site. Journal of Hydrology, 559, 392-410. doi: 10.1016/j.jhydrol.2018.02.024

Zhu, J., and Yeh, T. C. J. (2005). Characterization of aquifer heterogeneity using transient hydraulic tomography. Water Resources Research,41(7). doi:10.1029/2004wr003790

Zhu, J., and Yeh, T. C. J. (2006). Analysis of hydraulic tomography using temporal moments of drawdown recovery data. Water Resources Research,42(2). doi:10.1029/2005wr004309 


\section{Appendix A}

\section{Synthetic Pumping Tests (Using HGS)}

\section{Port 3}
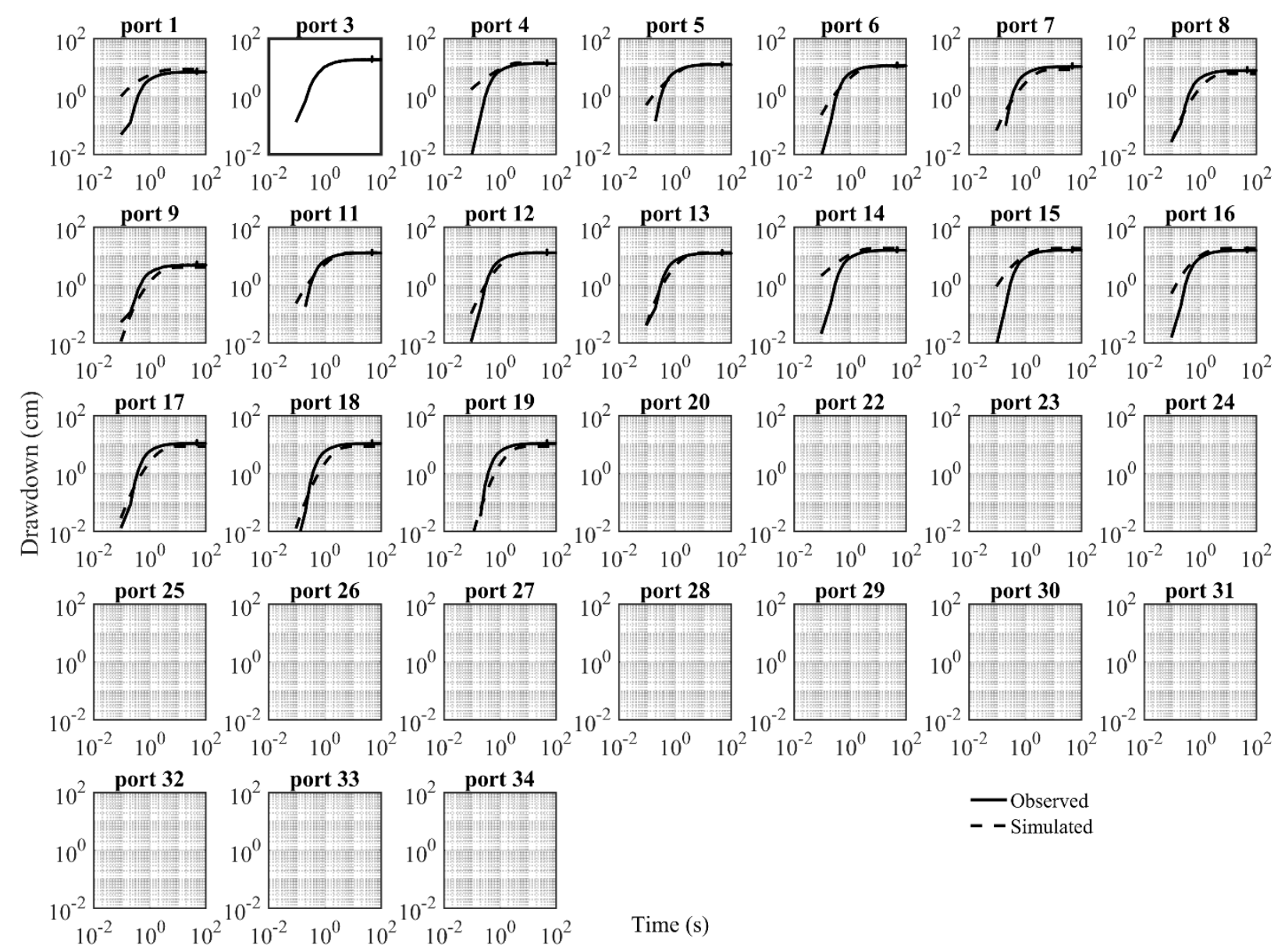

Figure A1: Observed (black solid line) and validated (blue dashed line) drawdown curves using HGS during a pumping test at port 3 . 


\section{Port 4}

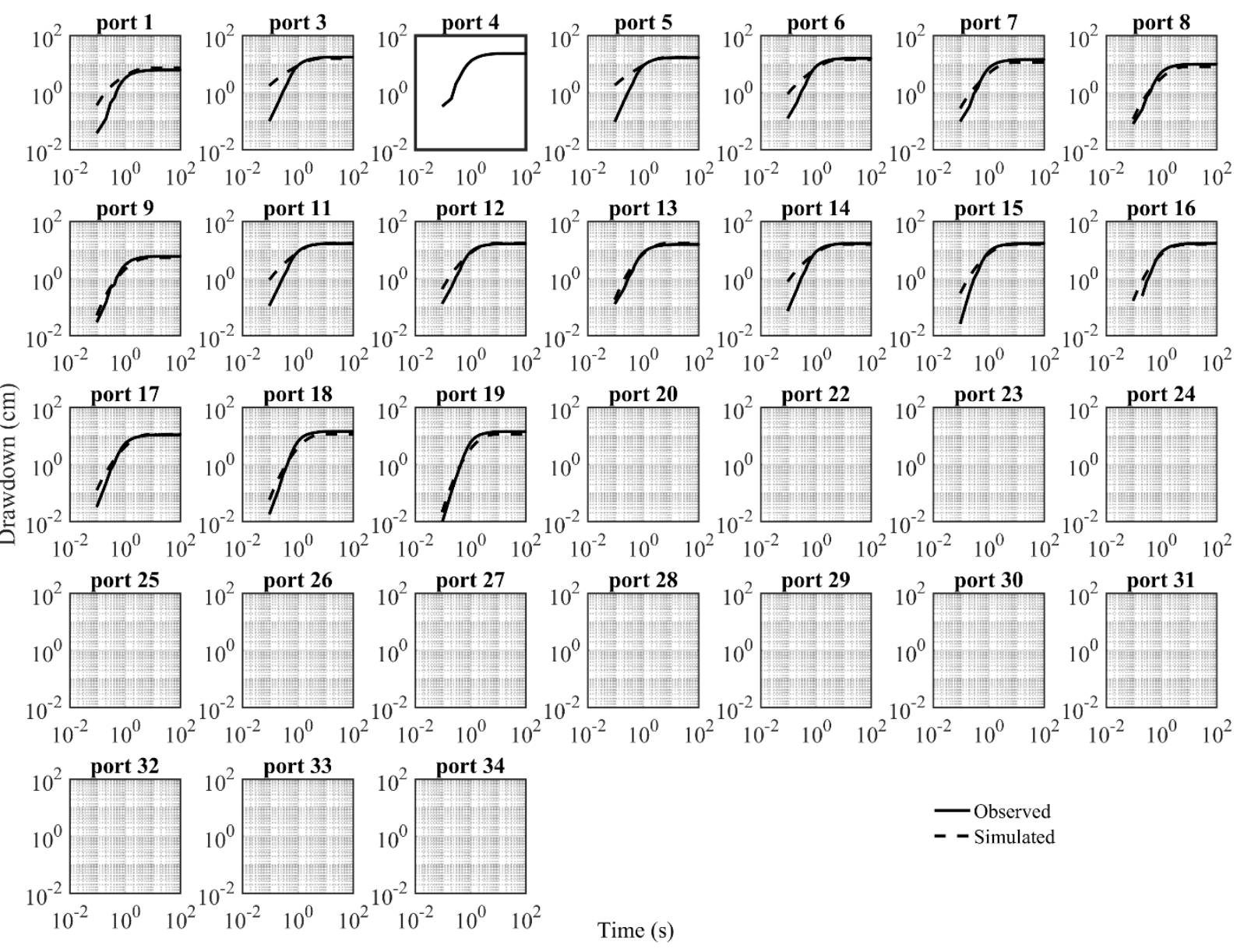

Figure A2: Observed (black solid line) and validated (blue dashed line) drawdown curves using HGS during a pumping test at port 4 . 


\section{Port 6}
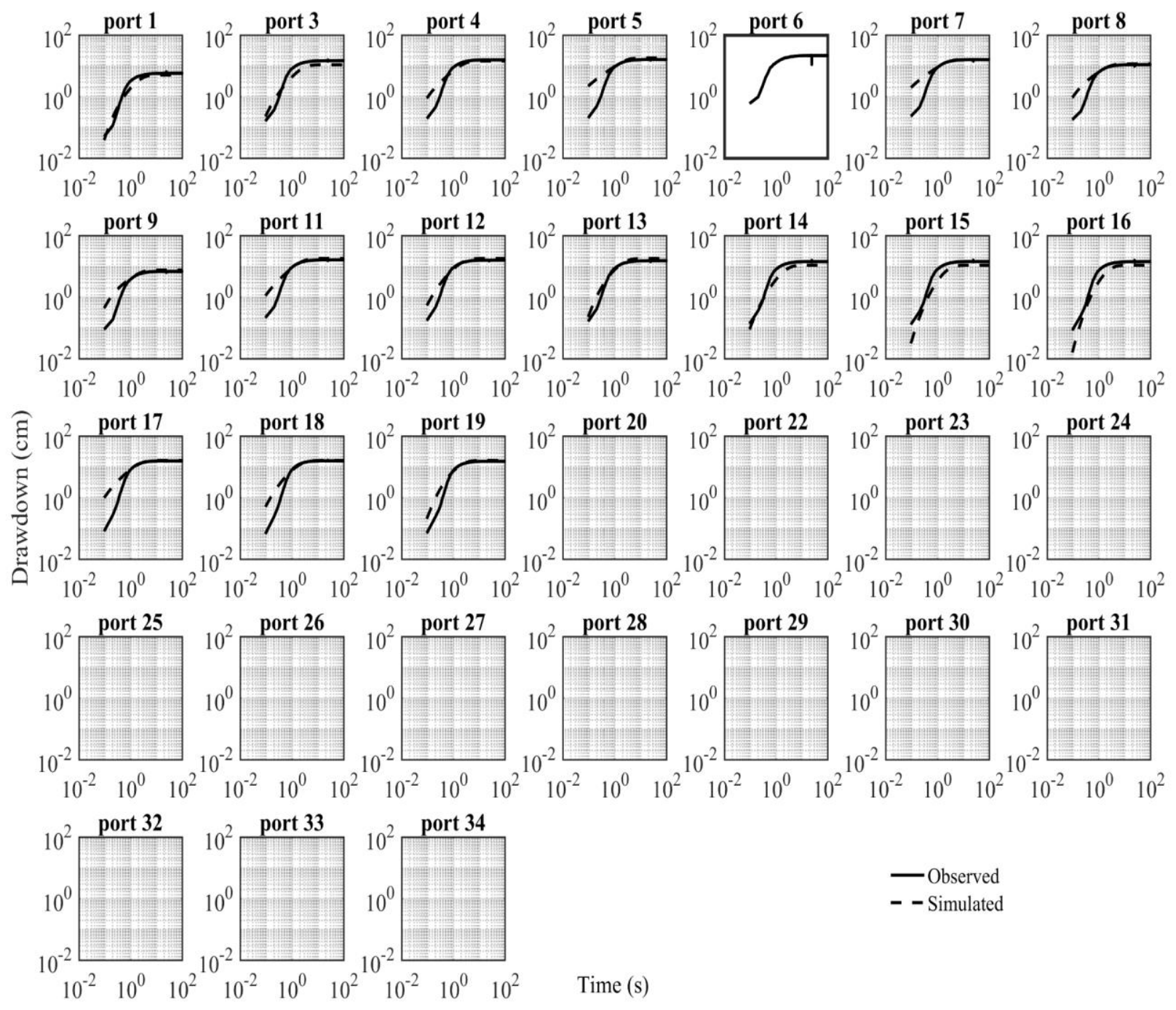

Figure A3: Observed (black solid line) and validated (blue dashed line) drawdown curves using HGS during a pumping test at port 6 . 


\section{Port 7}
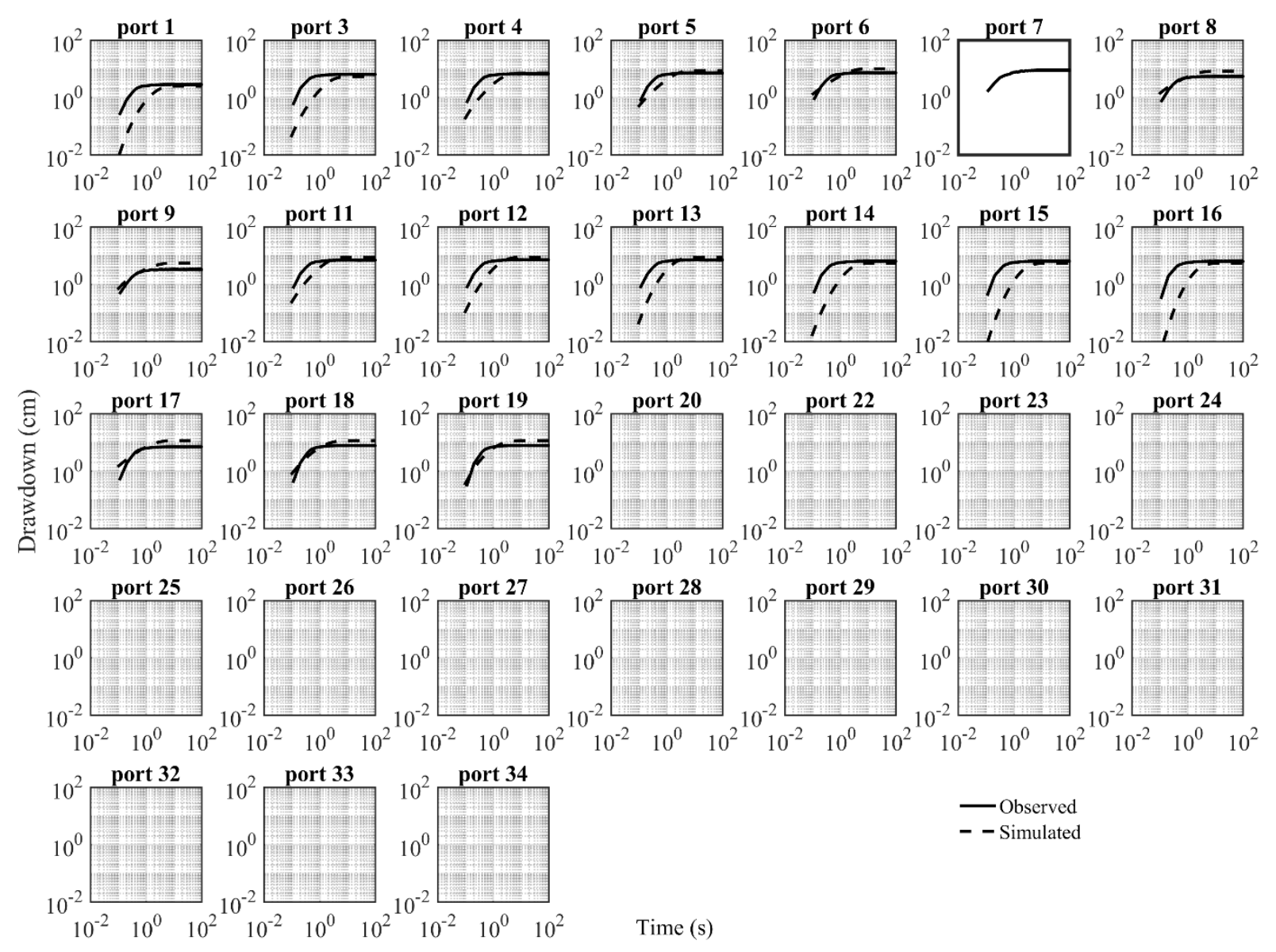

Figure A4: Observed (black solid line) and validated (blue dashed line) drawdown curves using HGS during a pumping test at port 7. 


\section{Port 12}
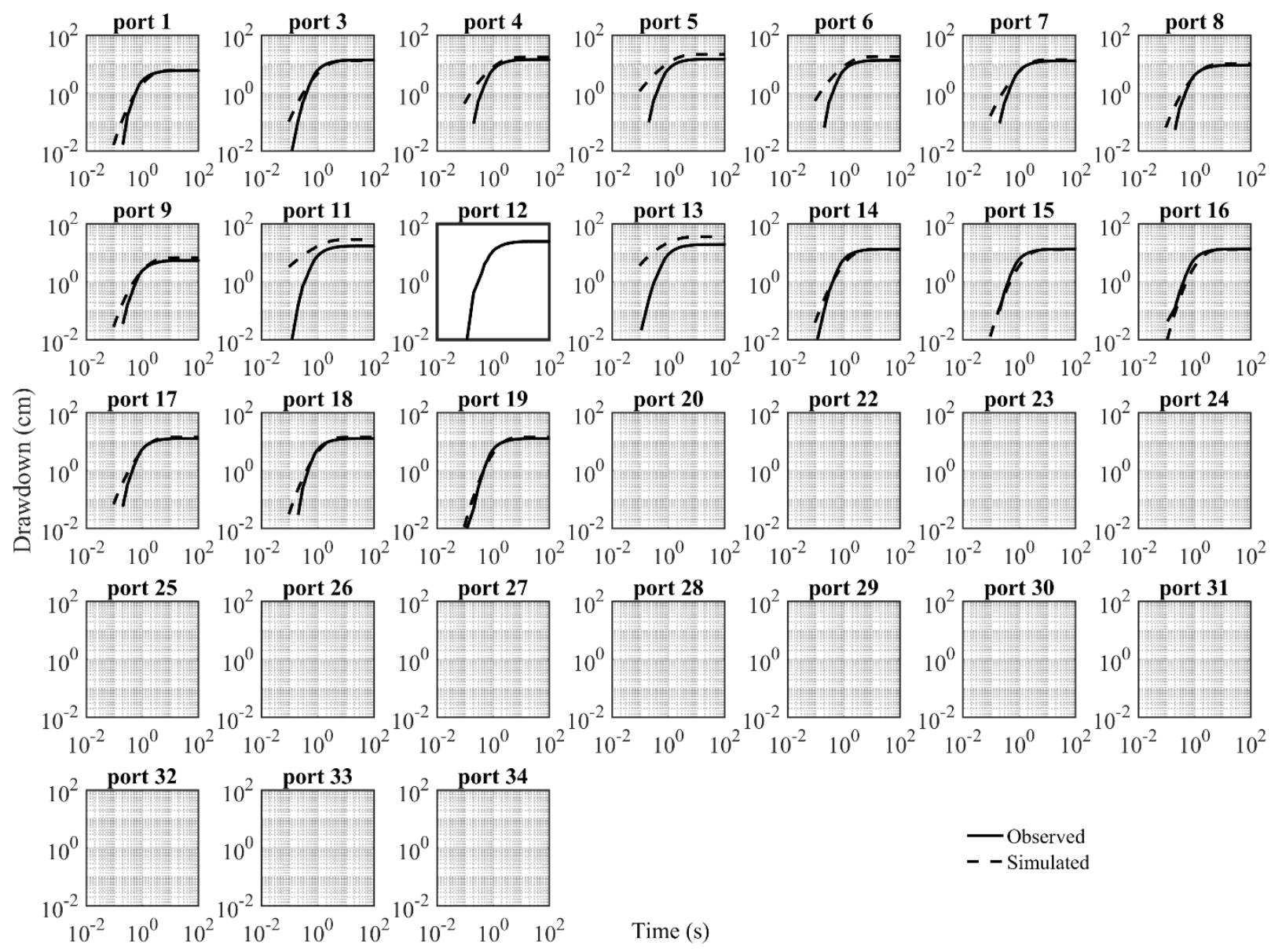

Figure A5: Observed (black solid line) and validated (blue dashed line) drawdown curves using HGS during a pumping test at port 12. 


\section{Port 15}
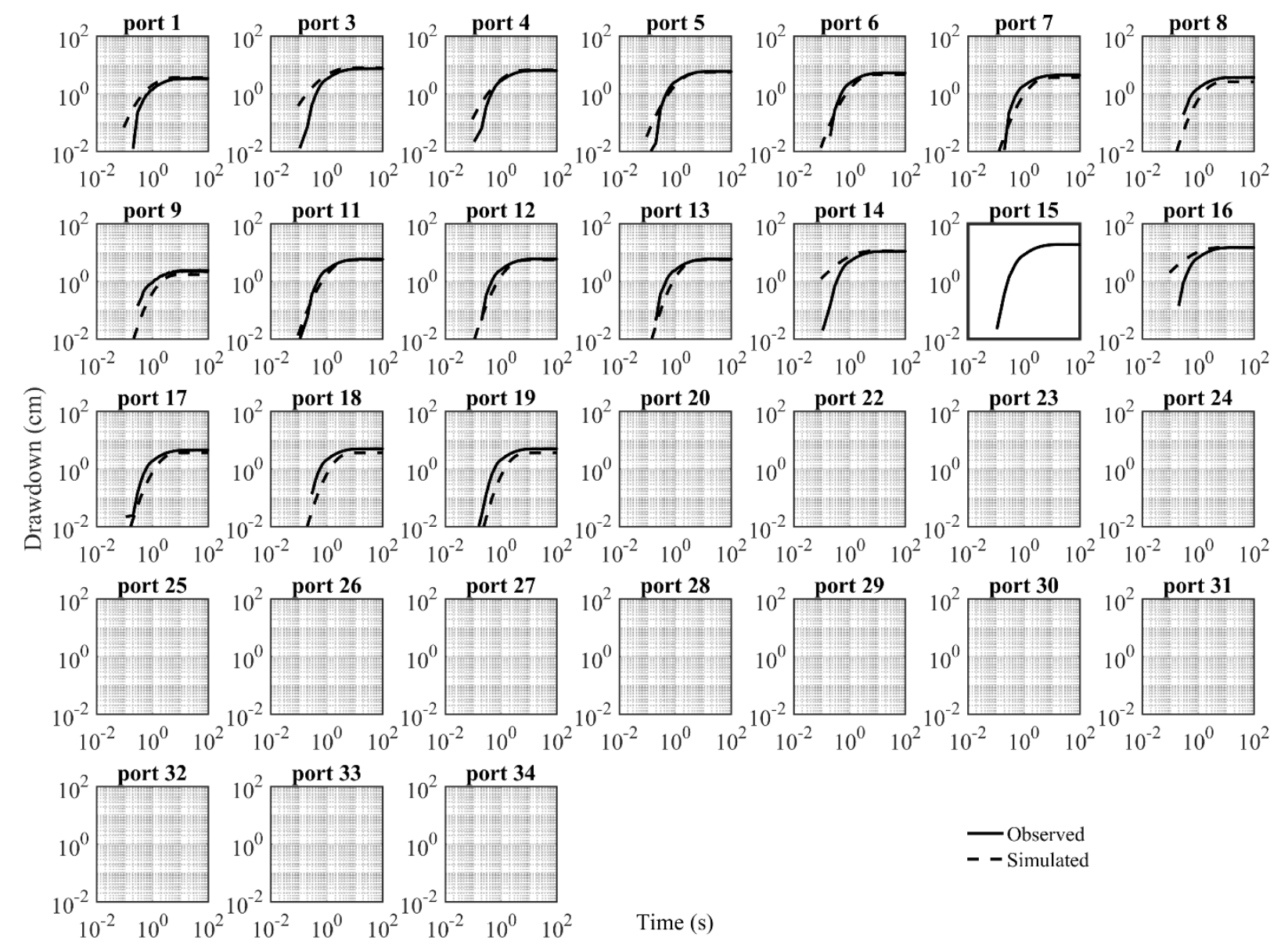

Figure A6: Observed (black solid line) and validated (blue dashed line) drawdown curves using HGS during a pumping test at port 15. 
Port 18

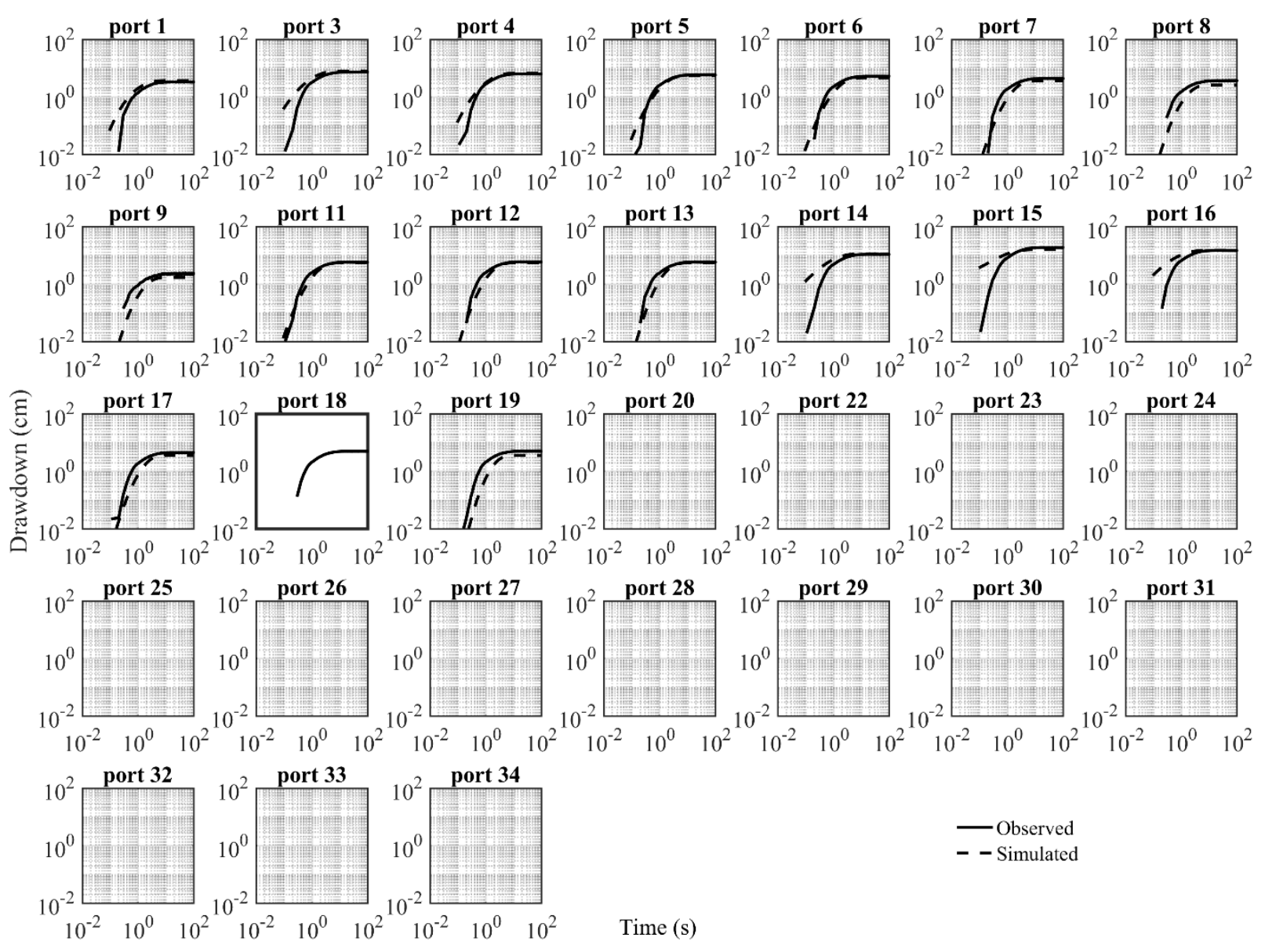

Figure A7: Observed (black solid line) and validated (blue dashed line) drawdown curves using HGS during a pumping test at port 18. 


\section{Appendix B}

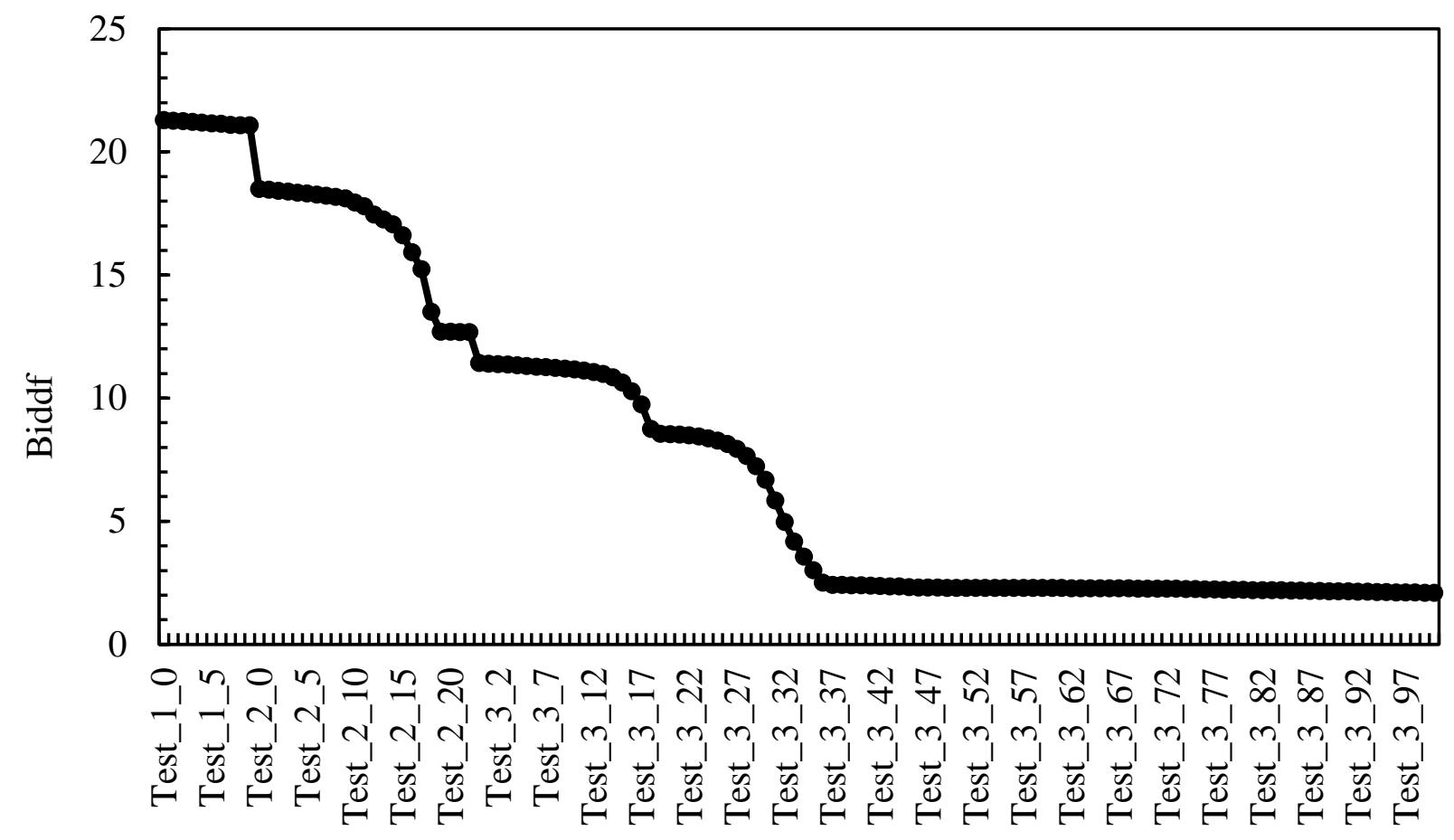

Figure B1: The biggest difference of head misfit during the iterations from the case without geologic information on synthetic data HT analysis. 


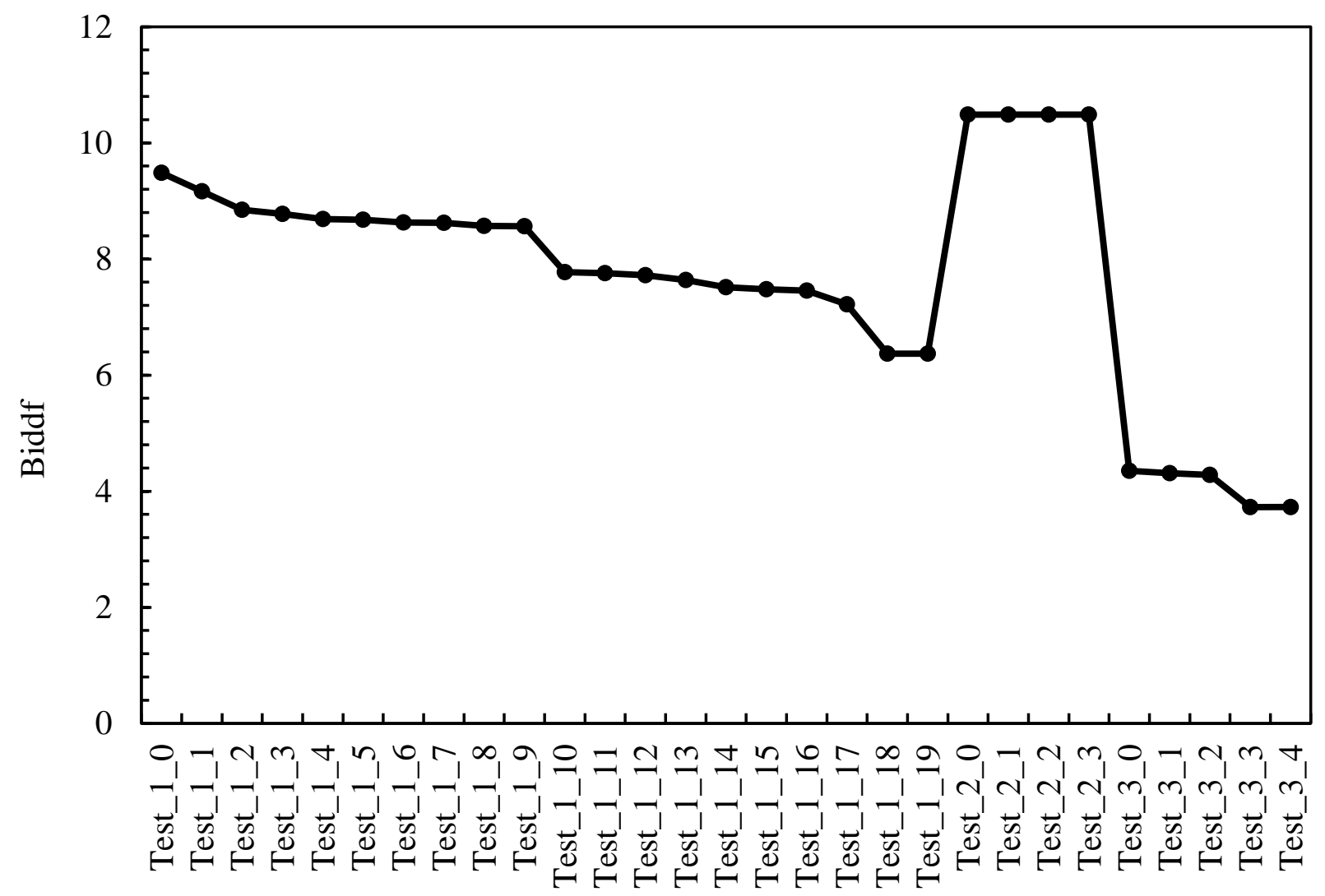

Figure B2: The biggest difference of head misfit during the iterations from the case with correct geologic information on synthetic data HT analysis. 


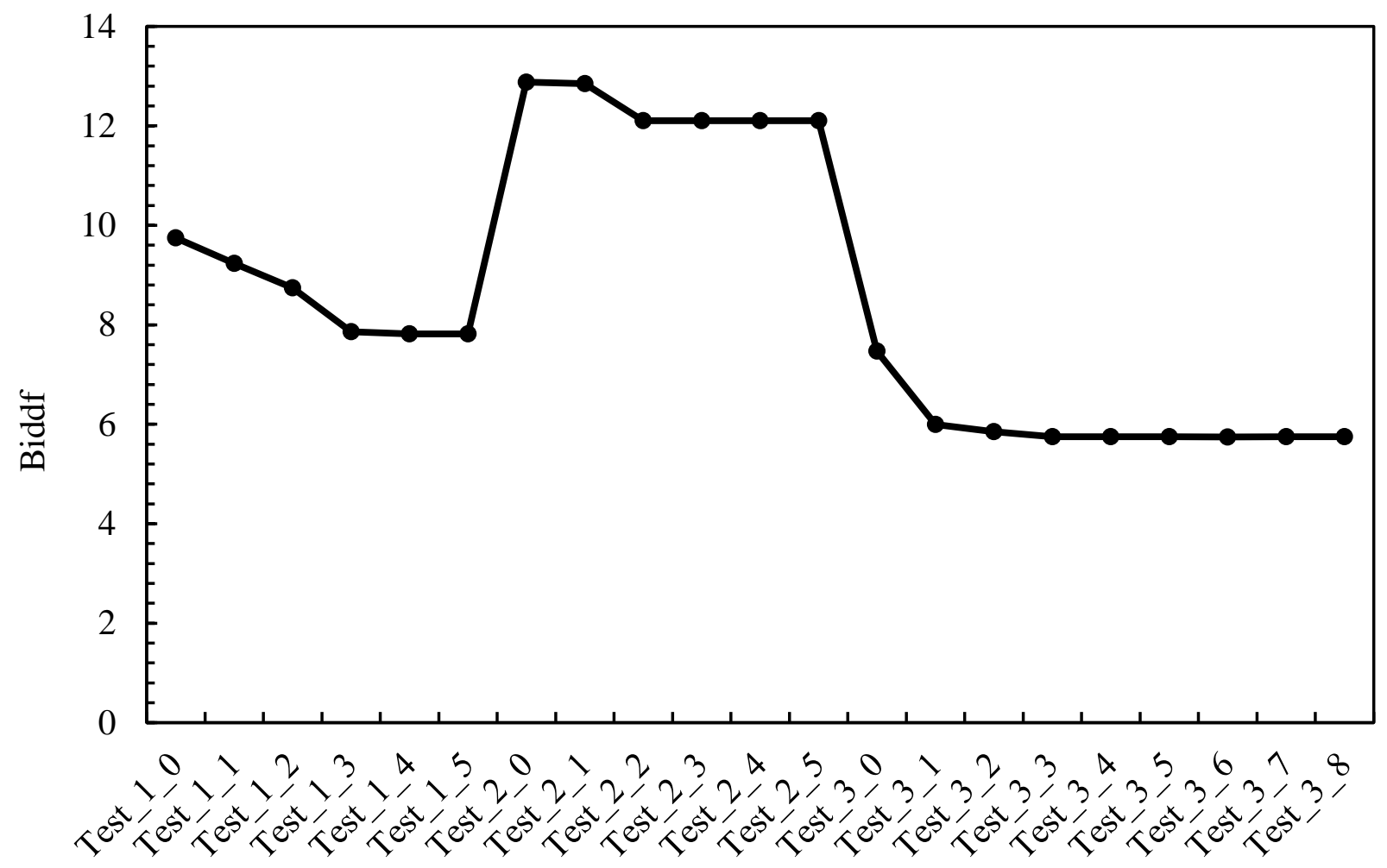

Figure B3: The biggest difference of head misfit during the iterations from the case with partially correct geologic information on synthetic data HT analysis. 


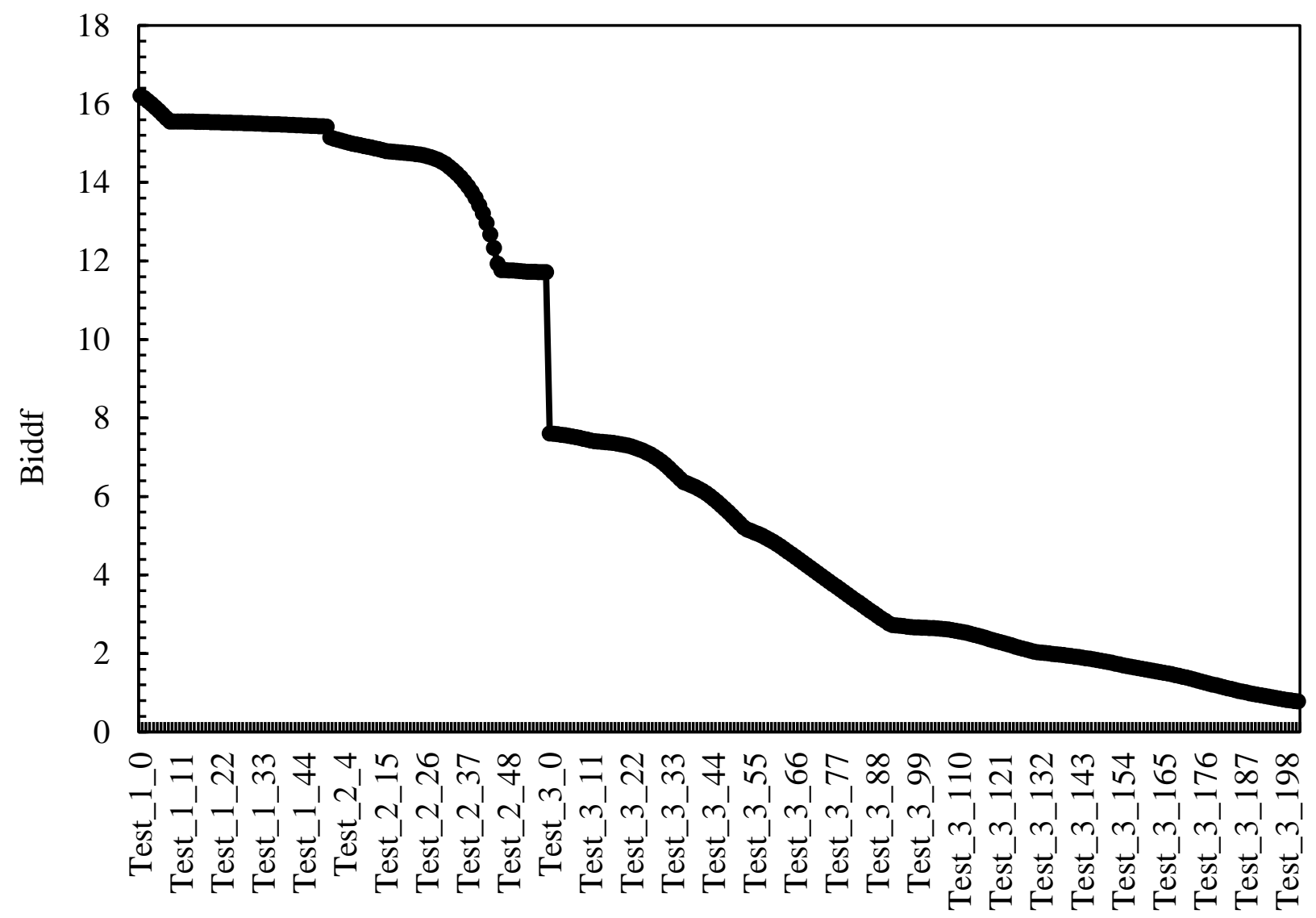

Figure B4: The biggest difference of head misfit during the iterations from the case without geologic information on lab data HT analysis. 


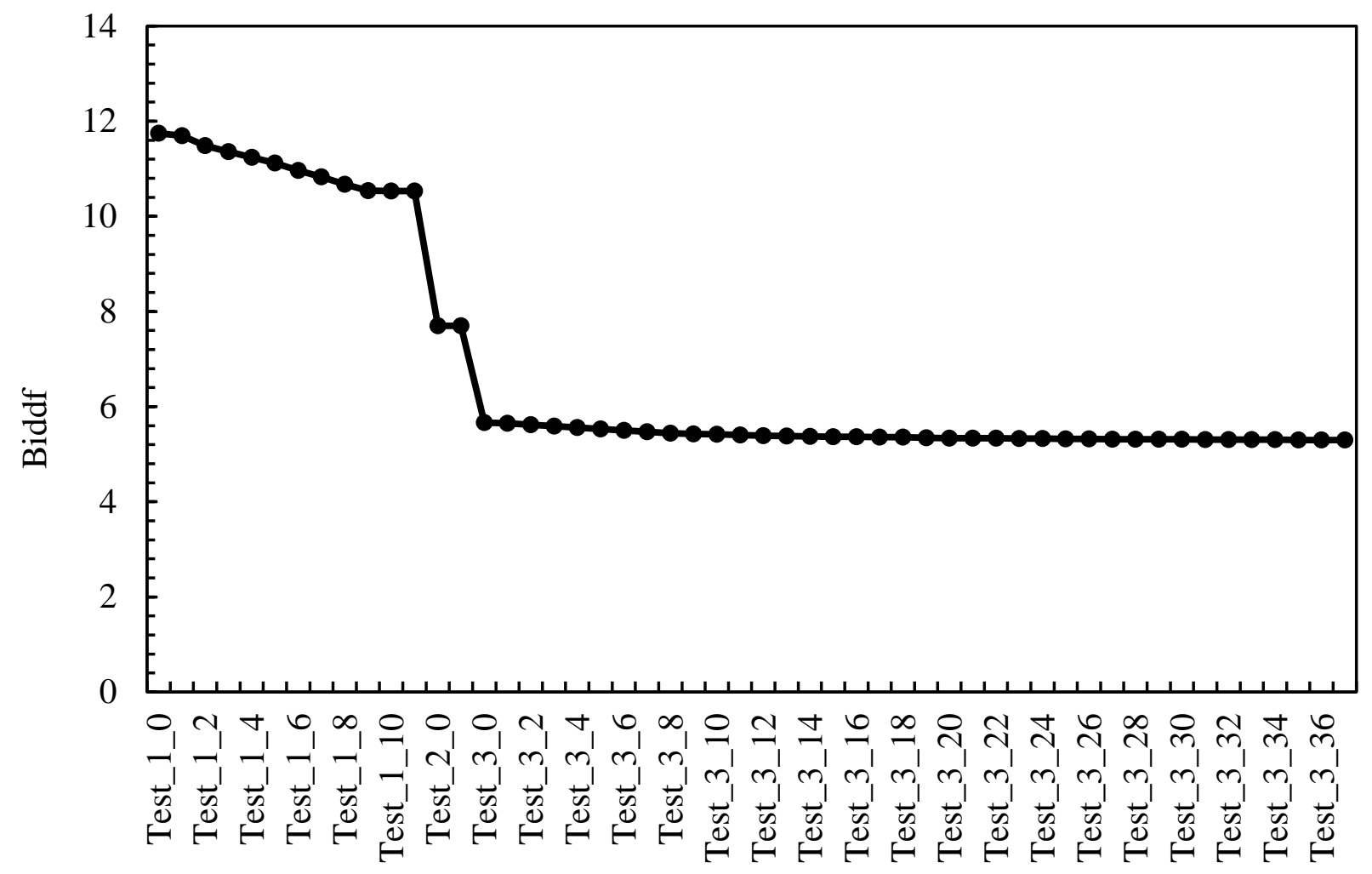

Figure B5: The biggest difference of head misfit during the iterations from the case with correct geologic information on lab data HT analysis. 


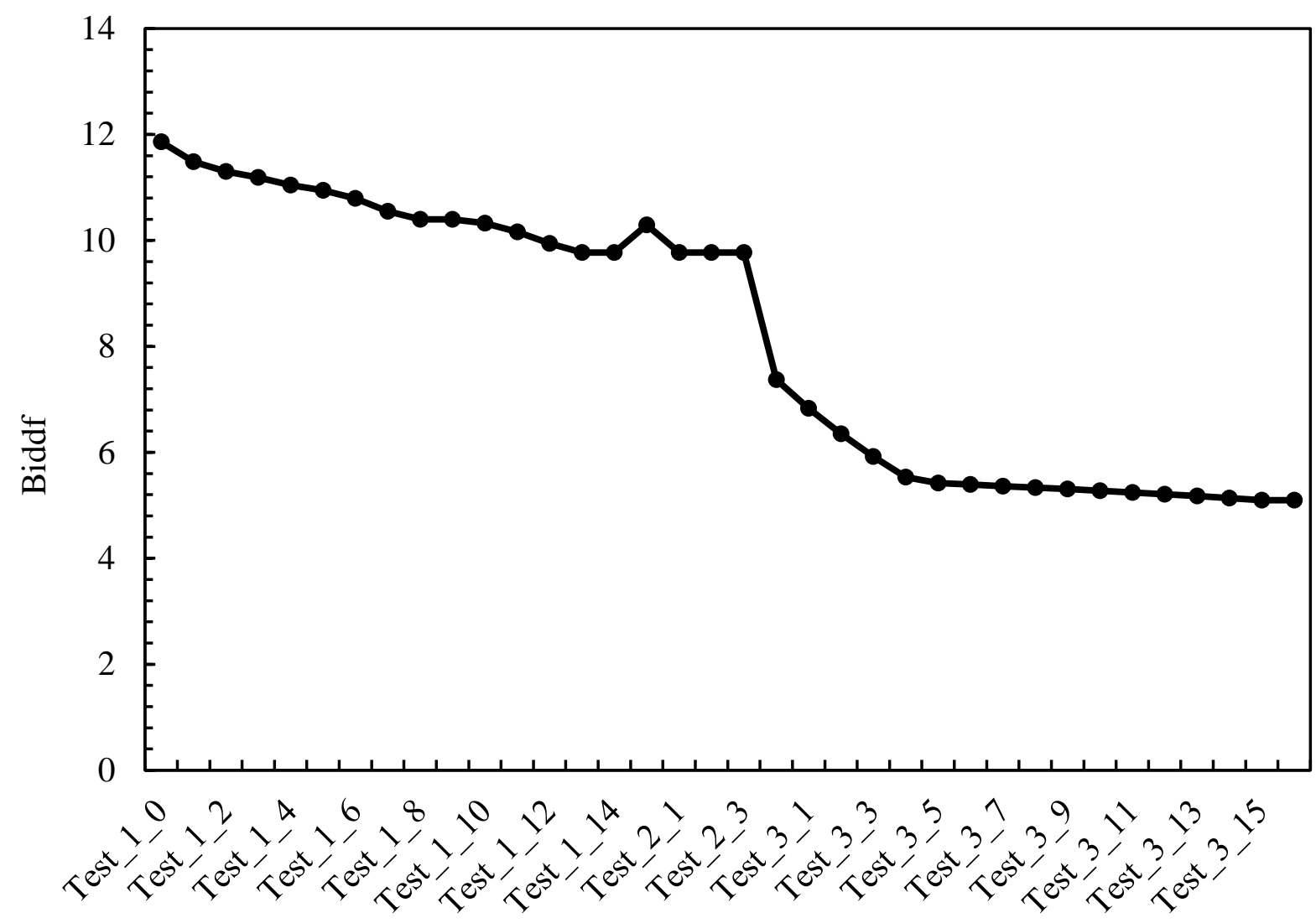

Figure B6: The biggest difference of head misfit during the iterations from the case with partially correct geologic information on lab data HT analysis. 


\section{Appendix C}

\section{THT Calibration and Predictions (Lab data)}

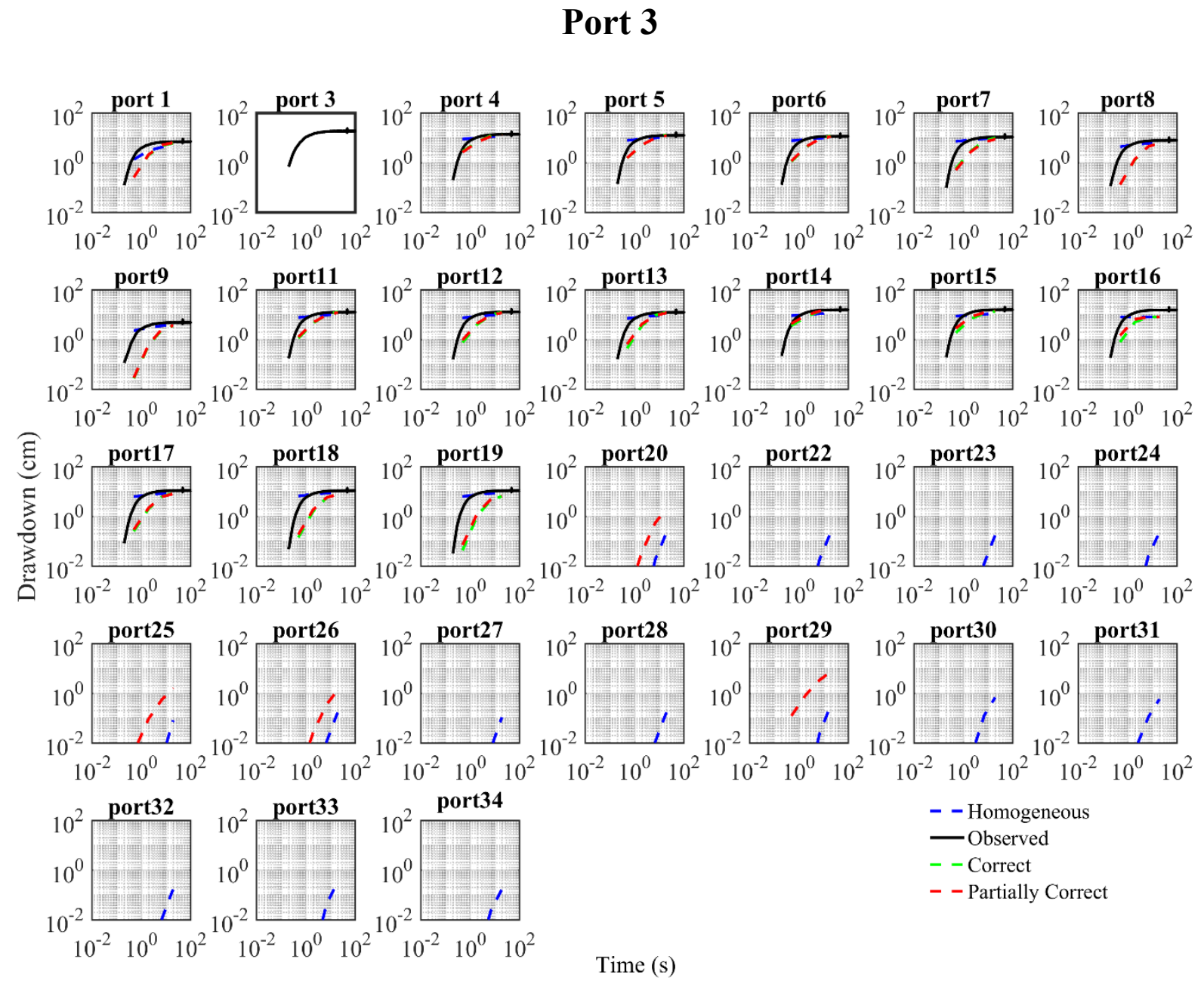

Figure C1: Observed and calibrated drawdown $(\mathrm{cm})$ versus time $(\mathrm{s})$ at ports during the pumping test at port 3. The dark blue dashed line represents results from the homogeneous case. The solid black line indicates results from the lab experiment. The green dashed line represents results from the correct fracture location case. The red dashed line indicates results from the partially correct fracture location case. 


\section{Port 7}
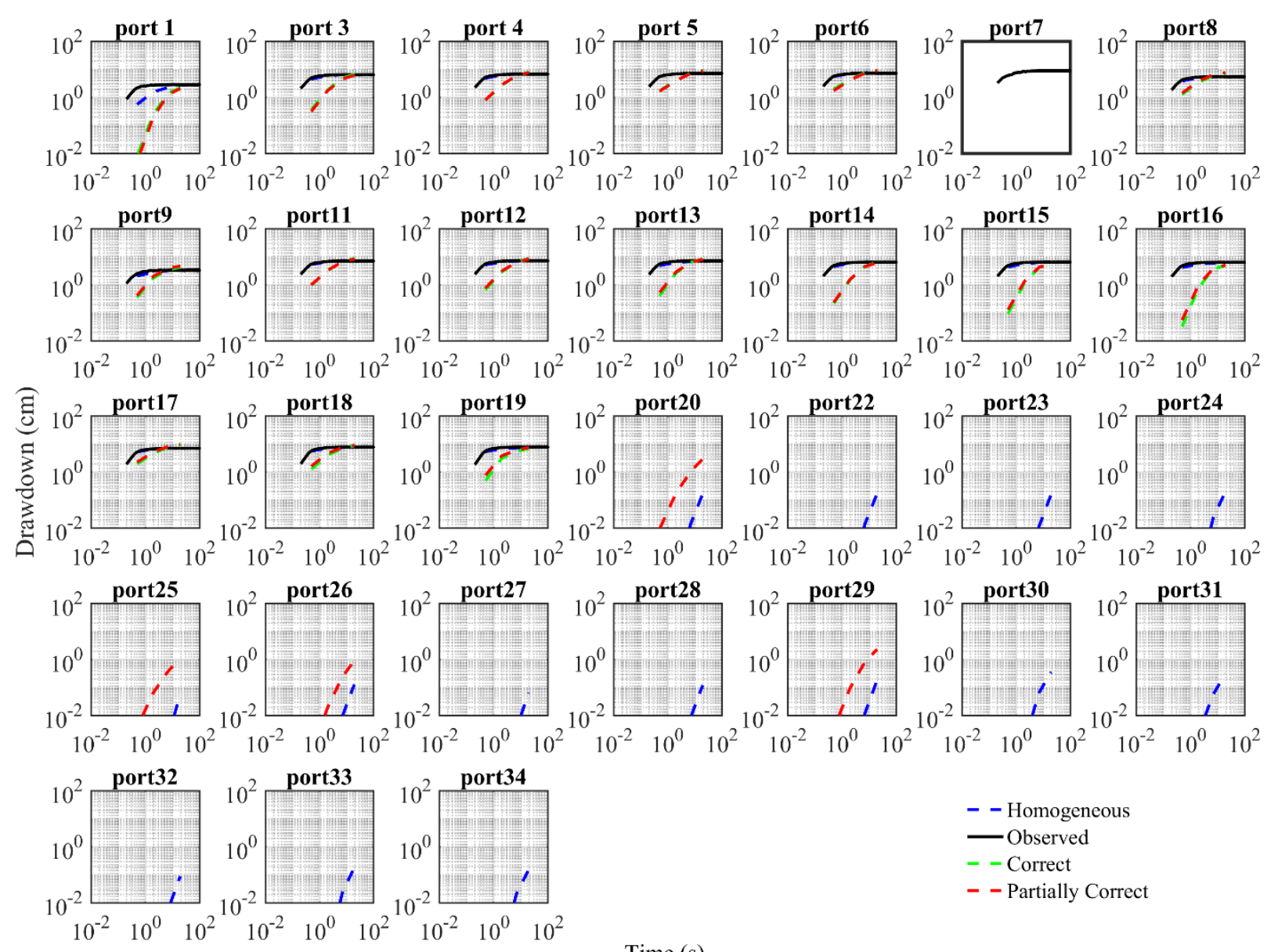

Time (s)

Figure C2: Observed and calibrated drawdown $(\mathrm{cm})$ versus time $(\mathrm{s})$ at ports during the pumping test at port 7. The dark blue dashed line represents results from the homogeneous case. The solid black line indicates results from the lab experiment. The green dashed line represents results from the correct fracture location case. The red dashed line indicates results from the partially correct fracture location case. 


\section{Port 6}

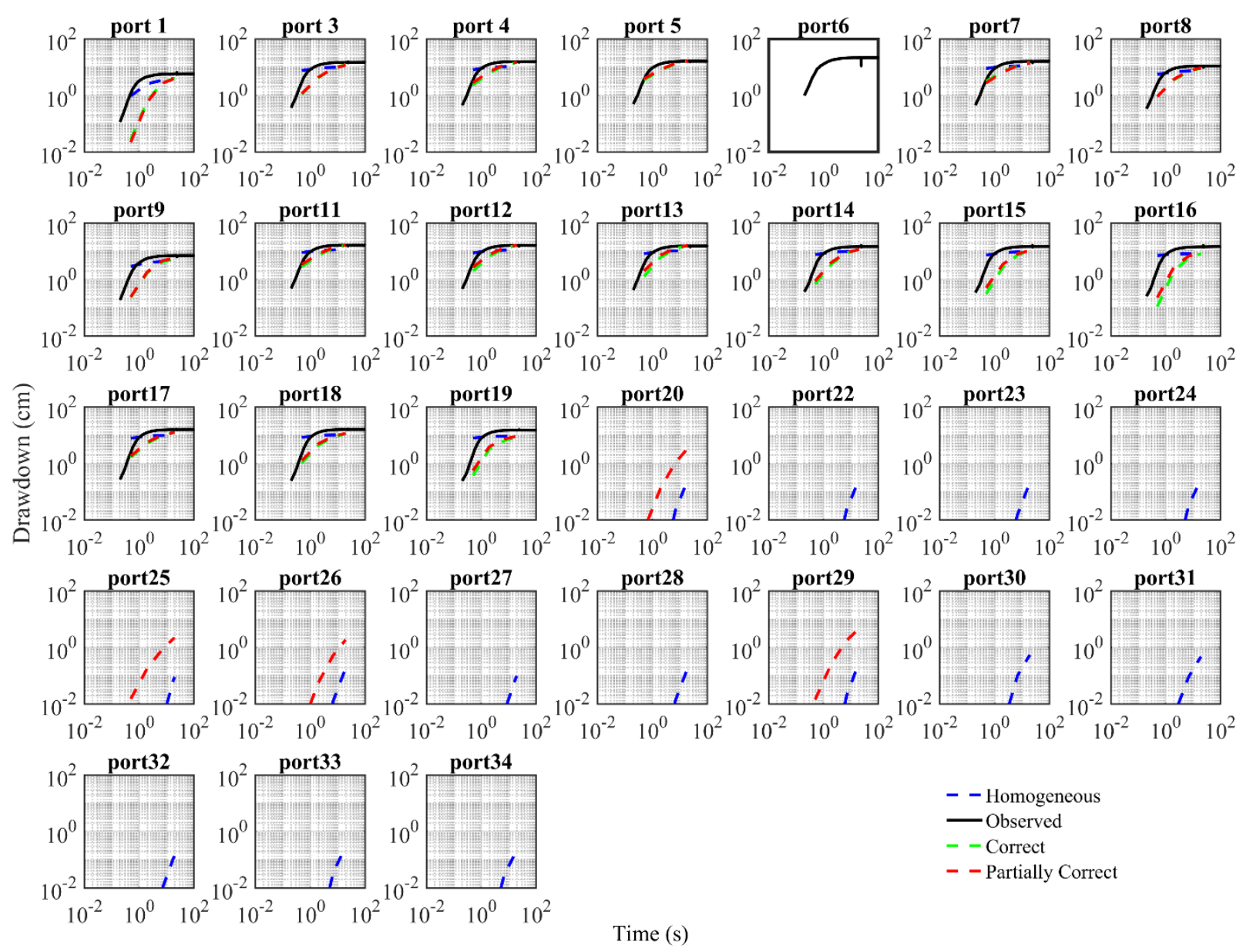

Figure C3: Observed and calibrated drawdown $(\mathrm{cm})$ versus time (s) at ports during the pumping test at port 6 . The dark blue dashed line represents results from the homogeneous case. The solid black line indicates results from the lab experiment. The green dashed line represents results from the correct fracture location case. The red dashed line indicates results from the partially correct fracture location case. 


\section{Port 12}
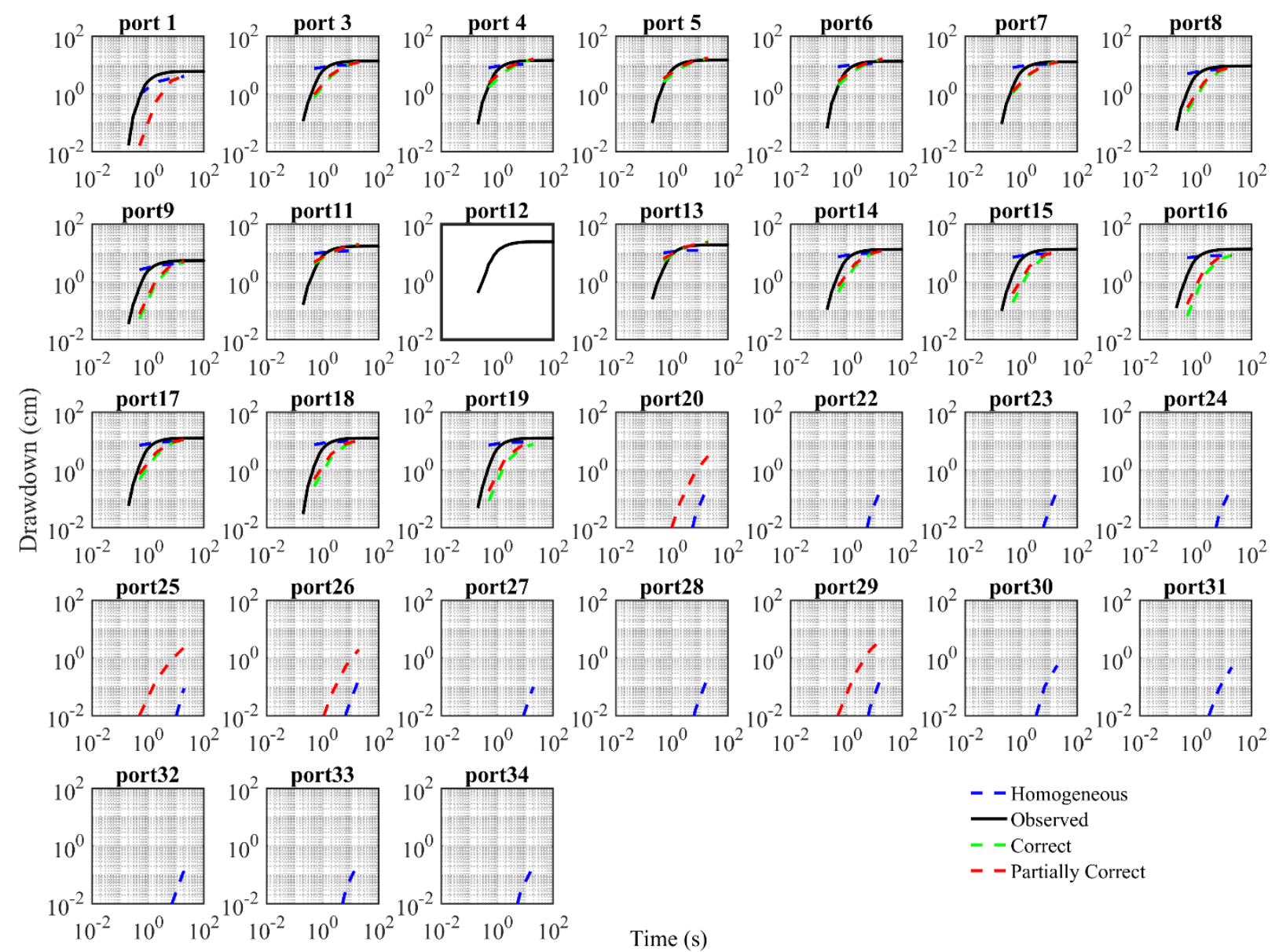

Time (s)

Figure C4: Observed and calibrated drawdown $(\mathrm{cm})$ versus time $(\mathrm{s})$ at ports during the pumping test at port 12. The dark blue dashed line represents results from the homogeneous case. The solid black line indicates results from the lab experiment. The green dashed line represents results from the correct fracture location case. The red dashed line indicates results from the partially correct fracture location case. 


\section{Port 15}
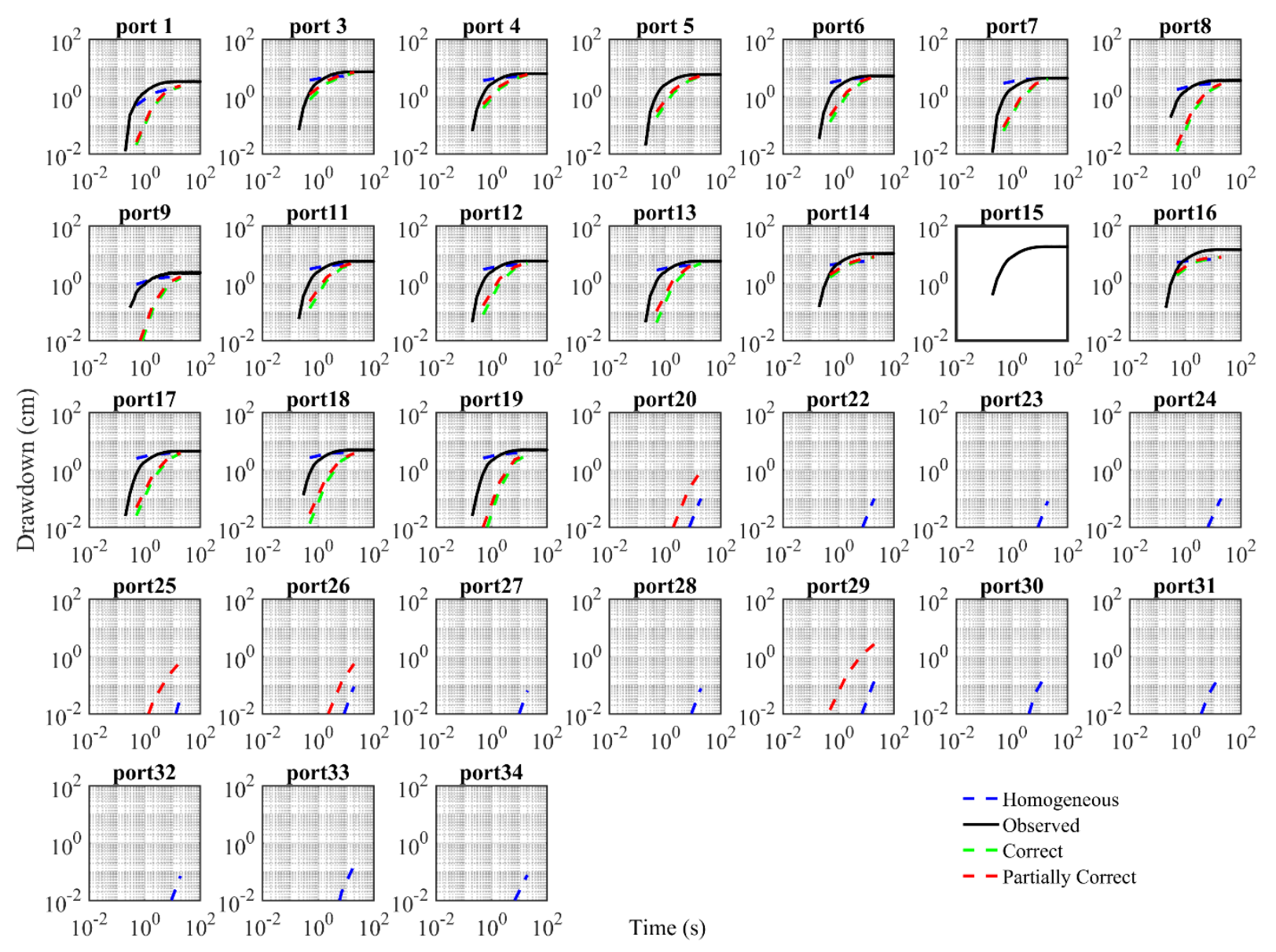

Figure C5: Observed and calibrated drawdown $(\mathrm{cm})$ versus time $(\mathrm{s})$ at ports during the pumping test at port 15. The dark blue dashed line represents results from the homogeneous case. The solid black line indicates results from the lab experiment. The green dashed line represents results from the correct fracture location case. The red dashed line indicates results from the partially correct fracture location case. 